NBER WORKING PAPER SERIES

\title{
WHERE IS THE LAND OF OPPORTUNITY? THE GEOGRAPHY OF INTERGENERATIONAL MOBILITY IN THE UNITED STATES
}

\author{
Raj Chetty \\ Nathaniel Hendren \\ Patrick Kline \\ Emmanuel Saez \\ Working Paper 19843 \\ http://www.nber.org/papers/w19843 \\ NATIONAL BUREAU OF ECONOMIC RESEARCH \\ 1050 Massachusetts Avenue \\ Cambridge, MA 02138 \\ January 2014
}

The opinions expressed in this paper are those of the authors alone and do not necessarily reflect the views of the Internal Revenue Service, the U.S. Treasury Department, or the National Bureau of Economic Research. This work is a component of a larger project examining the effects of tax expenditures on the budget deficit and economic activity. All results based on tax data in this paper are constructed using statistics originally reported in the SOI Working Paper "The Economic Impacts of Tax Expenditures: Evidence from Spatial Variation across the U.S.," approved under IRS contract TIRNO-12-P-00374 and presented at the National Tax Association meeting on November 22, 2013. We thank David Autor, Gary Becker, David Card, David Dorn, John Friedman, James Heckman, Nathaniel Hilger, Richard Hornbeck, Lawrence Katz, Sara Lalumia, Adam Looney, Pablo Mitnik, Jonathan Parker, Laszlo Sandor, Gary Solon, Danny Yagan, numerous seminar participants, and four anonymous referees for helpful comments. Sarah Abraham, Alex Bell, Shelby Lin, Alex Olssen, Evan Storms, Michael Stepner, and Wentao Xiong provided outstanding research assistance. This research was funded by the National Science Foundation, the Lab for Economic Applications and Policy at Harvard, the Center for Equitable Growth at UC-Berkeley, and Laura and John Arnold Foundation. Publicly available portions of the data and code, including intergenerational mobility statistics by commuting zone and county, are available at www.equality-of-opportunity.org.

NBER working papers are circulated for discussion and comment purposes. They have not been peerreviewed or been subject to the review by the NBER Board of Directors that accompanies official NBER publications.

(C) 2014 by Raj Chetty, Nathaniel Hendren, Patrick Kline, and Emmanuel Saez. All rights reserved. Short sections of text, not to exceed two paragraphs, may be quoted without explicit permission provided that full credit, including (C) notice, is given to the source. 
Where is the Land of Opportunity? The Geography of Intergenerational Mobility in the United States

Raj Chetty, Nathaniel Hendren, Patrick Kline, and Emmanuel Saez

NBER Working Paper No. 19843

January 2014, Revised June 2014

JEL No. H0,J0

\begin{abstract}
We use administrative records on the incomes of more than 40 million children and their parents to describe three features of intergenerational mobility in the United States. First, we characterize the joint distribution of parent and child income at the national level. The conditional expectation of child income given parent income is linear in percentile ranks. On average, a 10 percentile increase in parent income is associated with a 3.4 percentile increase in a child's income. Second, intergenerational mobility varies substantially across areas within the U.S. For example, the probability that a child reaches the top quintile of the national income distribution starting from a family in the bottom quintile is $4.4 \%$ in Charlotte but $12.9 \%$ in San Jose. Third, we explore the factors correlated with upward mobility. High mobility areas have (1) less residential segregation, (2) less income inequality, (3) better primary schools, (4) greater social capital, and (5) greater family stability. While our descriptive analysis does not identify the causal mechanisms that determine upward mobility, the publicly available statistics on intergenerational mobility developed here can facilitate future research on such mechanisms.
\end{abstract}

\author{
Raj Chetty \\ Department of Economics \\ Harvard University \\ 1805 Cambridge St. \\ Cambridge, MA 02138 \\ and NBER \\ chetty@fas.harvard.edu \\ Nathaniel Hendren \\ Harvard University \\ Department of Economics \\ Littauer Center Room 235 \\ Cambridge, MA 02138 \\ and NBER \\ nhendren@gmail.com
}

\author{
Patrick Kline \\ Department of Economics \\ UC, Berkeley \\ 508-1 Evans Hall \#3880 \\ Berkeley, CA 94720 \\ and NBER \\ pkline@econ.berkeley.edu \\ Emmanuel Saez \\ Department of Economics \\ University of California, Berkeley \\ 530 Evans Hall \#3880 \\ Berkeley, CA 94720 \\ and NBER \\ saez@econ.berkeley.edu
}




\section{Introduction}

The United States is often hailed as the "land of opportunity," a society in which a child's chances of success depend little on his family background. Is this reputation warranted? We show that this question does not have a clear answer because there is substantial variation in intergenerational mobility across areas within the U.S. The U.S. is better described as a collection of societies, some of which are "lands of opportunity" with high rates of mobility across generations, and others in which few children escape poverty.

We characterize intergenerational mobility using information from de-identified federal income tax records, which provide data on the incomes of more than 40 million children and their parents between 1996 and 2012. We organize our analysis into three parts.

In the first part, we present new statistics on intergenerational mobility in the U.S. as a whole. In our baseline analysis, we focus on U.S. citizens in the 1980-1982 birth cohorts - the oldest children in our data for whom we can reliably identify parents based on information on dependent claiming. We measure these children's income as mean total family income in 2011 and 2012, when they are approximately 30 years old. We measure their parents' income as mean family income between 1996 and 2000, when the children are between the ages of 15 and $20 .^{1}$

Following the prior literature (e.g., Solon 1999), we begin by estimating the intergenerational elasticity of income (IGE) by regressing log child income on log parent income. Unfortunately, we find that this canonical log-log specification yields very unstable estimates of mobility because the relationship between log child income and log parent income is non-linear and the estimates are sensitive to the treatment of children with zero or very small incomes. When restricting the sample between the 10th and 90th percentile of the parent income distribution and excluding children with zero income, we obtain an IGE estimate of 0.45. However, alternative specifications yield IGEs ranging from 0.26 to 0.70 , spanning most of the estimates in the prior literature. ${ }^{2}$

To obtain a more stable summary of intergenerational mobility, we use a rank-rank specification similar to that used by Dahl and DeLeire (2008). We rank children based on their incomes relative to other children in the same birth cohort. We rank parents of these children based on their incomes relative to other parents with children in these birth cohorts. We characterize mobility based on the

\footnotetext{
${ }^{1}$ We show that our baseline measures do not suffer from significant lifecycle or attenuation bias (Solon 1992, Zimmerman 1992, Mazumder 2005) by establishing that estimates of mobility stabilize by the time children reach age 30 and are not very sensitive to the number of years used to measure parent income.

${ }^{2}$ In an important recent study, Mitnik et al. (2014) propose a new dollar-weighted measure of the IGE and show that it yields more stable estimates. We discuss the differences between the new measure of mobility proposed by Mitnik et al. and the canonical definition of the IGE in Section IV.A.
} 
slope of this rank-rank relationship, which identifies the correlation between children's and parents positions in the income distribution. ${ }^{3}$

We find that the relationship between mean child ranks and parent ranks is almost perfectly linear and highly robust to alternative specifications. A 10 percentile point increase in parent rank is associated with a 3.41 percentile increase in a child's income rank on average. Children's college attendance and teenage birth rates are also linearly related to parent income ranks. A 10 percentile point increase in parent income is associated with a 6.7 percentage point (pp) increase in college attendance rates and a 3 pp reduction in teenage birth rates for women.

In the second part of the paper, we characterize variation in intergenerational mobility across commuting zones $(\mathrm{CZs})$. Commuting zones are geographical aggregations of counties that are similar to metro areas but cover the entire U.S., including rural areas (Tolbert and Sizer 1996). We assign children to commuting zones based on where they lived at age 16 - i.e., where they grew up - irrespective of whether they left that CZ afterward. When analyzing CZs, we continue to rank both children and parents based on their positions in the national income distribution, which allows us to measure children's absolute outcomes as we discuss below.

The relationship between mean child ranks and parent ranks is almost perfectly linear within commuting zones, allowing us to summarize the conditional expectation of a child's rank given his parents' rank with just two parameters: a slope and intercept. The slope measures relative mobility: the difference in outcomes between children from top vs. bottom income families within a CZ. The intercept measures the expected rank for children from families at the bottom of the income distribution. Combining the intercept and slope for a $\mathrm{CZ}$, we can calculate the expected rank of children from families at any given percentile $p$ of the national parent income distribution. We term this measure absolute mobility at percentile $p$. Measuring absolute mobility is valuable because increases in relative mobility have ambiguous normative implications, as they may be driven by worse outcomes for the rich rather than better outcomes for the poor.

We find substantial variation in both relative and absolute mobility across CZs. Relative mobility is lowest for children who grew up in the Southeast and highest in the Mountain West and the rural Midwest. Some CZs in the U.S. have relative mobility comparable to the highest mobility countries in the world, such as Canada and Denmark, while others have lower levels of mobility than any developed country for which data are available.

\footnotetext{
${ }^{3}$ The rank-rank slope and IGE both measure the degree to which differences in children's incomes are determined by their parents' incomes. We discuss the conceptual differences between the two measures in Section II.
} 
We find similar geographical variation in absolute mobility. We focus much of our analysis on absolute mobility at $p=25$, which we term "absolute upward mobility." This statistic measures the mean income rank of children with parents in the bottom half of the income distribution given linearity of the rank-rank relationship. Absolute upward mobility ranges from 35.8 in Charlotte to 46.2 in Salt Lake City among the 50 largest CZs. A 1 standard deviation (SD) increase in CZ-level upward mobility is associated with a $0.2 \mathrm{SD}$ improvement in a child's expected rank given parents at $p=25,60 \%$ as large as the effect of a 1 SD increase in his own parents' income. Other measures of upward mobility exhibit similar spatial variation. For instance, the probability that a child reaches the top fifth of the income distribution conditional on having parents in the bottom fifth is $4.4 \%$ in Charlotte, compared with $10.8 \%$ in Salt Lake City and $12.9 \%$ in San Jose. The CZ-level mobility statistics are robust to adjusting for differences in the local cost-of-living, shocks to local growth, and using alternative measures of income.

Absolute upward mobility is highly correlated with relative mobility: areas with high levels of relative mobility (low rank-rank slopes) tend to have better outcomes for children from low-income families. On average, children from families below percentile $p=85$ have better outcomes when relative mobility is greater; those above $p=85$ have worse outcomes. Location matters more for children growing up in low income families: the expected rank of children from low-income families varies more across CZs than the expected rank of children from high income families.

The spatial patterns of the gradients of college attendance and teenage birth rates with respect to parent income across CZs are very similar to the variation in intergenerational income mobility. This suggests that the spatial differences in mobility are driven by factors that affect children while they are growing up rather than after they enter labor market.

In the final part of the paper, we explore such factors by correlating the spatial variation in mobility with observable characteristics. To begin, we show that upward income mobility is significantly lower in areas with larger African-American populations. However, white individuals in areas with large African-American populations also have lower rates of upward mobility, implying that racial shares matter at the community level.

We then identify five factors that are strongly correlated with the variation in upward mobility across areas. The first is segregation: areas that are more residentially segregated by race and income have lower levels of mobility. Second, areas with more inequality as measured by Gini coefficients have less mobility, consistent with the "Great Gatsby curve" documented across countries (Krueger 2012, Corak 2013). Top 1\% income shares are not highly correlated with intergenera- 
tional mobility both across CZs within the U.S. and across countries, suggesting that the factors that erode the middle class may hamper intergenerational mobility more than the factors that lead to income growth in the upper tail. Third, proxies for the quality of the K-12 school system are positively correlated with mobility. Fourth, social capital indices (Putnam 1995) - which are proxies for the strength of social networks and community involvement in an area - are also positively correlated with mobility. Finally, mobility is significantly lower in areas with weaker family structures, as measured e.g. by the fraction of single parents. As with race, parents' marital status does not matter purely through its effects at the individual level. Children of married parents also have higher rates of upward mobility in communities with fewer single parents. Interestingly, we find no correlation between racial shares and upward mobility once we control for the fraction of single parents in an area.

We find modest correlations between upward mobility and local tax policies and no systematic correlation between mobility and local labor market conditions, rates of migration, or access to higher education. In a multivariable regression, the five key factors described above generally remain statistically significant predictors of both relative and absolute upward mobility, even in specifications with state fixed effects. However, we emphasize that these factors should not be interpreted as causal determinants of mobility because all of these variables are endogenously determined and our analysis does not control for numerous other unobserved differences across areas.

Our results build on an extensive literature on intergenerational mobility, reviewed by Solon (1999) and Black and Devereux (2011). Our estimates of the level of mobility in the U.S. as a whole are broadly consistent with prior results, with the exception of Mazumder's (2005) and Clark's (2014) IGE estimates, which imply much lower levels of intergenerational mobility. We discuss why our findings may differ from their results in Online Appendices D and E. Our focus on within-country comparisons offers two advantages over the cross-country comparisons that have been the focus of prior comparative work (e.g., Bjorklund and Jäntti 1997, Jäntti et al. 2006, Corak 2013). First, differences in measurement and methods make it difficult to reach definitive conclusions from cross-country comparisons (Solon 2002). The variables we analyze are measured using the same data sources across all CZs. Second, and more importantly, we characterize both relative and absolute mobility across CZs. The cross-country literature has focused exclusively on differences in relative mobility; much less is known about how the prospects of children from low-income families vary across countries when measured on a common absolute scale (Ray 2010). 
Our analysis also relates to the literature on neighborhood effects, reviewed by Jencks and Mayer (1990) and Sampson, Morenoff and Gannon-Rowley (2002). Unlike recent experimental work on neighborhood effects (e.g., Katz, Kling and Liebman 2001, Oreopoulos 2003), our descriptive analysis does not shed light on whether the differences in outcomes across areas are due to the causal effect of neighborhoods or differences in the characteristics of people living in those neighborhoods. However, in a followup paper, Chetty and Hendren (2014) show that a substantial portion of the spatial variation documented here is driven by causal effects of place by studying families that move across areas with children of different ages.

The paper is organized as follows. We begin in Section II by defining the measures of intergenerational mobility that we study and discussing their conceptual properties. Section III describes the data. Section IV reports estimates of intergenerational mobility at the national level. In Section $\mathrm{V}$, we present estimates of absolute and relative mobility by commuting zone. Section VI reports correlations of our mobility measures with observable characteristics of commuting zones. Section VII concludes. Statistics on intergenerational mobility and related covariates are publicly available by commuting zone, metropolitan statistical area, and county on the project website.

\section{Measures of Intergenerational Mobility}

At the most general level, studies of intergenerational mobility seek to measure the degree to which a child's social and economic opportunities depend upon his parents' income or social status. Because opportunities are difficult to measure, virtually all empirical studies of mobility measure the extent to which a child's income (or occupation) depends upon his parents' income (or occupation). ${ }^{4}$ Following this approach, we aim to characterize the joint distribution of a child's lifetime pre-tax family income $\left(Y_{i}\right)$, and his parents' lifetime pre-tax family income $\left(X_{i}\right) .^{5}$

In large samples, one can characterize the joint distribution of $\left(Y_{i}, X_{i}\right)$ non-parametrically, and we provide such a characterization in the form of a $100 \times 100$ centile transition matrix below. However, in order to provide a parsimonious summary of the degree of mobility and compare rates of mobility across areas, it is useful to characterize the joint distribution using a small set of statistics. We divide measures of mobility into two classes that capture different normative

\footnotetext{
${ }^{4}$ This simplification is not innocuous, as a child's realized income may differ from his opportunities. For instance, children of wealthy parents may choose not to work or may choose lower-paying jobs, which would reduce the persistence of income across generations relative to the persistence of underlying opportunities.

${ }^{5}$ If taxes and transfers do not generate rank-reversals (as is typically the case in practice), using post-tax income instead of pre-tax income would have no impact on our preferred rank-based measures of mobility. See Mitnik et al. (2014) for a comparison of pre-tax and post-tax measures of the intergenerational elasticity of income.
} 
concepts: relative mobility and absolute mobility. In this section, we define a set of statistics that we use to measure these two concepts empirically and compare their conceptual properties.

Relative Mobility. One way to study intergenerational mobility is to ask, "What are the outcomes of children from low-income families relative to those of children from high-income families?" This question, which focuses on the relative outcomes of children from different parental backgrounds, has been the subject of most prior research on intergenerational mobility (Solon 1999, Black et al. 2011).

The canonical measure of relative mobility is the elasticity of child income with respect to parent income $\left(\frac{d E\left[\log Y_{i} \mid X_{i}=x\right]}{d \log x}\right)$, commonly termed the intergenerational income elasticity (IGE). The most common method of estimating the IGE is to regress $\log$ child income $\left(\log Y_{i}\right)$ on $\log$ parent income $\left(\log X_{i}\right)$, which yields a coefficient of

$$
I G E=\rho_{X Y} \frac{S D\left(\log Y_{i}\right)}{S D\left(\log X_{i}\right)}
$$

where $\rho_{X Y}=\operatorname{Corr}\left(\log X_{i}, \log Y_{i}\right)$ is the correlation between $\log$ child income and parent income and $S D()$ denotes the standard deviation. The IGE is a relative mobility measure because it measures the difference in (log) outcomes between children of high vs. low income parents.

An alternative measure of relative mobility is the correlation between child and parent ranks (Dahl and Deleire 2008). Let $R_{i}$ denote child $i$ 's percentile rank in the income distribution of children and $P_{i}$ denote parent $i$ 's percentile rank in the income distribution of parents. Regressing the child's rank $R_{i}$ on his parents' rank $P_{i}$ yields a regression coefficient $\rho_{P R}=\operatorname{Corr}\left(P_{i}, R_{i}\right)$, which we term the rank-rank slope. ${ }^{6}$ The rank-rank slope $\rho_{P R}$ measures the association between a child's position in the income distribution and his parents' position in the distribution.

To understand the connection between the IGE and the rank-rank slope, note that the correlation of $\log$ incomes $\rho_{X Y}$ and the correlation of ranks $\rho_{P R}$ are closely related scale-invariant measures of the degree to which child income depends on parent income. ${ }^{7}$ Hence, (1) implies that the IGE combines the dependence features captured by the rank-rank slope with the ratio of standard deviations of income across generations. ${ }^{8}$ The IGE differs from the rank-rank slope to the extent that inequality changes across generations. Intuitively, a given increase in parents' incomes

\footnotetext{
${ }^{6}$ The regression coefficient equals the correlation coefficient because both child and parent ranks follow a Uniform distribution by construction.

${ }^{7}$ For example, if parent and child income follow a bivariate log Normal distribution, $\rho_{P R}=6 \operatorname{ArcSin}\left(\rho_{X Y} / 2\right) / \pi \approx$ $3 \rho_{X Y} / \pi=0.95 \rho_{X Y}$ when $\rho_{X Y}$ is small (Trivedi and Zimmer 2007).

${ }^{8}$ More generally, the joint distribution of parent and child incomes can be decomposed into two components: the joint distribution of parent and child percentile ranks (the copula) and the marginal distributions of parent and child income. The rank-rank slope depends purely on the copula, while the IGE combines both components.
} 
has a greater impact on the level of children's incomes when inequality is greater among children than parents.

We estimate both the IGE and the rank-rank slope to distinguish differences in mobility from differences in inequality and to provide a comparison to the prior literature. However, we focus primarily on rank-rank slopes because they prove to be much more robust across specifications and are thus more suitable for comparisons across areas from a statistical perspective.

Absolute Mobility. A different way to measure intergenerational mobility is to ask, "What are the outcomes of children from families of a given income level in absolute terms?" For example, one may be interested in measuring the mean outcomes of children whose grow up in low-income families. Absolute mobility may be of greater normative interest than relative mobility. Increases in relative mobility (i.e., a lower IGE or rank-rank slope) could be undesirable if they are caused by worse outcomes for the rich. In contrast, increases in absolute mobility at a given income level, holding fixed absolute mobility at other income levels, unambiguously increase welfare if one respects the Pareto principle (and if welfare depends purely on income).

We consider three statistical measures of absolute mobility. Our primary measure, which we term absolute upward mobility, is the mean rank (in the national child income distribution) of children whose parents are at the 25 th percentile of the national parent income distribution. ${ }^{9}$ At the national level, this statistic is mechanically related to the rank-rank slope and does not provide any additional information about mobility. ${ }^{10}$ However, when we study small areas within the U.S., a child's rank in the national income distribution is effectively an absolute outcome because incomes in a given area have little impact on the national distribution.

The second measure we analyze is the probability of rising from the bottom quintile to the top quintile of the income distribution (Corak and Heisz 1999, Hertz 2006), which can be interpreted as a measure of the fraction of children who achieve the "American Dream." Again, when the quintiles are defined in the national income distribution, these transition probabilities can be interpreted as measures of absolute outcomes in small areas. Our third measure is the probability that a child has family income above the poverty line conditional on having parents at the 25 th percentile. Because the poverty line is defined in absolute dollar terms in the U.S., this statistic measures the fraction

\footnotetext{
${ }^{9}$ This measure is the analog of the rank-rank slope in terms of absolute mobility. The corresponding analog of the IGE is the mean log income of children whose parents are at the 25 th percentile. We do not study this statistic because it is very sensitive to the treatment of zeros and small incomes.

${ }^{10}$ We show below that the rank-rank relationship is approximately linear. Because child and parent ranks each have a mean of 0.5 by construction in the national distribution, the mean rank of children with parents at percentile $p$ is simply $0.5+\rho_{P R}(p-0.5)$. Conceptually, the slope is the only free parameter in the linear national rank-rank relationship. Intuitively, if one child moves up in the income distribution in terms of ranks, another must come down.
} 
of children who achieve a given absolute living standard. ${ }^{11}$

It is useful to analyze multiple measures of mobility because the appropriate measure of intergenerational mobility depends upon one's normative objective (Fields and Ok 1999). Fortunately, we find that the patterns of spatial variation in absolute and relative mobility are very similar using alternative measures. In addition, we provide non-parametric transition matrices and marginal distributions that allow readers to construct measures of mobility beyond those we consider here.

\section{Data}

We use data from federal income tax records spanning 1996-2012. The data include both income tax returns (1040 forms) and third-party information returns (e.g., W-2 forms), which give us information on the earnings of those who do not file tax returns. We provide a detailed description of how we construct our analysis sample starting from the raw population data in Online Appendix A. Here, we briefly summarize the key variable and sample definitions. Note that in what follows, the year always refers to the tax year (i.e., the calendar year in which the income is earned).

\section{III.A Sample Definitions}

Our base dataset of children consists of all individuals who (1) have a valid Social Security Number or Individual Taxpayer Identification Number, (2) were born between 1980-1991, and (3) are U.S. citizens as of 2013. We impose the citizenship requirement to exclude individuals who are likely to have immigrated to the U.S. as adults, for whom we cannot measure parent income. We cannot directly restrict the sample to individuals born in the U.S. because the database only records current citizenship status.

We identify the parents of a child as the first tax filers (between 1996-2012) who claim the child as a child dependent and were between the ages of 15 and 40 when the child was born. If the child is first claimed by a single filer, the child is defined as having a single parent. For simplicity, we assign each child a parent (or parents) permanently using this algorithm, regardless of any subsequent changes in parents' marital status or dependent claiming. ${ }^{12}$

\footnotetext{
${ }^{11}$ Another intuitive measure of upward mobility is the fraction of children whose income exceeds that of their parents. This statistic turns out to be problematic for our application because we measure parent and child income at different ages and because it is very sensitive to differences in local income distributions.

$1212 \%$ of children in our core sample are claimed as dependents by different individuals in subsequent years. To ensure that this potential measurement error in linking children to parents does not affect our findings, we show that we obtain similar estimates of mobility for the subset of children who are never claimed by other individuals (row 9 of Online Appendix Table VII).
} 
If parents never file a tax return, we cannot link them to their child. Although some low-income individuals do not file tax returns in a given year, almost all parents file a tax return at some point between 1996 and 2012 to obtain a tax refund on their withheld taxes and the Earned Income Tax Credit (Cilke 1998). We are therefore able to identify parents for approximately $95 \%$ of the children in the 1980-1991 birth cohorts. The fraction of children linked to parents drops sharply prior to the 1980 birth cohort because our data begin in 1996 and many children begin to the leave the household starting at age 17 (Online Appendix Table I). This is why we limit our analysis to children born during or after 1980 .

Our primary analysis sample, which we refer to as the core sample, includes all children in the base dataset who (1) are born in the 1980-82 birth cohorts, (2) for whom we are able to identify parents, and (3) whose mean parent income between 1996-2000 is strictly positive (which excludes $1.2 \%$ of children). ${ }^{13}$ For some robustness checks, we use the extended sample, which imposes the same restrictions as the core sample, but includes all birth cohorts from 1980-1991. There are approximately 10 million children in the core sample and 44 million children in the extended sample.

Statistics of Income Sample. Because we can only reliably link children to parents starting with the 1980 birth cohort in the population tax data, we can only measure earnings of children up to age 32 (in 2012) in the full sample. To evaluate whether estimates of intergenerational mobility would change significantly if earnings were measured at later ages, we supplement our analysis using annual cross-sections of tax returns maintained by the Statistics of Income (SOI) division of the Internal Revenue Service prior to 1996. The SOI cross-sections provide identifiers for dependents claimed on tax forms starting in 1987, allowing us to link parents to children back to the 1971 birth cohort using an algorithm analogous to that described above (see Online Appendix A for further details). The SOI cross-sections are stratified random samples of tax returns with a sampling probability that rises with income; using sampling weights, we can calculate statistics representative of the national distribution. After linking parents to children in the SOI sample, we use population tax data to obtain data on income for children and parents, using the same definitions as in the core sample. There are approximately 63,000 children in the 1971-79 birth cohorts in the SOI sample (Online Appendix Table II).

\footnotetext{
${ }^{13}$ We limit the sample to parents with positive income because parents who file a tax return (as required to link them to a child) yet have zero income are unlikely to be representative of individuals with zero income and those with negative income typically have large capital losses, which are a proxy for having significant wealth.
} 


\section{III.B Variable Definitions and Summary Statistics}

In this section, we define the key variables we use to measure intergenerational mobility. We measure all monetary variables in 2012 dollars, adjusting for inflation using the consumer price index (CPI-U).

Parent Income. Following Lee and Solon (2009), our primary measure of parent income is total pre-tax income at the household level, which we label parent family income. More precisely, in years where a parent files a tax return, we define family income as Adjusted Gross Income (as reported on the 1040 tax return) plus tax-exempt interest income and the non-taxable portion of Social Security and Disability benefits. In years where a parent does not file a tax return, we define family income as the sum of wage earnings (reported on form W-2), unemployment benefits (reported on form 1099-G), and gross social security and disability benefits (reported on form SSA-1099) for both parents. ${ }^{14}$ In years where parents have no tax return and no information returns, family income is coded as zero. ${ }^{15}$

Our baseline income measure includes labor earnings and capital income as well as unemployment insurance, social security, and disability benefits. It excludes non-taxable cash transfers such as TANF and SSI, in-kind benefits such as food stamps, all refundable tax credits such as the EITC, non-taxable pension contributions (e.g., to 401(k)'s), and any earned income not reported to the IRS. Income is always measured prior to the deduction of individual income taxes and employee-level payroll taxes.

In our baseline analysis, we average parents' family income over the five years from 1996 to 2000 to obtain a proxy for parent lifetime income that is less affected by transitory fluctuations (Solon 1992). We use the earliest years in our sample to best reflect the economic resources of parents while the children in our sample are growing up. ${ }^{16}$ We evaluate the robustness of our findings using data

\footnotetext{
${ }^{14}$ The database does not record W-2's and other information returns prior to 1999, so non-filer's income is coded as 0 prior to 1999. Assigning non-filing parents 0 income has little impact on our estimates because only $2.9 \%$ of parents in our core sample do not file in each year prior to 1999 and most non-filers have very low W-2 income. For instance, in 2000, median W-2 income among non-filers was $\$ 29$. Furthermore, we show below that defining parent income based on data from 1999-2003 (when W-2 data are available) yields virtually identical estimates (Table I, row 5). Note that we never observe self-employment income for non-filers and therefore code it as zero; given the strong incentives for individuals with children to file created by the EITC, most non-filers likely have very low levels of self-employment income as well.

${ }^{15}$ Importantly, these observations are true zeros rather than missing data. Because the database covers all tax records, we know that these individuals have 0 taxable income.

${ }^{16}$ Formally, we define mean family income as the mother's family income plus the father's family income in each year from 1996 to 2000 divided by 10 (or divided by 5 if we only identify a single parent). For parents who do not change marital status, this is simply mean family income over the 5 year period. For parents who are married initially and then divorce, this measure tracks the mean family incomes of the two divorced parents over time. For parents who are single initially and then get married, this measure tracks individual income prior to marriage and
} 
from other years and using a measure of individual parent income instead of family income. We define individual income as the sum of individual W-2 wage earnings, UI benefits, SSDI payments, and half of household self-employment income (see Online Appendix A for details).

Child Income. We define child family income in exactly the same way as parent family income. In our baseline analysis, we average child family income over the last two years in our data (2011 and 2012), when children are in their early 30's. We report results using alternative years to assess the sensitivity of our findings. For children, we define household income based on current marital status rather than marital status at a fixed point in time. Because family income varies with marital status, we also report results using individual income measures for children, constructed in the same way as for parents.

College Attendance. We define college attendance as an indicator for having one or more 1098-T forms filed on one's behalf when the individual is aged 18-21. Title IV institutions - all colleges and universities as well as vocational schools and other post-secondary institutions eligible for federal student aid - are required to file 1098-T forms that report tuition payments or scholarships received for every student. Because the 1098-T forms are filed directly by colleges independent of whether an individual files a tax return, we have complete records on college attendance for all children. The 1098-T data are available from 1999-2012. Comparisons to other data sources indicate that 1098-T forms capture college enrollment quite accurately overall (Chetty, Friedman, and Rockoff 2014, Appendix B). ${ }^{17}$

College Quality. Using data from 1098-T forms, Chetty, Friedman, and Rockoff (2014 forthcoming) construct an earnings-based index of "college quality" using the mean individual wage earnings at age 31 of children born in 1979-80 based on the college they attended at age 20. Children who do not attend college are included in a separate "no college" category in this index. We assign each child in our sample a value of this college quality index based on the college in which they were enrolled at age 20. We then convert this dollar index to percentile ranks within each birth cohort. The children in the no-college group, who constitute roughly $54 \%$ of our core sample, all have the same value of the college quality index. Breaking ties at the mean, we assign all of these children

total family income (including the new spouse's income) after marriage. These household measures of income increase with marriage and naturally do not account for cohabitation; to ensure that these features do not generate bias, we assess the robustness of our results to using individual measures of income.

${ }^{17}$ Colleges are not required to file 1098- $\mathrm{T}$ forms for students whose qualified tuition and related expenses are waived or paid entirely with scholarships or grants. However, the forms are frequently available even for such cases, presumably because of automated reporting to the IRS by universities. Approximately 6\% of 1098-T forms are missing from 2000-2003 because the database contains no 1098-T forms for some small colleges in these years. To verify that this does not affect our results, we confirm that our estimates of college attendance by parent income gradients are very similar for later birth cohorts (not reported). 
a college quality rank of approximately $54 / 2=27 .^{18}$

Teenage Birth. We define a woman as having a teenage birth if she ever claims a dependent who was born while she was between the ages of 13 and 19. This measure is an imperfect proxy for having a teenage birth because it only covers children who are claimed as dependents by their mothers. Nevertheless, the aggregate level and spatial pattern of teenage births in our data are closely aligned with estimates based on the American Community Survey. ${ }^{19}$

Summary Statistics. Online Appendix Table III reports summary statistics for the core sample. Median parent family income is $\$ 60,129$ (in 2012 dollars). Among the $30.6 \%$ of children matched to single parents, $72.0 \%$ are matched to a female parent. Children in our core sample have a median family income of $\$ 34,975$ when they are approximately 30 years old. $6.1 \%$ of children have zero income in both 2011 and 2012. 58.9\% are enrolled in a college at some point between the ages of 18 and 21 and $15.8 \%$ of women have a teenage birth.

In Online Appendix B and Appendix Table IV, we show that the total cohort size, labor force participation rate, distribution of child income, and other demographic characteristics of our core sample line up closely with corresponding estimates in the Current Population Survey and American Community Survey. This confirms that our sample covers roughly the same nationally representative population as previous survey-based research.

\section{National Statistics}

We begin our empirical analysis by characterizing the relationship between parent and child income at the national level. We first present a set of baseline estimates of relative mobility and then evaluate the robustness of our estimates to alternative sample and income definitions. ${ }^{20}$

\section{IV.A Baseline Estimates}

In our baseline analysis, we use the core sample (1980-82 birth cohorts) and measure parent income as mean family income from 1996-2000 and child income as mean family income in 2011-12, when

\footnotetext{
${ }^{18}$ The exact value varies across cohorts. For example, in the 1980 birth cohort, $55.1 \%$ of children do not attend college. We assign these children a rank of $55.1 / 2+0.02=27.7 \%$ because $0.2 \%$ of children in the 1980 birth cohort attend colleges whose mean earnings are below the mean earnings of those not in college.

${ }^{19} 15.8 \%$ of women in our core sample have teenage births; the corresponding number is $14.6 \%$ in the 2003 ACS. The unweighted correlation between state-level teenage birth rates in the tax data and the ACS is 0.80 .

${ }^{20}$ We do not present estimates of absolute mobility at the national level because absolute mobility in terms of percentile ranks is mechanically related to relative mobility at the national level (see Section II). While one can compute measures of absolute mobility at the national level based on mean incomes (e.g., the mean income of children whose parents are at the 25th percentile), there is no natural benchmark for such a statistic as it has not been computed in other countries or time periods.
} 
children are approximately 30 years old. Figure Ia presents a binned scatter plot of the mean family income of children versus the mean family income of their parents. To construct this figure, we divide the horizontal axis into 100 equal-sized (percentile) bins and plot mean child income vs. mean parent income in each bin. ${ }^{21}$ This binned scatter plot provides a non-parametric representation of the conditional expectation of child income given parent income, $E\left[Y_{i} \mid X_{i}=x\right]$. The regression coefficients and standard errors reported in this and all subsequent binned scatter plots are estimated on the underlying microdata using OLS regressions.

The conditional expectation of children's income given parents' income is strongly concave. Below the 90th percentile of parent income, a $\$ 1$ increase in parent family income is associated with a 33.5 cent increase in average child family income. In contrast, between the 90th and 99th percentile, a $\$ 1$ increase in parent income is associated with only a 7.6 cent increase in child income.

Log-Log Intergenerational Elasticity Estimates. Partly motivated by the non-linearity of the relationship in Figure Ia, the canonical approach to characterizing the joint distribution of child and parent income is to regress the log of child income on the log of parent income (as discussed in Section II), excluding children with zero income. This regression yields an estimated intergenerational elasticity (IGE) of 0.344 , as shown in the first column of row 1 of Table I.

Unfortunately, this estimate turns out to be quite sensitive to changes in the regression specifications for two reasons, illustrated in Figure Ib. First, the relationship between log child income and log parent income is highly non-linear, consistent with the findings of Corak and Heisz (1999) in Canadian tax data. This is illustrated in the series in circles in Figure Ib, which plots mean log child income vs. mean log family income by percentile bin, constructed using the same method as Figure Ia. Because of this non-linearity, the IGE is sensitive to the point of measurement in the income distribution. For example, restricting the sample to observations between the 10th and 90th percentile of parent income (denoted by the vertical dashed lines in the graph) yields a considerably higher IGE estimate of 0.452 .

Second, the log-log specification discards observations with zero income. The series in triangles in Figure Ib plots the fraction of children with zero income by parental income bin. This fraction varies from $17 \%$ among the poorest families to $3 \%$ among the richest families. Dropping children with zero income therefore overstates the degree of intergenerational mobility. The way in which these zeros are treated can change the IGE dramatically. For instance, including the zeros by

\footnotetext{
${ }^{21}$ For scaling purposes, we exclude the top bin (parents in the top 1\%) in this figure only; mean parent income in this bin is $\$ 1,408,760$ and mean child income is $\$ 113,846$.
} 
assigning those with zero income an income of $\$ 1$ (so that the log of their income is zero) raises the estimated IGE to 0.618 , as shown in row 2 of Table I. If instead we treat those with 0 income as having an income of $\$ 1,000$, the estimated IGE becomes 0.413 . These exercises show that small differences in the way children's income is measured at the bottom of the distribution can produce substantial variation in IGE estimates.

Columns 2-7 in Table I replicate the baseline specification in Column 1 for alternative subsamples analyzed in the prior literature. Columns 2-5 split the sample by the child's gender and the parents' marital status in the year they first claim the child. Column 6 replicates Column 1 for the extended sample of 1980-85 birth cohorts. Column 7 restricts the sample to children whose mothers are between the ages of 24-28 and fathers are between 26-30 (a five year window around the median age of birth). This column eliminates variation in parent income correlated with differences in parent age at child birth and restricts the sample to parents who are less than 50 years old when we measure their incomes (for children born in 1980). Across these subsamples, the IGE estimates range from 0.264 (for children of single parents, excluding children with zero income) to 0.697 (for male children, recoding zeroes to $\$ 1$ ).

The IGE is unstable because the income distribution is not well approximated by a bivariate Log-Normal distribution, a result that was not apparent in smaller samples used in prior work. This makes it difficult to obtain reliable comparisons of mobility across samples or geographical areas using the IGE. For example, income measures in survey data are typically top-coded and sometimes include transfers and other sources of income that increase incomes at the bottom of the distribution, which may lead to larger IGE estimates than those obtained in administrative datasets such as the one used here.

In a recent paper, Mitnik et al. (2014) propose a new measure of the IGE, the elasticity of expected child income with respect to parent income $\left(\frac{d \log E\left[Y_{i} \mid X_{i}=x\right]}{d \log x}\right)$, which they show is more robust to the treatment of small incomes. In large samples, one can estimate this parameter by regressing the log of mean child income in each percentile bin (plotted in Figure Ia) on the log of mean parent income in each bin. In Online Appendix C, we show that Mitnik et al.'s statistic can be interpreted as a dollar-weighted average of elasticities (placing greater weight on high income children), whereas the traditional IGE weights all individuals with positive income equally. These two parameters need not coincide in general and the "correct" parameter depends upon the policy question one seeks to answer. However, it turns out that in our data, the Mitnik et al. dollarweighted IGE estimate is 0.335 , very similar to our baseline IGE estimate of 0.344 when excluding 
children with zero income (Online Appendix Figure Ia). ${ }^{22}$

In another recent study, Clark (2014) argues that traditional estimates of the IGE understate the persistence of status across generations because they are attenuated by fluctuations in realized individual incomes across generations. To resolve this problem, Clark estimates the IGE based on surname-level means of income in each generation and obtains a central IGE estimate of 0.8 , much larger than that in prior studies. In our data, estimates of mobility based on surname means are similar to our baseline estimates based on individual income data (Online Appendix Table V). One reason that Clark (2014) may obtain larger estimates of intergenerational persistence is that his focus on distinctive surnames partly identifies the degree of convergence in income between racial or ethnic groups (Borjas 1992) rather than across individuals (see Online Appendix D for further details). ${ }^{23}$

Rank-Rank Estimates. Next, we present estimates of the rank-rank slope, the second measure of relative mobility discussed in Section II. We measure the percentile rank of parents $P_{i}$ based on their positions in the distribution of parent incomes in the core sample. Similarly, we define children's percentile ranks $R_{i}$ based on their positions in the distribution of child incomes within their birth cohorts. Importantly, this definition allows us to include zeros in child income. ${ }^{24}$ Unless otherwise noted, we hold the definition of these ranks fixed based on positions in the aggregate distribution, even when analyzing subgroups.

Figure IIa presents a binned scatter plot of the mean percentile rank of children $E\left[R_{i} \mid P_{i}=p\right]$ vs. their parents' percentile rank $p$. The conditional expectation of a child's rank given his parents' rank is almost perfectly linear. Using an OLS regression, we estimate that a one percentage point (pp) increase in parent rank is associated with a $0.341 \mathrm{pp}$ increase in the child's mean rank, as reported in row 4 of Table I. The rank-rank slope estimates are generally quite similar across subsamples, as shown in Columns 2-7 of Table I.

Figure IIb compares the rank-rank relationship in the U.S. with analogous estimates for Denmark constructed using data from Boserup, Kopczuk and Kreiner (2013) and estimates for Canada

\footnotetext{
${ }^{22}$ Mitnik et al. (2014) find larger estimates of the dollar-weighted IGE in their sample of tax returns. A useful direction for further work would be to understand why the two samples yield different IGE estimates.

${ }^{23}$ For example, Clark (2014, page 60, Figure 3.10) compares the outcomes of individuals with the surname "Katz" (a predominantly Jewish name) vs. "Washington" (a predominantly black name). This comparison generates an implied IGE close to 1, which partly reflects the fact that the black-white income gap has changed very little over the past few decades. Estimates of the IGE based on individual-level data (or pooling all surnames) are much lower because there is much more social mobility within racial groups.

${ }^{24}$ In the case of ties, we define the rank as the mean rank for the individuals in that group. For example, if $10 \%$ of a birth cohort has zero income, all children with zero income would receive a percentile rank of 5 .
} 
constructed from the decile transition matrix reported by Corak and Heisz (1999). ${ }^{25}$ The relationship between child and parent ranks is nearly linear in Denmark and Canada as well, suggesting that the rank-rank specification provides a good summary of mobility across diverse environments. The rank-rank slope is 0.180 in Denmark and 0.174 in Canada, nearly half that in the U.S.

Importantly, the smaller rank-rank slopes in Denmark and Canada do not necessarily mean that children from low-income families in these countries do better than those in the U.S. in absolute terms. It could be that children of high-income parents in Denmark and Canada have worse outcomes than children of high-income parents in the U.S. One cannot distinguish between these possibilities because the ranks are defined within each country. One advantage of the withinU.S. CZ-level analysis implemented below is that it naturally allows us to study both relative and absolute outcomes by analyzing children's performance on a fixed national scale.

Transition Matrices. Table II presents a quintile transition matrix: the probability that a child is in quintile $m$ of the child income distribution conditional on his parent being in quintile $n$ of the parent income distribution. One statistic of particular interest in this matrix is the probability of moving from the bottom quintile to the top quintile, a simple measure of success that we return to below. This probability is $7.5 \%$ in the U.S., compared with $11.7 \%$ in Denmark (Boserup, Kopczuk and Kreiner 2013) and 13.4\% in Canada (Corak and Heisz 1999). In this sense, the chances of achieving the "American Dream" are considerably higher for children in Denmark and Canada than those in the U.S.

In Online Data Table I, we report a 100 x 100 percentile-level transition matrix for the U.S. Using this matrix and the marginal distributions for child and parent income in Online Data Table II, one can construct any mobility statistic of interest for the U.S. population. ${ }^{26}$

\section{IV.B Robustness of Baseline Estimates}

We now evaluate the robustness of our estimates of intergenerational mobility to alternative specifications. We begin by evaluating two potential sources of bias emphasized in prior work: lifecycle bias and attenuation bias.

\footnotetext{
${ }^{25}$ Both the Danish and Canadian studies use administrative earnings information for large samples as we do here. The Danish sample, which was constructed to match the analysis sample in this paper as closely as possible, consists of children in the 1980-81 birth cohorts and measures child income based on mean income between 2009-11. Child income in the Danish sample is measured at the individual level and parents' income is the mean of the two biological parents' income from 1997-1999, irrespective of their marital status. The Canadian sample is less comparable to our sample, as it consists of male children in the 1963-66 birth cohorts and studies the link between their mean earnings from 1993-95 and their fathers' mean earnings from 1978-82.

${ }^{26}$ All of the online data tables are available at http://www.equality-of-opportunity.org/index.php/data.
} 
Lifecycle Bias. Prior research has shown that measuring children's income at early ages can understate intergenerational persistence in lifetime income because children with high lifetime incomes have steeper earnings profiles when they are young (Haider and Solon, 2006, Grawe, 2006, Solon 1999). To evaluate whether our baseline estimates suffer from such lifecycle bias, Figure IIIa plots estimates of the rank-rank slope by the age at which the child's income is measured. We construct the series in circles by measuring children's income as mean family income in 2011-2012 and parent income as mean family income between 1996-2000, as in our baseline analysis. We then replicate the OLS regression of child income rank on parent income rank for each birth cohort between 1980-1990. For children in the 1980 birth cohort, we measure earnings in 2011-12 at age 31-32 (denoted by 32 in the figure); for the 1990 cohort, we measure earnings at age 21-22. ${ }^{27}$ The rank-rank slope rises very steeply in the early 20's as children enter the labor force, but stabilizes around age 30 . It increases by $2.1 \%$ from age 30 to 31 and $0.2 \%$ from age 31 to 32 .

To obtain estimates beyond age 32, we use the SOI 0.1\% random sample described in Section III.A, which contains data back to the 1971 birth cohort. The series in triangles in Figure IIIa replicates the analysis above within the SOI sample, using sampling weights to recover estimates representative of the population. The estimates in the SOI sample are very similar to those in the full population prior to age 32. After age 32, the estimates remain roughly constant. These findings indicate that rank-rank correlations exhibit little lifecycle bias provided that child income is measured after age 30, as in our baseline definition.

We also find that estimates of the IGE using the traditional log-log specification (limiting the sample between the 10th and 90th percentiles of the parent income distribution) stabilize around age 30, as shown in Online Appendix Figure IIa. In the population data, the IGE estimate is a strictly concave function of age and rises by only $1.7 \%$ from age 31 to 32 . The SOI $0.1 \%$ sample exhibits a similar, albeit noisier, pattern.

An analogous lifecycle bias can arise if parent income is measured at very old or young ages. In Online Appendix Figure IIb we plot the rank-rank slope using the core sample, varying the 5-year window used to measure parent income from a starting year of 1996 (when mothers are 41 years old on average) to 2010 (when mothers are 55 years old). The rank-rank estimates exhibit virtually no variation with the age of parent income measurement within this range.

A closely related concern is that parent income at earlier ages might matter more for children's

\footnotetext{
${ }^{27}$ We obtain very similar results if we instead track a single cohort and vary age by measuring earnings in different calendar years.
} 
outcomes, e.g. if resources in early childhood are relevant for child development (e.g., Heckman 2006, Duncan, Ziol-Guest and Kalil 2010). While we cannot measure parent income before age 14 for children in our core sample, we can measure parent income at earlier ages for later birth cohorts. In Chetty et al. (2014), we use data from the 1993 birth cohort and regress an indicator for college attendance at age 19 on parent income rank in each year from 1996 to 2012 . We reproduce the coefficients from those regressions in Online Appendix Figure IIc. The relationship between college attendance rates and parent income rank is virtually constant when children are between ages 3 and 19. Once again, this result indicates that the point at which parent income is measured (provided parents are between ages 30-55) does not significantly affect intergenerational associations, at least in administrative earnings records. ${ }^{28}$

Attenuation Bias. Income in a single year is a noisy measure of lifetime income, which attenuates estimates of intergenerational persistence (Solon (1992)). To evaluate whether our baseline estimates suffer from such attenuation bias, Figure IIIb plots estimates of the rank-rank slope, varying the number of years used to calculate mean parent family income. In this figure, we plot the slope from an OLS regression of child rank on parent rank (as in Row 4, Column 1 of Table I), varying the number of years used to calculate mean parent income from one (1996 only) to 17 (1996-2012). The rank-rank slope based on five years of data (0.341) is 6.6\% larger than the slope based on one year of parent income (0.320). Solon (1992) finds a 33\% increase in the IGE (from 0.3 to 0.4 ) when using a five-year average instead of one year of data in the PSID. We find less attenuation bias for three reasons: (1) income is measured with less error in the tax data than in the PSID, (2) we use family income measures rather than individual income, which fluctuates more across years, and (3) we use a rank-rank specification rather than a log-log specification, which is more sensitive to income fluctuations at the bottom of the distribution.

Mazumder (2005) reports that even five-year averages of parent income yield attenuated estimates of intergenerational persistence relative to longer time averages. Contrary to this result, we find that the rank-rank slope is virtually unchanged by adding more years of data beyond five years: the estimated slope using 15 years of data to measure parent income (0.350) is only $2.8 \%$ larger than the baseline slope of 0.341 using 5 years of data. We believe our results differ because we directly measure parent income, whereas Mazumder imputes parent income based on race and

\footnotetext{
${ }^{28}$ While we cannot measure income before the year in which children turn 3 , the fact that the college-income gradient is not declining from ages 3-19 makes it unlikely that the gradient is significantly larger prior to age 2 . Parent income ranks in year $t$ have a correlation of 0.91 with parent income ranks in year $t+1,0.77$ in year $t+5$, and 0.65 in year $t+15$. The decay in this autocorrelation would generate a decreasing slope in the gradient in Online Appendix Figure IIc if there were a discontinuous jump in the gradient prior to age 2 .
} 
education for up to $60 \%$ of the observations in his sample, with a higher imputation rate when measuring parent income using more years (see Online Appendix E for further details). Such imputations are analogous to instrumenting for income with race and education, which is known to yield upward-biased estimates of intergenerational persistence (Solon 1992).

We analyze the impact of varying the number of years used to measure the child's income in Online Appendix Figure IId. The rank-rank slope increases very little when increasing the number of years used to compute child family income, with no detectable change once one averages over at least two years, as in our baseline measure. An ancillary implication of this result is that our estimates of intergenerational mobility are not sensitive to the calendar year in which we measure children's incomes. This finding is consistent with the results of Chetty et al. (2014), who show that estimates of intergenerational mobility do not vary significantly across birth cohorts when income is measured at a fixed age.

Alternative Income Definitions. In rows 5-8 of Table I, we explore the robustness of the baseline rank-rank estimate to alternative definitions of child and parent income. In row 5 , we verify that the missing W-2 data from 1996-1998 does not create significant bias by defining parent income as mean income from 1999-2003. The rank-rank estimates are virtually unchanged with this redefinition.

In row 6 , we define the parent's rank based on the individual income of the parent with higher mean income from 1999-2003. ${ }^{29}$ This specification eliminates the mechanical variation in family income driven by the number of parents in the household, which could overstate the persistence of income across generations if parent marital status has a direct effect of children's outcomes. The rank-rank correlation falls by approximately $10 \%$, from 0.341 to 0.312 when we use top parent income. The impact of using individual parent income instead of family income is modest because (1) most of the variation in parent income across households is not due to differences in marital status and (2) the mean ranks of children with married parents are only 4.6 percentile points higher than those with single parents.

Next, we consider alternative income definitions for the children. Here, one concern is that children of higher income parents may be more likely to marry, again exaggerating the observed persistence in family income relative to individual income. Using individual income to measure the child's rank has differential impacts by the child's gender, consistent with Chadwick and Solon

\footnotetext{
${ }^{29}$ We use 1999-2003 income here because we cannot allocate earnings across spouses before 1999, as W-2 forms are available starting only in 1999. Note that top income rank differs from family income rank even for single parents because some individuals get married in subsequent years and because these individuals are ranked relative to the population, not relative to other single individuals.
} 
(2002). For male children, using individual income instead of family income reduces the rank-rank correlation from 0.336 in the baseline specification to 0.317 , a $6 \%$ reduction. For female children, using individual income reduces the rank-rank correlation from 0.346 to 0.257 , a $26 \%$ reduction. The change may be larger for women because women from high income families tend to marry high-income men and may choose not to work.

Finally, in row 8 of Table I, we define a measure of child income that excludes capital and other non-labor income using the sum of individual wage earnings, UI benefits, SSDI benefits, and Schedule C self-employment income. We divide self-employment income by two for married individuals. This individual earnings measure also yields virtually identical estimates of the rankrank slope.

\section{IV.C Intermediate Outcomes: College Attendance and Teenage Birth}

We supplement our analysis of intergenerational income mobility by studying the relationship between parent income and two intermediate outcomes for children: college attendance and teenage birth.

The series in circles in Figure IVa presents a binned scatter plot of the college attendance rate of children vs. the percentile rank of parent family income using the core sample. College attendance is defined as attending college in one or more years between the ages 18 and 21. The relationship between college attendance rates and parental income rank is again virtually linear, with a slope of 0.675. That is, moving from the lowest-income to highest-income parents increases the college attendance rate by 67.5 percentage points, similar to the estimates reported by Bailey and Dynarski (2011) using survey data.

The series in triangles in Figure IVa plots college quality ranks vs. parent ranks. We define a child's college quality rank based on the mean earnings at age 30 of students who attended each college at age 20 . The $54 \%$ of children who do not attend college at age 20 are included in this analysis and are assigned the mean rank for the non-college group, which is approximately $54 / 2=$ 27 (see Section III.B for details). The relationship between college quality rank and parent income rank is convex because most children from low-income families do not attend college and hence increases in parent income have little impact on college quality rank at the bottom. To account for this non-linearity, we regress college quality ranks on a quadratic function of parent income rank and define the gradient in college quality as the difference in the predicted college quality rank for children with parents at the 75 th percentile and children with parents at the 25 th percentile. The 
P25-75 gap in college quality ranks is 19.1 percentiles in our core sample.

Figure IVb plots teenage birth rates for female children vs. parent income ranks. Teenage birth is defined (for females only) as having a child when the mother is aged 13-19. There is a 29.8 percentage point gap in teenage birth rates between children from the highest- and lowest-income families.

These correlations between intermediate outcomes and parent income ranks do not vary significantly across subsamples or birth cohorts, as shown in rows 9-11 of Table I. The strength of these correlations indicates that much of the divergence between children from low vs. high income families emerges well before they enter the labor market, consistent with the findings of prior work (e.g., Neal and Johnson 1996, Cameron and Heckman 2001, Bhattacharya and Mazumder 2011).

\section{Spatial Variation in Mobility}

We now turn to our central goal of characterizing the variation in intergenerational mobility across areas within the U.S. We begin by defining measures of geographic location. We then present estimates of relative and absolute mobility by area and assess the robustness of these estimates to alternative specifications.

\section{V.A Geographical Units}

To characterize the variation in children's outcomes across areas, one must first partition the U.S. into a set of geographical areas in which children grow up. One way to conceptualize the choice of a geographical partition is using a hierarchical model in which children's outcomes depend upon conditions in their immediate neighborhood (e.g., peers or resources in their city block), local community (e.g., the quality of schools in their county), and broader metro area (e.g., local labor market conditions). To fully characterize the geography of intergenerational mobility, one would ideally estimate all of the components of such a hierarchical model.

As a first step toward this goal, we characterize intergenerational mobility at the level of commuting zones $(\mathrm{CZs})$. CZs are aggregations of counties based on commuting patterns in the 1990 Census constructed by Tolbert and Sizer (1996) and introduced to the economics literature by Dorn (2009). Since CZs are designed to span the area in which people live and work, they provide a natural starting point as the coarsest partition of areas. CZs are similar to metropolitan statistical areas (MSA), but unlike MSAs, they cover the entire U.S., including rural areas. There are 741 CZs in the U.S.; on average, each CZ contains 4 counties and has a population of 380,000. See 
Online Appendix Figure III for an illustration of the Boston CZ.

We focus on CZ-level variation because mobility statistics in very small neighborhoods are likely to be heavily affected by sorting. Because property prices are typically homogeneous within narrow areas and home values are highly correlated with parent income, comparisons within a small neighborhood effectively condition on a proxy for parent income. As a result, the variation in parent income across individuals in a small area (such as a city block) must be correlated with other latent factors that could affect children's outcomes directly, making it difficult to interpret the resulting mobility estimates. ${ }^{30}$ Nevertheless, to obtain some insight into within-CZ variation, we also report statistics on intergenerational mobility by county in Online Data Table III. There is almost as much variance in intergenerational mobility across counties within a $\mathrm{CZ}$ as there is across CZs, suggesting that the total amount of geographical variation may be even greater than that documented below. ${ }^{31}$

We permanently assign each child to a single CZ based on the ZIP code from which his or his parent filed their tax return in the first year the child was claimed as a dependent. We interpret this CZ as the area where a child grew up. Because our data begin in 1996, location is measured in 1996 for $95.9 \%$ of children in our core sample. ${ }^{32}$ For children in our core sample of 1980-82 birth cohorts, we therefore typically measure location when children were approximately 15 years old. For the children in the more recent birth cohorts in our extended sample, location is measured at earlier ages. Using these more recent cohorts, we find that $83.5 \%$ of children live in the same $\mathrm{CZ}$ at age 16 as they did at age 5. Furthermore, we verify that the spatial patterns for the outcomes we can measure at earlier ages (college attendance and teenage birth) are similar if we define CZs based on location at age 5 instead of age 16 .

The CZ where a child grew up does not necessarily correspond to the CZ he lives in as an adult when we measure his income (at age 30) in 2011-12. In our core sample, $38 \%$ of children live in a different CZ in 2012 relative to where they grew up.

\footnotetext{
${ }^{30}$ For example, it would be difficult to estimate the degree of intergenerational mobility on Park Avenue in Manhattan because any families with low observed income in such a high-property-value area would have to be latently wealthy to be able to afford to live there.

${ }^{31}$ We also report statistics by MSA in Online Data Table IV. For CZs that intersect MSAs, correlations between CZ-level and MSA-level mobility statistics exceed 0.9 .

${ }^{32}$ Location is measured after 1996 for approximately $3 \%$ of children because they were linked to parents based on tax returns filed after 1996. We have no information on location for the remaining $1 \%$ of children in the national sample because the ZIP code listed on the parent's tax returns is invalid or missing (see Online Appendix Table I); these children are excluded from the analysis in the remainder of the paper.
} 


\section{V.B Measures of Relative and Absolute Mobility}

In our baseline analysis, we measure mobility at the CZ level using the core sample (1980-82 birth cohorts) and the definitions of parent and child family income described in III.B. Importantly, we continue to rank both children and parents based on their positions in the national income distribution (rather than the distribution within their $\mathrm{CZ}$ ).

We begin by examining the rank-rank relationship in selected CZs. Figure Va presents a binned scatter plot of the mean child rank vs. parent rank for children who grew up in the Salt Lake City, UT (circles) or Charlotte, NC (triangles) commuting zones. The rank-rank relationship is virtually linear in both of these CZs. The linearity of the rank-rank relationship is a remarkably robust property across CZs, as illustrated for the 20 largest CZs in Online Appendix Figure IV.

Exploiting this approximate linearity, we summarize the conditional expectation of a child's rank given his parents' rank in each CZ using two parameters: a slope and an intercept. Let $R_{i c}$ denote the national income rank (among children in his birth cohort) of child $i$ who grew up in CZ c. Similarly, let $P_{i c}$ denote his parent's rank in the income distribution of parents in the core sample. We estimate the slope and intercept of the rank-rank relationship in $\mathrm{CZ} c$ by regressing child rank on parent rank:

$$
R_{i c}=\alpha_{c}+\beta_{c} P_{i c}+\varepsilon_{i c}
$$

The slope of the rank-rank relationship $\left(\beta_{c}\right)$ in (2) measures degree of relative mobility in $\mathrm{CZ} c$, as defined in Section II. In Salt Lake City, $\beta_{c}=0.264 .{ }^{33}$ The difference between the expected ranks of children born to parents at the top and bottom of the income distribution is $\bar{r}_{100, c}-\bar{r}_{0, c}=100 \times \beta_{c}=$ 26.4 in Salt Lake City. There is much less relative mobility (i.e., much greater persistence of income across generations) in Charlotte, where $\bar{r}_{100}-\bar{r}_{0}=39.7$.

Following the discussion in Section II, we define absolute mobility at percentile $p$ in $\mathrm{CZ} c$ as the expected rank of a child who grew up in $\mathrm{CZ} c$ with parents who have a national income rank of $p$ :

$$
\bar{r}_{p c}=\alpha_{c}+\beta_{c} p
$$

We focus much of our analysis on average absolute mobility for children from families with belowmedian parent income in the national distribution $\left(E\left[R_{i c} \mid P_{i c}<50\right]\right)$, which we term absolute upward mobility. ${ }^{34}$ Because the rank-rank relationship is linear, the average rank of children with below-

\footnotetext{
${ }^{33}$ We always measure percentile ranks on a $0-100$ scale and slopes on a $0-1$ scale, so $\alpha_{c}$ ranges from $0-100$ and $\beta_{c}$ ranges from 0 to 1 in (3).

${ }^{34}$ We integrate over the national parent income distribution rather than the local distribution when defining $E\left[R_{i c} \mid P_{i c}<50\right]$ to ensure that our cross-CZ comparisons are not affected by differences in local income distributions.
} 
median parent income equals the average rank of children with parents at the 25th percentile in the national distribution $\left(\bar{r}_{25, c}=\alpha_{c}+25 \beta_{c}\right)$, illustrated by the dashed vertical line in Figure Va. Absolute upward mobility is $\bar{r}_{25}=46.2$ in Salt Lake City, compared with $\bar{r}_{25}=35.8$ in Charlotte. That is, among families earning $\$ 28,800$ - the 25 th percentile of the national parent family income distribution - children who grew up in Salt Lake City are on average 10 percentile points higher in their birth cohort's income distribution at age 30 than children who grew up in Charlotte.

Absolute mobility is higher in Salt Lake City not just for below-median families, but at all percentiles $p$ of the parent income distribution. The gap in absolute outcomes is largest at the bottom of the income distribution and nearly zero at the top. Hence, the greater relative mobility in this particular comparison comes purely from better absolute outcomes at the bottom of the distribution rather than worse outcomes at the top. Of course, this is not always the case. Figure Vb shows that San Francisco has substantially higher relative mobility than Chicago: $\bar{r}_{100}-\bar{r}_{0}=25.0$ in San Francisco vs. $\bar{r}_{100}-\bar{r}_{0}=39.3$ in Chicago. But part of the greater relative mobility in San Francisco comes from worse outcomes for children from high-income families. Below the 60th percentile, children in San Francisco have better outcomes than those in Chicago; above the 60th percentile, the reverse is true.

The comparisons in Figure V illustrate the importance of measuring both relative and absolute mobility. Any social welfare function based on mean income ranks that respects the Pareto principle would rate Salt Lake City above Charlotte. But normative comparisons of San Francisco and Chicago depend on the weight one puts on relative vs. absolute mobility (or, equivalently, on the weights one places on absolute mobility at each percentile $p$ ).

\section{V.C Baseline Estimates by $C Z$}

We estimate (2) using OLS to calculate absolute upward mobility $\left(\bar{r}_{25, c}=\alpha_{c}+25 \beta_{c}\right)$ and relative mobility $\left(\beta_{c}\right)$ by CZ. The estimates for each CZ are reported in Online Data Table V.

Absolute Upward Mobility. Figure VIa presents a heat map of absolute upward mobility. We construct this map by dividing CZs into deciles based on their estimated value of $\bar{r}_{25, c}$. Lighter colors represent deciles with higher levels of $\bar{r}_{25, c} \cdot{ }^{35}$ Upward mobility varies significantly across

We focus on the absolute outcomes of children from low-income families both because the outcomes of disadvantaged youth are a central focus of policy interest and because there is more variation across areas in the outcomes of children from low-income families than those from high-income families, as we show in Figure VII below. However, the CZ-level statistics in Online Data Tables V and VI can be used to analyze spatial variation in the outcomes of children from high-income families.

${ }^{35}$ We cannot estimate mobility for $32 \mathrm{CZs}$ in which we have fewer than 250 children in the core sample, shown by the cross-hatched areas in the maps in Figure VI. These CZs account for less than $0.05 \%$ of the U.S. population in 
areas. CZs in the top decile have $\bar{r}_{25, c}>52.0$, while those in the bottom decile have $\bar{r}_{25, c}<37.4$. Note that the 37 th percentile of the family income distribution for children at age 30 is $\$ 22,900$, while the 52 nd percentile is $\$ 35,500$; hence, the difference in upward mobility across areas translates to substantial differences in children's incomes.

Pooling all CZs, the unweighted standard deviation (SD) of $\bar{r}_{25, c}$ is 5.68; the population-weighted $\mathrm{SD}$ is 3.34. The unconditional SD of children's income ranks (which have a Uniform distribution) is $100 / \sqrt{12}=28.9$. Hence, a 1 SD improvement in CZ "quality" - as measured by its level of absolute upward mobility $\bar{r}_{25, c}$ - is associated with a $5.68 / 28.9=0.20$ SD increase in the expected income rank of children whose parents are at the 25 th percentile. ${ }^{36}$ For comparison, a 1 SD increase in parent income rank is associated with a 0.34 SD increase in a child's income rank (Figure IIa). Hence, a 1 SD improvement in CZ quality is associated with $60 \%$ as large an increase in a child's income as a $1 \mathrm{SD}$ increase in his own parent's income.

There are three broad spatial patterns in upward mobility evident in Figure VIa. First, upward mobility varies substantially at the regional level. Upward mobility is lowest in the Southeast and highest in the Great Plains. The West Coast and Northeast also have high rates of upward mobility, though not as high as the Great Plains.

Second, there is substantial within-region variation as well. Using unweighted CZ-level regressions of the upward mobility estimates on Census division and state fixed effects, we estimate that $53 \%$ of the cross-CZ variance in absolute upward mobility is within the nine Census divisions and $36 \%$ is within states. For example, many parts of Texas exhibit relatively high rates of upward mobility, unlike much of the rest of the South. Ohio exhibits much lower rates of upward mobility than nearby Pennsylvania. The statistics also pick up much more granular variation in upward mobility. For example, South Dakota generally exhibits very high levels of upward mobility, with the exception of a few areas in the Southwest corner of the state. These areas are some of the largest Native American reservations in the U.S. and are well known to suffer from very high rates of persistent poverty.

the 2000 Census. In Online Appendix Figure V, we present a version of this map in which we use data from the 1980-85 cohorts to estimate mobility for the CZs that have fewer than 250 observations in the core (1980-82) sample. The estimates of mobility in the CZs with missing data are quite similar to those in neighboring CZs, consistent with the spatial autocorrelation evident in the rest of the map.

${ }^{36}$ An analogous calculation using the estimates of college attendance gradients by CZ in Section IV.C below implies that a $1 \mathrm{SD}$ increase in CZ quality is associated with a $0.19 \mathrm{SD}$ (9.3 percentage point) increase in college attendance rates for children with parents at the 25th percentile. Using data from the PSID, Solon, Page and Duncan (2002, p390) estimate that a $1 \mathrm{SD}$ increase in neighborhood quality is associated with a $0.32 \mathrm{SD}$ increase in years of education. We find less variation in outcomes across neighborhoods presumably because commuting zones are much larger than the PSID sampling clusters analyzed by Solon, Page, and Duncan. 
The third generic pattern is that urban areas tend to exhibit lower levels of intergenerational mobility than rural areas on average. For instance, children from low-income families who grow up in the Chicago area have significantly lower incomes at age 30 than those who grow up in rural areas in Illinois. On average, urban areas - which we define as CZs that intersect MSAs - have upward mobility of $\bar{r}_{25, c}=41.7$, while rural areas have $\bar{r}_{25, c}=45.8$. In interpreting this comparison, it is important to recall that our definition of geography is based on where children grew up, not where they live as adults. $44.6 \%$ of children who grow up in rural areas live in urban areas at age 30. Among those who rose from the bottom quintile of the national income distribution to the top quintile, $55.2 \%$ of children who grew up in rural areas live in urban areas at age 30 .

Table III shows statistics on intergenerational mobility for the 50 largest CZs by population. Among these cities, absolute upward mobility ranges from 46.2 in the Salt Lake City area to 35.8 in Charlotte (Column 4). There is considerable variation even between nearby cities: Pittsburgh is ranked second in terms of upward mobility among large metro areas, while Cleveland - approximately 100 miles away - is ranked in the bottom 10. Upward mobility is especially low in certain cities in the "Rust Belt" such as Indianapolis and Columbus and cities in the Southeast such as Atlanta and Raleigh. The fact that children who grow up in low-income families in Atlanta and Raleigh fare poorly is especially noteworthy because these cities are generally considered to be booming cities in the South with relatively high rates of job growth.

In Column 5 of Table III, we consider an alternative measure of upward mobility: the probability that a child born to a family in the bottom quintile of the national income distribution reaches the top quintile of the national income distribution. ${ }^{37}$ To improve precision in smaller CZs, we estimate this probability pooling the 1980-1985 birth cohorts. ${ }^{38}$ The ranking of areas based on this statistic is similar to that based on the mean rank measure of upward mobility. The probability that a child from the lowest quintile of parental income rises to the top quintile is $10.8 \%$ in Salt Lake City, compared with $4.4 \%$ in Charlotte. The city with the highest probability of moving from the bottom fifth to the top fifth is San Jose, where the probability (12.9\%) is nearly three times that

\footnotetext{
${ }^{37}$ In principle, differences in local income distributions within the bottom quintile could generate differences in this probability. In an earlier version of this analysis (v1.0 available on the project website), we accounted for these differences by calculating the chance of reaching the top quintile separately for each percentile and computed the unweighted mean across the percentiles, effectively integrating over the national parent income distribution. The adjusted CZ-level transition probabilities obtained using this approach were virtually identical to the raw transition probabilities we report in this paper.

${ }^{38}$ We verify that including more recent cohorts does not generate significant bias by showing that the national transition matrix based on the 1980-85 cohorts (Online Appendix Table VI) is virtually identical to the matrix based on the 1980-82 cohorts in Table II. We report the quintile transition matrix for each CZ in Online Data Table VI and provide statistics on the marginal distributions of parent and child income by CZ in Online Data Table VII.
} 
in Charlotte. The chances of rising from the bottom fifth to the top fifth for children growing up in San Jose are comparable to those in Denmark and Canada (see Section IV.A). Note that if parent income played no role in determining children's outcomes, all the quintile transition probabilities would be $20 \%$. Hence, the variation in rates of upward mobility across areas is large relative to the maximum plausible range of 0 to $20 \%$.

In Column 6 of Table III, we consider another measure of absolute upward mobility: the probability that a child has family income above the poverty line conditional on having parents at the 25th percentile (see Online Appendix F for details on the construction of this measure). This statistic also generates very similar rankings across CZs, confirming that our results are not sensitive to the way in which we measure upward mobility.

Relative Mobility. Figure VIb presents a heat map of relative mobility. This map is constructed in the same way as Panel $\mathrm{A}$, dividing CZs into deciles based on the rank-rank slope $\beta_{c}$. In this map, lighter areas denote areas with greater relative mobility (lower $\beta_{c}$ ). Relative mobility also varies substantially across areas. The expected rank of children from the richest vs. poorest families differs by more than 40.2 percentiles in CZs in the bottom decile of relative mobility. The corresponding gap is less than 23.5 percentiles for CZs in the top decile.

The geographical patterns in relative mobility in Panel B are similar to those for absolute upward mobility in Panel A. The unweighted correlation across CZs between the two measures is -0.68 ; the population-weighted correlation is -0.61 . This indicates that areas with greater relative mobility tend to have better absolute outcomes for children from low-income families.

To investigate the connection between absolute and relative mobility more systematically, let $\mu_{p c}=E\left[R_{i c} \mid P_{i c}=p\right]$ denote a child's expected rank given a parent rank of $p$ in $\mathrm{CZ} c$. We estimate $\mu_{p c}$ in each CZ non-parametrically as the mean value of $R_{i c}$ for children in each percentile bin of the parent income distribution $p=0, \ldots, 99 .^{39}$ For each of the 100 values of $p$, we estimate an unweighted OLS regression of $\mu_{p c}$ on relative mobility $\beta_{c}$ with one observation per CZ:

$$
\mu_{p c}=a+\gamma_{p} \beta_{c}+\eta_{p c}
$$

In this equation, $\gamma_{p}$ measures the association across $\mathrm{CZs}$ between a 1 unit increase in $\beta_{c}$ (i.e., greater

\footnotetext{
${ }^{39}$ The expected value $\mu_{p c}$ differs from $\bar{r}_{p c}$ defined above because $\mu_{p c}$ is estimated non-parametrically using only data in percentile bin $p$, whereas $\bar{r}_{p c}$ is calculated based on the linear approximation to the rank-rank relationship in (3). In practice, the two estimates are extremely similar. For instance, in the 100 largest CZs, where $\mu_{p c}$ is estimated with very little error, the correlation between $\mu_{p c}$ and $\bar{r}_{p c}$ exceeds 0.99 . We use the linear approximation $\bar{r}_{p c}$ in most of our analysis to obtain more precise estimates of absolute mobility in smaller CZs. However, because the goal of the exercise here is to evaluate the relationship between relative mobility $\beta_{c}$ and absolute mobility at each percentile non-parametrically, we use $\mu_{p c}$ here.
} 
intergenerational persistence) and the mean rank of children with parents at the $p^{\text {th }}$ percentile of the national income distribution. A negative coefficient $\left(\hat{\gamma}_{p}<0\right)$ implies that CZs with greater relative mobility generate better mean outcomes for children with parents at percentile $p$.

Figure VIIa plots the coefficients $\hat{\gamma}_{p}$ at each parent income percentile $p$ along with a linear fit to the coefficients. The coefficients $\hat{\gamma}_{p}$ are increasing with $p$ : CZs with greater relative mobility (lower $\beta_{c}$ ) produce better outcomes for children from lower income families. The best linear fit crosses 0 at $p=85.1$. Hence, increases in relative mobility are associated with better outcomes for children who grow up in families below the 85th percentile on average. For families at the 85th percentile, differences in relative mobility across CZs are uncorrelated with a child's mean rank. For families in the top $15 \%$, living in a $\mathrm{CZ}$ with greater relative mobility is associated with worse outcomes on average for children. Observe that $\gamma_{p}$ reaches only 0.2 for the richest families but is nearly -0.8 for the poorest families. This shows that differences in relative mobility across CZs are associated with much larger differences in absolute mobility for children from low-income families than high-income families. $^{40}$

Figure VIIb presents a schematic that illustrates the intuition underlying the preceding results. This figure plots hypothetical rank-rank relationships in two representative CZs, one of which has more relative mobility than the other. Figure VIIa implies that in such a pairwise comparison, the rank-rank relationship "pivots" at the 85th percentile on average. This is why the spatial patterns of absolute mobility at $p=25$ and relative mobility in Figure VI look similar.

Because the pivot point is high in the income distribution, differences in relative mobility have a smaller effect on children's percentile ranks in high-income families than low-income families. ${ }^{41}$ This may be because the rich are able to insulate themselves from differences in the local environment. If the differences in relative mobility across areas are caused by differences in local policies, this result suggests that policies that improve relative mobility may be able to improve the outcomes of children from poor families without hurting children from high income families significantly.

\footnotetext{
${ }^{40}$ If the rank-rank relationship were perfectly linear, the relationship plotted in Figure VIIa would be perfectly linear and $\gamma_{100}-\gamma_{0}=1$ mechanically. The slight deviation from linearity at the bottom of the distribution evident in Figure $\mathrm{V}$ generates the slight deviation of $\gamma_{100}-\gamma_{0}$ from 1.

${ }^{41}$ It bears emphasis that this result applies to percentile ranks rather than mean income levels. Because the income distribution has a thick upper tail, a given difference in percentile ranks translates to a much larger difference in mean incomes in the upper tail of the income distribution. The probability that children of affluent parents become very high income "superstars" may therefore differ significantly across areas.
} 


\section{V.D Robustness of Spatial Patterns}

We assess the robustness of the spatial patterns in mobility along several dimensions. The results of this robustness analysis are reported in Online Appendix F and Appendix Table VII; we present a brief summary here.

We begin by considering changes in sample definitions: limiting the sample to male vs. female children, married vs. single parents, and later birth cohorts (for which we measure children's location at earlier ages). Measures of both absolute and relative mobility across areas in these subsamples generally have a correlation of more than 0.9 with the corresponding baseline measures reported above. Restricting the sample to hold the parents' ages at the birth of child fixed, limiting the sample to children who stay in the $\mathrm{CZ}$ where they grew up as adults, and limiting the sample to children linked to only one parent in all years yield very similar estimates of mobility across areas.

We also find that the spatial patterns are highly robust to using alternative measures of income used in Table I. For example, using individual income instead of family income or wage earnings instead of total income yields very spatial patterns.

We evaluate whether adjusting for differences in cost-of-living across areas affects our estimates by dividing parents' income by a local price index (based on the ACCRA survey) for the CZ where their child grew up and the child's income by the price index for the CZ where he lives in 2012 to obtain real income measures. Measures of intergenerational mobility based on real incomes are very highly correlated with our baseline measures. The degree of upward mobility - i.e., the difference between the child's rank and the parent's rank - is essentially unaffected by adjusting for local prices because few children move to areas with very different levels of cost of living relative to their parents (see Appendix F for details).

Because we measure parent income before 2000 and child income in 2011-12, part of the variation in upward mobility across areas could be driven by shocks to local economic growth. While growth shocks - e.g., from the discovery of a natural resource such as oil - are a real source of upward mobility, one may be interested in isolating variation in mobility attributable to more stable factors that can be manipulated by policy. We assess the extent to which economic growth is responsible for the spatial variation in upward mobility in two ways. First, we define parent income as mean family income in 2011-12, the same years in which we measure child income. Insofar as local economic growth raises the incomes of both parents and children, this measure nets out the effects of growth on mobility. Second, we regress upward mobility on the CZ-level growth rate from 2000- 
2010 and calculate residuals. Both of these growth-adjusted mobility measures have a correlation of more than 0.8 with our baseline measures, indicating that most of the spatial variation in upward mobility is not driven by differences in growth rates.

Finally, we consider a set of alternative statistics for relative and absolute mobility. Estimating relative mobility based on parent and child ranks in the local income distribution yields estimates that are very highly correlated with our baseline estimates based on national ranks. We also show that the two alternative measures of upward mobility analyzed in Table III - the probability of rising from the bottom fifth to the top fifth and the probability of having income above the poverty line conditional on having parents at the 25th percentile - also generate very similar spatial patterns, with correlations above 0.9 with our baseline mean rank measure of upward mobility (Online Appendix Figure VI).

\section{V.E Intermediate Outcomes: College Attendance and Teenage Birth}

To better understand the sources of the spatial variation in intergenerational income mobility, we characterize spatial variation in the three intermediate outcomes analyzed in Figure IV: college attendance rates, college quality rank, and teenage birth rates. We first regress each of these outcomes on parent national income rank in each CZ $c$ using specifications analogous to (2). We then characterize spatial variation in two measures of mobility for each outcome using the regression estimates: the slope coefficient, which is analogous to our measure of relative mobility above, and the predicted outcome for children with parents at the 25th percentile, which is analogous to our measure of absolute mobility. ${ }^{42}$

We present heat maps for the relative and absolute mobility measures for the three intermediate outcomes in Online Appendix Figures VII-IX; the CZ-level data underlying these maps are reported in Online Data Table V. There is substantial spatial variation in all three intermediate outcomes and the variation is highly correlated with the variation in the intergenerational income mobility. For example, college attendance rates for children with parents at the 25 th percentile vary from less than $32.4 \%$ in bottom decile of CZs to more than $55.6 \%$ in the top decile of CZs. The unweighted correlation between college attendance rates at the 25th percentile and mean income ranks at the 25th percentile (absolute upward mobility) across CZs is 0.71 (Online Appendix Table VII, row 23). Similarly, teenage birth rates for female children whose parents are at the 25 th percentile vary

\footnotetext{
${ }^{42}$ Because the relationship between college quality rank and parent rank is not linear, we regress college quality ranks on a quadratic function of parent income rank and define the relative mobility measure for college quality as the difference in the predicted college quality rank for children with parents at the 75th percentile and children with parents at the 25th percentile, as in Figure IVa.
} 
from less than $15.4 \%$ in bottom-decile of CZs to more than $29.4 \%$ in the top decile. The correlation between teen birth rates and absolute upward mobility is -0.61 .

An important implication of these results is that much of the difference in intergenerational mobility across areas emerges while children are teenagers, well before they enter the labor market as adults. ${ }^{43}$ This suggests that the spatial variation in income mobility is driven by factors that either directly affect children at early ages (such as the quality of schools or social structure) or anticipatory behavioral responses to subsequent differences (such as returns to education in the local labor market). We explore mechanisms that have such properties in the next section.

\section{Correlates of Intergenerational Mobility}

Why do some areas of the U.S. exhibit much higher rates of upward mobility than others? As a first step toward answering this question, we correlate our measures of intergenerational mobility with local area characteristics. Naturally, such correlations cannot be interpreted as causal mechanisms. Our goal is merely to document a set of stylized facts to guide the search for causal determinants and the development of new models of intergenerational mobility.

We correlate our mobility statistics with various factors that have been discussed in the sociology and economics literature, such as segregation and inequality. Because most of these factors are slowmoving and we have estimates of intergenerational income mobility for essentially one birth cohort, we focus on cross-sectional correlations rather than changes over time. For most covariates, we use data from the 2000 Census and other publicly available datasets because many variables cannot be consistently measured in earlier years. See Online Appendix G for details on the construction of the covariates analyzed in this section and Online Data Table VIII for CZ-level data on each of the covariates.

Figure VIII presents a summary of our correlational results. It plots the unweighted univariate correlation between absolute upward mobility and various CZ-level characteristics, using all CZs with available data for the relevant variable. We consider several proxies for each broad factor (segregation, inequality, etc.). The dots show the point estimate of the correlation and the horizontal lines show a $95 \%$ confidence interval, based on standard errors clustered at the state level. The sign of the correlation is shown in parentheses next to each variable. In Online Appendix Table VIII, we report these correlations as well as estimates from several alternative specifications: including state

\footnotetext{
${ }^{43}$ Further supporting this claim, we find a strong positive correlation of 0.63 between teenage labor force participation rates (between the ages of 14 and 16) and upward mobility (see Figure VIII and Online Appendix H).
} 
fixed effects, weighting CZs by population, restricting to urban areas, and controlling for differences in racial demographics and income growth (see Online Appendix $\mathrm{H}$ for details). These alternative specifications generally yield very similar results to the baseline estimates shown in Figure VIII. Most importantly, the correlations discussed below hold even in specifications with state fixed effects, showing that the results are not just driven by broad regional differences across the South vs. other parts of the country. We also show in Online Appendix Table VIII that the factors that are positively associated with absolute upward mobility are generally positively associated with relative mobility (i.e., are negatively correlated with rank-rank slopes).

In the remainder of this section, we discuss correlations of mobility with the categories in Figure VIII that have the strongest relationship with mobility: racial demographics, segregation, income inequality, school quality, social capital, and family structure. We discuss results for four other broad categories for which we find weaker correlations - local tax policies, higher education, labor market conditions, and migration - in Online Appendix H.

\section{VI.A Race}

Perhaps the most obvious pattern from the maps in Figure VI is that intergenerational mobility is lower in areas with larger African-American populations, such as the Southeast. Indeed, the unweighted correlation between upward mobility and the fraction of black residents in the CZ (based on the 2000 Census) is -0.580 , as shown in the first row of Figure VIII.

This correlation could be driven by two very different channels. One channel is an individuallevel race effect: black children may have lower incomes than white children conditional on parent income, and hence areas with a larger black population may have lower upward mobility. An alternative possibility is a place-level race effect: areas with large black populations might have lower rates of upward mobility for children of all races.

To distinguish between these two channels, we would ideally control for race at the individual level, essentially asking whether whites have lower rates of upward mobility in areas with a larger black population. Unfortunately, we do not observe each individual's race in our data. As an alternative, we predict race based on the parent's 5-digit ZIP code (in the year they first claim their child as a dependent). We use data from the 2000 Census to measure racial shares by ZIP code. Figure IXa replicates the map of absolute upward mobility $\left(\bar{r}_{25, c}\right)$ by CZ, restricting the sample to ZIP codes within each $\mathrm{CZ}$ in which at least $80 \%$ of the residents are non-hispanic 
whites. ${ }^{44}$ In this subsample, $91 \%$ of individuals are white. The spatial pattern in Figure IXa is very similar to that in the original map for the full sample in Figure VIa. Most notably, even in this predominantly white sample, rates of upward mobility remain low in the Southeast and are much higher in the West. Among the $604 \mathrm{CZs}$ for which we are able to compute upward mobility measures for predominantly white individuals, the unweighted correlation between upward mobility for the predominantly white sample and the full sample is 0.91 .

In Figure IXb, we generalize this approach to assess how the spatial pattern of upward mobility changes as we restrict the sample to be increasingly white. To construct this figure, we first compute upward mobility in each $\mathrm{CZ}$, restricting the sample to individuals living in ZIP codes that are more than $w \%$ white, which we denote by $\bar{r}_{25, c}^{w}$. We then regress $\bar{r}_{25, c}^{w}$ on $\bar{r}_{25, c}$, our baseline estimates of upward mobility based on the full sample, using an unweighted OLS regression with one observation per $\mathrm{CZ}$ with available data. We vary $w$ from $0 \%$ to $95 \%$ in increments of $5 \%$ and plot the resulting regression coefficients in Figure IXb against the fraction of white individuals in each of the subsamples. When $w=0$, the regression coefficient is 1 by construction because $\bar{r}_{25, c}=\bar{r}_{25, c}^{w=0}$. Since $68 \%$ of the U.S. population is white, the first point on the figure is $(0.68$, 1 ). The point generated by the $w=80 \%$ threshold is $(0.91,0.84)$, consistent with the map in Figure IXa. The dotted lines show a 95\% confidence interval for the regression coefficients based on standard errors clustered at the state level.

If the variation in upward mobility across areas were entirely driven by heterogeneity in outcomes across race at the individual level, the coefficient in Figure IXb would fall to zero as the fraction white in the sample converged to 1, as illustrated by the dashed line. Intuitively, if all of the spatial variation in Figure VIa were driven by individual-level differences in race, there would be no spatial variation left in a purely white sample. The data reject this hypothesis: even in the subsample with more than $95 \%$ white individuals, the regression coefficient remains at 0.89 .

The main lesson of this analysis is that both blacks and whites living in areas with large AfricanAmerican populations have lower rates of upward income mobility. ${ }^{45}$ There are many potential mechanisms for such a correlation, including differences in the institutions and industries that developed in areas with large African-American populations. We are unable to distinguish between

\footnotetext{
${ }^{44}$ We continue to estimate $\bar{r}_{25, c}$ at the CZ level in this map, but we only include ZIP-5's within each CZ in which $80 \%$ or more of the residents are white. To facilitate comparison to Figure VI, we color the entire CZ based on this statistic, including ZIP-5's whose own white share is below $80 \%$. CZs that have fewer than 250 children who grew up in ZIP codes where more than $80 \%$ of the residents are white are omitted (and shown with cross-hatch shading).

${ }^{45}$ To be clear, this result does not imply that race does not matter for children's outcomes at the individual level, as shown e.g. by Mazumder (2011). Our finding is simply that there is spatial heterogeneity in upward mobility even conditional on race.
} 
these mechanisms in our data; instead, we next turn to one such mechanism that has received the greatest attention in prior work: segregation. The U.S. has a historical legacy of greater segregation in areas with more blacks. Such segregation could potentially affect both low-income whites and blacks, as racial segregation is often associated with income segregation.

\section{VI.B Segregation}

Prior work has argued that segregation has harmful effects on disadvantaged individuals through various channels: reducing exposure to successful peers and role models, decreasing funding for local public goods such as schools, or hampering access to nearby jobs (Wilson 1987, Massey and Denton 1993, Cutler and Glaeser 1997). In this subsection, we evaluate these hypotheses by exploring the correlation between intergenerational mobility and various measures of segregation (shown in the second panel of Figure VIII and Online Appendix Table VIII).

We begin by measuring racial segregation using a Theil (1972) index, constructed using data from the 2000 Census as in Iceland (2004). Let $\phi_{r}$ denote the fraction of individuals of race $r$ in a given CZ, with four racial groups: whites, blacks, hispanics, and others. We measure the level of racial diversity in the CZ by an entropy index: $E=\sum \phi_{r} \log _{2} \frac{1}{\phi_{r}}$, with $\phi_{r} \log _{2} \frac{1}{\phi_{r}}=0$ when $\phi_{r}=0$. Letting $j=1, \ldots, N$ index census tracts in the $\mathrm{CZ}$, we analogously measure racial diversity within

each tract as $E_{j}=\sum \phi_{r j} \log _{2} \frac{1}{\phi_{r j}}$ where $\phi_{r j}$ denotes the fraction of individuals of race $r$ in tract $j$. We define the degree of racial segregation in the $\mathrm{CZ}$ as

$$
H=\sum_{j}\left[\frac{\operatorname{pop}_{j}}{\text { pop }_{\text {total }}} \frac{E-E_{j}}{E}\right]
$$

where $\operatorname{pop}_{j}$ denotes the total population of tract $j$ and poptotal denotes the total population of the CZ. Intuitively, $H$ measures the extent to which the racial distribution in each Census tract deviates from the overall racial distribution in the $\mathrm{CZ}$. The segregation index $H$ is maximized at $H=1$ when there is no racial heterogeneity within census tracts, in which case $E_{j}=0$ in all tracts. It is minimized at $H(p)=0$ when all tracts have racial composition identical to the $\mathrm{CZ}$ as a whole, so that $E_{j}=E$.

Column 1 of Table IV reports the coefficient estimate from an unweighted OLS regression of absolute upward mobility $\bar{r}_{25, c}$ on the racial segregation index, with one observation per CZ. In this and all subsequent regressions, we standardize the dependent variable and all independent variables to have mean 0 and standard deviation 1 within the estimation sample. Hence, the coefficients in the univariate regressions can be interpreted as correlation coefficients. Standard errors are clustered 
by state to account for spatial correlation across CZs.

More racially segregated areas have less upward mobility. The unweighted correlation between upward mobility and the racial segregation index in Column 1 is $-0.361 .{ }^{46}$ Column 2 shows that the correlation remains at -0.360 in urban areas, i.e. CZs that overlap with metropolitan statistical areas (MSAs).

Next, we turn to the relationship between income segregation and upward mobility. Following Reardon and Firebaugh (2002) and Reardon (2011), we begin by measuring the degree to which individuals below the $p^{\text {th }}$ percentile of the local household income distribution are segregated from individuals above the $p^{\text {th }}$ percentile in each CZ using a two-group Theil index $H(p)$. Here, entropy in a given area is $E(p)=p \log _{2} \frac{1}{p}+(1-p) \log _{2} \frac{1}{1-p}$ and the index $H(p)$ is defined using the formula in (4). Building on this measure, Reardon (2011) defines the overall level of income segregation in a given $\mathrm{CZ}$ as

$$
\text { income segregation }=2 \log (2) \int_{p} E(p) H(p) d p \text {. }
$$

This measure is simply a weighted average of segregation at each percentile $p$, with greater weight placed on percentiles in the middle of the income distribution, where entropy $E(p)$ is maximized. We implement (5) using data from the 2000 Census, which reports income binned in 16 categories. Following Reardon (2011, Appendix 3), we measure $H(p)$ at each of these cutoffs and take a weighted sum of these values to calculate income segregation.

In Column 3 of Table IV, we regress absolute upward mobility on the income segregation index; see Online Appendix Figure Xb for the corresponding non-parametric binned scatter plot. The correlation between income segregation and upward mobility is -0.393 , consistent with the findings of Graham and Sharkey (2013) using survey data. Interestingly, areas with a larger black population exhibit greater income segregation: the correlation between the fraction of black individuals in a $\mathrm{CZ}$ and the income segregation index is 0.264 (s.e. 0.082). Hence, the negative relationship between income segregation and upward mobility could partly explain why low-income white children fare more poorly in areas with large African-American populations.

In Column 4, we decompose the effects of segregation in different parts of the income distribution. Following Reardon and Bischoff (2011), we define the "segregation of poverty" as $H(p=25)$, i.e. the extent to which individuals in the bottom quartile are segregated from those above the 25th percentile. We analogously define the segregation of affluence as $H(p=75)$. Column 4 regresses

\footnotetext{
${ }^{46}$ Online Appendix Figure Xa presents a non-parametric binned scatter plot corresponding to this regression; see Online Appendix $\mathrm{H}$ for details on the construction of this figure.
} 
upward mobility on both segregation of poverty and affluence. Segregation of poverty has a strong negative association with upward mobility, whereas segregation of affluence does not. Column 5 shows that the same pattern holds when restricting the sample to urban areas. These results suggest that the isolation of low-income families (rather than the isolation of the rich) may be most detrimental for low income children's prospects of moving up in the income distribution.

Another mechanism by which segregation may diminish upward mobility is through spatial mismatch in access to jobs (Kain 1968, Kasarda 1989, Wilson 1996). We explore this mechanism in Column 6 by correlating upward mobility with the fraction of individuals who commute less than 15 minutes to work in the CZ, based on data from the 2000 Census. Areas with less sprawl (shorter commutes) have significantly higher rates of upward mobility; the correlation between commute times and upward mobility is 0.605 . Column 7 shows that commute times remain a significant predictor of upward mobility in a multivariable regression but income segregation does not.

These results are consistent with the view that the negative impacts of segregation may operate by making it more difficult to reach jobs or other resources that facilitate upward mobility. But any such spatial mismatch explanation must explain why the gradients emerge before children enter the labor market, as shown in Section V.E. A lack of access to nearby jobs cannot directly explain why children from low-income families are also more likely to have teenage births and less likely to attend college in cities with low levels of upward mobility. However, spatial mismatch could produce such patterns if it changes children's behavior because they have fewer successful role models or reduces their perceived returns to education.

\section{VI.C Income Levels and Inequality}

In this subsection, we explore the correlation between properties of the local income distribution mean income levels and inequality - and intergenerational mobility.

Mean Income Levels. The third section of Figure VIII shows that the mean level of household income in a CZ (as measured in the 2000 Census) is essentially uncorrelated with upward mobility (see Online Appendix Figure XIa for the corresponding non-parametric binned scatter plot). Children in low-income families who grow up in the highest-income CZs (with mean incomes of $\$ 47,600$ per year) reach almost exactly the same percentile of the national income distribution on average as those who grow up in the lowest-income areas (with mean incomes of $\$ 21,900$ ).

Income Inequality. Prior work has documented a negative correlation between income inequality and intergenerational mobility across countries (e.g., Corak 2013). This "Great Gatsby" curve 
(Krueger 2012) has attracted attention because it suggests that greater inequality within a generation could reduce social mobility. We explore whether there is an analogous relationship across areas within the U.S. by correlating upward mobility with the Gini coefficient of parent income within each CZ. We compute the Gini coefficient for parents in our core sample within each CZ as Gini $=\frac{2}{\bar{X}_{c}} \operatorname{Cov}\left(X_{i c}, P_{i c}\right)$, where $\bar{X}_{c}$ is the mean family income (from 1996-2000) of parents in CZ $c$ and $\operatorname{Cov}\left(X_{i c}, P_{i c}\right)$ is the covariance between the income level $\left(X_{i c}\right)$ and the percentile rank $\left(P_{i c}\right)$ of parents in CZ c. The correlation between the Gini coefficient and upward mobility is - 0.578 (see also Online Appendix Figure XIb).

An alternative measure of inequality is the portion of income within a $\mathrm{CZ}$ that accrues to the richest households, e.g. those in the top 1\%. This measure is of particular interest because the rise in inequality in the U.S. over the past three decades was driven primarily by an increase in top income shares (Piketty and Saez 2003). We calculate top 1\% income shares using the distribution of parent family income within each CZ. The correlation between upward mobility and the top $1 \%$ income share is only -0.190 (see also Online Appendix Figure XIc), much weaker than that with the Gini coefficient.

We investigate why the Gini coefficient and top $1 \%$ share produce different results in Table V, which is constructed in the same way as Table IV. Column 1 replicates the regression corresponding to the raw correlation between the Gini coefficient and upward mobility as a reference. We decompose the Gini coefficient into inequality coming from the upper tail and the rest of the income distribution by defining the bottom $99 \%$ Gini as the Gini coefficient minus the top $1 \%$ income share. The bottom $99 \%$ Gini can be interpreted as the deviation of the Lorenz curve from perfect equality amongst households in the bottom 99\%. Column 2 of Table V shows that a 1 SD increase in the bottom $99 \%$ Gini is associated with a 0.634 SD reduction in upward mobility. In contrast, a 1 SD increase in the top $1 \%$ share is associated with only a 0.123 SD reduction in upward mobility. Column 3 shows that in urban areas (CZs that overlap with MSAs), the pattern is even more stark: upper tail inequality is uncorrelated with upward mobility, whereas the Gini coefficient within the bottom $99 \%$ remains very highly strongly correlated with upward mobility.

Another measure of inequality within the bottom $99 \%$ is the size of the middle class in the CZ, which we define as the fraction of parents in the $\mathrm{CZ}$ who have family incomes between the 25th and 75 th percentiles of the national parent income distribution. Column 4 of Table V shows that upward mobility is strongly positively correlated with the size of the middle class.

Finally, Column 5 of Table V replicates Column 2 using relative mobility $\beta_{c}$ as the dependent 
variable. The bottom $99 \%$ Gini coefficient is strongly positively associated with this measure. That is, greater inequality in the bottom $99 \%$ is negatively related to relative mobility. ${ }^{47}$ But once again, the top $1 \%$ share is uncorrelated with relative mobility.

Comparison to Cross-Country Evidence. Next, we explore whether the size of the middle class is more strongly correlated with intergenerational mobility than upper tail inequality in the crosscountry data as well. In Column 6 of Table V, we replicate Corak's (2013, Figure 1) result that there is a strong positive correlation between the Gini coefficient (as measured in survey data on income in 1985) and the intergenerational elasticity (IGE) using data from 13 developed countries compiled by Corak (2013). ${ }^{48}$ In Column 7, we include the top $1 \%$ income share in each country, based on statistics from the World Top Incomes Database. As in the within-U.S. analysis, there is little correlation between the top $1 \%$ income share and intergenerational mobility across countries. Column 8 shows that results are similar if one uses inequality measures from 2005 instead of 1985.

We conclude that there is a robust negative correlation between inequality within the current generation of adults and mobility across generations. However, intergenerational mobility is primarily correlated with inequality among the bottom $99 \%$ and not the extreme upper tail inequality of the form that has increased dramatically in recent decades. Interestingly, this pattern parallels the results we obtained for segregation above: segregation of affluence is not significantly correlated with intergenerational mobility, while segregation of poverty is negatively associated with mobility.

\section{VI.D School Quality}

In the fourth panel of Figure VIII, we study the correlation between mobility and various proxies for school quality. We first consider two proxies for inputs into school quality: mean public school expenditures per student and mean class sizes based on data from the National Center for Education Statistics (NCES) for the 1996-97 school year. We find a positive correlation between public school expenditures and upward mobility, but the correlation is not as strong or robust as with measures of inequality or segregation. There is a strong negative correlation between class size and upward mobility (Columns 1 and 2 of Online Appendix Table VIII) when pooling all CZs. However, there is no correlation between upward mobility and class size in more urban areas (Columns 3 and 4).

One shortcoming of input-based measures of school quality is that they may capture relatively

\footnotetext{
${ }^{47}$ Because parent and child ranks are measured in the national income distribution, there is no mechanical relationship between the level of inequality within the CZs income distribution and the rank-rank slope.

${ }^{48}$ We obtain estimates of the Gini coefficient by country from the OECD Income Distribution Database. We interpret these estimates as applying to the bottom $99 \%$ because surveys typically do not capture the thickness of the top tail due to top-coding.
} 
little of the variation in school quality (Hanushek 2003). To address this problem, we construct output-based proxies for school quality based on test scores and dropout rates adjusted for differences in parent income. We obtain data on mean grade 3-8 math and English test scores by CZ from the Global Report Card. The Global Report Card converts school-district-level scores on statewide tests to a single national scale by benchmarking statewide test scores to scores on the National Assessment of Educational Progress (NAEP) tests. We obtain data on high school dropout rates from the NCES for the 2000-01 school year, restricting the sample to CZs in which at least $75 \%$ of school districts have non-missing data. We regress test scores on mean parent family income (from 1996-2000) in the core sample and compute residuals to obtain an income-adjusted measure of test score gains. We construct an income-adjusted measure of dropout rates analogously.

The income-adjusted test score and dropout rates are very highly correlated with upward mobility across all specifications, as shown in the fourth panel of Figure VIII. In the baseline specification, the magnitude of the correlation between both measures and upward mobility is nearly 0.6. These results are consistent with the hypothesis that the quality of schools - as judged by outputs rather than inputs - plays a role in upward mobility. At a minimum, they strengthen the view that much of the difference in intergenerational income mobility across areas emerges while children are relatively young.

\section{VI.E Social Capital}

Several studies have emphasized the importance of social capital - the strength of social networks and engagement in community organizations in local areas - for social and economic outcomes (e.g., Coleman 1988, Borjas 1992, Putnam 1995). We explore the relationship between mobility and measures of social capital used in prior work in the fifth panel of Figure VIII.

Our primary proxy for social capital is the social capital index constructed by Rupasingha and Goetz (2008), which we aggregate to the CZ level using population-weighted means. This index is comprised of voter turnout rates, the fraction of people who return their census forms, and various measures of participation in community organizations. The correlation between upward mobility and social capital is 0.641 in our baseline specification, an estimate that is quite robust across alternative specifications. Interestingly, one of the original measures proposed by Putnam (1995) the number of bowling alleys in an area - has an unweighted correlation of 0.562 with our measures of absolute upward mobility.

We also consider two other proxies for social capital: the fraction of religious individuals (based 
on data from the Association of Religion Data Archives) and the rate of violent crime (using data from the Uniform Crime Report). Religiosity is very strongly positively correlated with upward mobility, while crime rates are negatively correlated with mobility.

\section{VI.F Family Structure}

Many have argued that family stability plays a key role in children's outcomes (see e.g., Becker 1991, Murray 1984, Murray 2012). To evaluate this hypothesis, we use three measures of family structure in the CZ based on data from the 2000 Census: (1) the fraction of children living in single-parent households, (2) the fraction of adults who are divorced, and (3) the fraction of adults who are married. All three of these measures are very highly correlated with upward mobility, as shown in the sixth panel of Figure VIII.

The fraction of children living in single-parent households is the single strongest correlate of upward income mobility among all the variables we explored, with a raw unweighted correlation of -0.76 (see Online Appendix Figure XIIa for the corresponding non-parametric binned scatter plot). One natural explanation for this spatial correlation is an individual-level effect: children raised by a single parent may have worse outcomes than those raised by two parents (e.g., Thomas and Sawhill 2002, Lamb 2004). To test whether this individual-level effect drives the spatial correlation, we calculate upward mobility in each CZ based only on the subsample of children whose own parents are married. The correlation between upward mobility and the fraction of single parents in their $\mathrm{CZ}$ remains at -0.66 even in this subgroup (Online Appendix Figure XIIb). Hence, family structure correlates with upward mobility not just at the individual level but also at the community level, perhaps because the stability of the social environment affects children's outcomes more broadly. The association between mobility and family structure at the community level echoes our findings in Section VI.A on the community-level effects of racial shares.

\section{VI.G Comparison of Alternative Explanations}

In Table VI, we assess which of the five factors identified above - segregation, inequality, school quality, social capital, and family structure - are the strongest predictors of upward mobility in multivariable regressions that control for race and other covariates. Based on the analysis above, we first identify the proxy that has the strongest and most robust univariate correlation with upward mobility in each category: the fraction of working individuals who commute less than 15 minutes to work (segregation), the bottom 99\% Gini coefficient (inequality), high school dropout rates adjusted 
for income differences (school quality), the social capital index, and the fraction of children with single parents (family structure). ${ }^{49}$ As in preceding regression specifications, we normalize all the dependent and independent variables to have a standard deviation of 1 in the estimation sample for each regression in Table VI. ${ }^{50}$

We begin in Column 1 with an unweighted OLS regression of absolute upward mobility $\bar{r}_{25, c}$ on the five factors, pooling all CZs. All of the factors except the Gini coefficient are significant predictors of the variation in absolute upward mobility in this specification. Together, the five factors explain $76 \%$ of the variance in upward mobility across areas. Column 2 shows that the coefficients remain similar when state fixed effects are included. Column 3 shows that the estimates are roughly similar when restricting the sample to urban areas (CZs that intersect MSAs). Across all the specifications, the strongest and most robust predictor is the fraction of children with single parents.

In Column 4, we use relative mobility $\beta_{c}$ as the dependent variable instead of absolute upward mobility. The fraction of single-parents and commute times are strong predictors of differences in relative mobility across areas, but the other factors are not statistically significant. To understand why this is the case, in Column 5 we replicate Column 4 but exclude the fraction of children with single parents. In this specification, all four of the remaining factors - including the Gini coefficient - are strong predictors of the variation in relative mobility across CZs. Column 6 replicates the specification in Column 5 using absolute upward mobility as the dependent variable. Once again, all four factors are strong predictors of upward mobility when the fraction of single parents is excluded. These results suggest that the fraction of single parents may capture some of the variation in the other factors, most notably the level of income inequality.

In the last two columns of Table VI, we explore the role of racial demographics vs. the other explanatory factors. Column 7 shows that when we regress absolute upward mobility on both the fraction of single-parent families in the $\mathrm{CZ}$ and the share of black residents, black shares are no longer significantly correlated with upward mobility. Column 8 shows that the correlation of upward mobility with black shares is slightly positive and statistically significant when we include controls for all five explanatory factors. These results support the view that the strong correlation

\footnotetext{
${ }^{49}$ We obtain similar results if we combine the various proxies into a single index for each factor using weights from an OLS regression of absolute upward mobility on the proxies within each category.

${ }^{50}$ We code the high school dropout rate as 0 for $126 \mathrm{CZs}$ in which dropout rate data are missing for more than $25 \%$ of the districts in the $\mathrm{CZ}$ and include an indicator for having a missing high school dropout rate. We do the same for $16 \mathrm{CZs}$ that have missing data on social capital. We normalize these variables to have mean 0 and standard deviation 1 among the CZs with non-missing data.
} 
of upward mobility with race operates through channels beyond the direct effect of race on mobility.

Overall, the results in Table VI indicate that the differences in upward mobility across areas are better explained by a combination of the factors identified above rather than any single factor. However, the regression coefficients should be interpreted with caution for two reasons. First, the regression may place greater weight on factors that are measured with less error rather than those that are truly the strongest determinants of mobility. Second, all of the independent variables are endogenously determined. These limitations make it difficult to identify which of the factors is the most important determinant of upward mobility.

\section{Conclusion}

This paper has used population data to present a new portrait of intergenerational income mobility in the United States. Intergenerational mobility varies substantially across areas. For example, the probability that a child reaches the top quintile of the national income distribution starting from a family in the bottom quintile is $4.4 \%$ in Charlotte but $12.9 \%$ in San Jose. The spatial variation in intergenerational mobility is strongly correlated with five factors: (1) residential segregation, (2) income inequality, (3) school quality, (4) social capital, and (5) family structure.

In this paper, we have presented a cross-sectional snapshot of intergenerational mobility for a single set of birth cohorts. In a companion paper (Chetty et al. 2014), we study trends in mobility over time. We find that the level of intergenerational mobility (national rank-rank slope) has remained stable for the 1971-1993 birth cohorts in the U.S., especially in comparison to the degree of variation across areas. A natural question given the results of the two papers is whether the cross-sectional correlations documented here are consistent with the time trends in mobility. To answer this question, we predict the trend in the rank-rank slope implied by changes in the five key correlates over time (see Online Appendix I and Appendix Figure XIII). The predicted changes are quite small because the factors move in opposing directions. For example, the increase in inequality and single parenthood rates in recent decades predict a small decline in mobility in recent decades. In contrast, the decline in racial segregation and high school dropout rates predict an increase in mobility of similar magnitude. Overall, the cross-sectional correlations documented here are consistent with the lack of a substantial time trend in mobility in recent decades.

The main lesson of our analysis is that intergenerational mobility is a local problem, one that could potentially be tackled using place-based policies (Kline and Moretti 2014). Going forward, a key question is why some areas of the U.S. generate higher rates of mobility than others. We 
hope that future research will be able to shed light on this question by using the mobility statistics constructed here (available online at the county by birth cohort level) to study the impacts of local policy changes. 


\section{ONLINE APPENDICES}

\section{A. Data Construction}

Core and Extended Samples. We begin with the universe of individuals in the Death Master (also known as the Data Master-1) file produced by the Social Security Administration. This file includes information on year of birth and gender for all persons in the United States with a Social Security Number or Individual Taxpayer Identification Number. We restrict this sample to all individuals who are current US citizens as of March 2013. The Data Master-1 file does not contain historical citizenship status, and thus we can only restrict to a sample who are currently US citizens as of the time at which we access the data. We further restrict to individuals who are alive through the end of 2012. The resulting dataset contains 47.8 million children across all cohorts 1980-1991 (Appendix Table I). We measure parent and child income, location, college attendance, and all other variables using data from the IRS Databank, a balanced panel covering all individuals in the United States who appear on any tax form between 1996-2012.

For each child, we define the parent(s) as the first person(s) who claim the child as a dependent on a 1040 tax form. If parents are married but filing separately, we assign the child both parents. To eliminate dependent claiming by siblings or grandparents, in the case of a potential match to married parents or single mothers, we require the mother to be age 15-40 at the birth of the child. ${ }^{51}$ In the case of a match to a single father, we require the father to be age 15-40 at the birth of the child. If no such eligible match occurs in 1996, the first year of our data, we search subsequent years (through 2011) until a valid match is found.

Once we match a child to parent(s), we hold this definition of parents fixed regardless of subsequent dependent claims or changes in marital status. For example, a child matched to married parents in 1996 who divorce in 1997 will always be matched to the two original parents. Conversely, a child matched to a single parent in 1996 that marries in 1997 will be considered matched to a single parent, though spouse income will be included in our definition of parent income because we measure parent income at the family level in our baseline analysis.

To reduce the effects of outliers and measurement error in the upper tail of the income distribution, we use data from the IRS Statistics of Income (SOI) manually perfected cross-sectional files spanning 1996-2011 (see below for details on these files). If an individual's adjusted gross income exceeds $\$ 10$ million, we look for the individual in the SOI sample; if present, we use the SOI measure of adjusted gross income and wage income as reported on a F1040 return. If not, we replace the adjusted gross income with the total wages reported on the filed F1040 contained in the databank. Because the IRS Databank includes tax year 2012 whereas the SOI sample does not, we top code income at $\$ 100$ million for all individuals in 2012 . These adjustments in the upper tail affect $0.017 \%$ of parents in our core sample (or, equivalently, $1.7 \%$ of parents in the top $1 \%$ of the income distribution).

For most of our analysis, we measure parent income at the household level. For certain robustness checks, we measure individual parent income as follows. For married parents, we define each parent's individual earnings as the sum of wage earnings from form W-2, unemployment benefits from form 1099-G, and Social Security and Disability benefits from form SSA-1099 for that individual. Individual earnings excludes capital and other non-labor income. To incorporate these sources

\footnotetext{
${ }^{51}$ Children can be claimed as a dependent only if they are aged less than 19 at the end of the year (less than 24 if enrolled as a student) or are disabled. A dependent child is a biological child, step child, adopted child, foster child, brother or sister, or a descendant of one of these (for example, a grandchild or nephew). Children must be claimed by their custodial parent, i.e. the parent with whom they live for over half the year. Furthermore, the custodial parent must provide more than $50 \%$ of the support to the child. Hence, working children who support themselves for more than $50 \%$ cannot be claimed as dependents. See IRS Publication 501 for further details.
} 
of income, we add half of family non-labor income - defined as total family income minus total family earnings reported on form 1040 - to each parent's individual earnings. We divide non-labor earnings equally between spouses because we cannot identify which spouse earns non-labor income from the 1040 tax return. For single parents, individual income is the same as family income.

Statistics of Income Sample. Starting in 1987, the IRS Statistics of Income cross sections which are stratified random samples of tax returns - contain dependent information, allowing us to link children to parents. We use the 1987-2011 SOI cross-sections to construct a sample of children born in the 1971-1991 birth cohorts and correct for errors in the upper tail of the income distribution as described above. For each SOI cross-section from 1987 to 2007, we first identify all dependent children between the ages of 12 and 16 who are alive at age 30 . We then pool all the SOI cross-sections that give us information for a given birth cohort. For example, the 1971 cohort is represented by children claimed at age 16 in 1987, while the 1991 cohort is comprised by children claimed at ages 12-16 in 2003-2007. Using the sampling weights for the SOI cross-sections (see Internal Revenue Service (2013) for details), each cohort-level dataset is representative of the population of children claimed on tax returns between the ages of 12 and 16 in that birth cohort.

Unlike in the population-based samples, we do not limit the SOI sample to children who are currently citizens because citizenship data are not fully populated for birth cohorts prior to 1980 and because we begin from a sample of children claimed by parents rather than the universe of children who currently appear in the population data (which includes later immigrants). In the years where the SOI and population-based samples overlap, we obtain very similar estimates in both samples. The citizenship restriction has a minor impact because the vast majority of children claimed as dependents between the ages of 12-16 are U.S. citizens as adults. We also do not impose any age restrictions on the parents in the SOI sample. In the population-based sample, some children are claimed by different adults across years and the age restriction is useful to discriminate between these potential parents. In the SOI sample, each child can only be linked to the parents who claim him in the cross-section file, so the age restriction would not play such a role. In practice, this restriction has little impact, as the age distribution of parents in the SOI sample is very similar to that in the core sample using the population data.

Children whose parents are sampled in multiple SOI cross-sections appear multiple times in the SOI sample. There are 228,295 unique children in the SOI sample and 523,700 total observations. The SOI sample grows from 4,383 unique children in 1971 to 21,231 unique children in 1991 because we have more cross-sections to link parents to children in more recent cohorts and because the size of the SOI cross-sections has increased over time (Appendix Table II). To be consistent with the core sample definition of parent income, we define parent income as the 5-year average of parent family income from 1996-2000 in the IRS Databank.

We provide additional information on the SOI sample in Chetty et al. (2014). Using sampling weights, we show that the SOI sample represents roughly $85 \%$ of children in each birth cohort (based on vital statistics counts) from 1971-1979, the cohorts we use to obtain estimates of intergenerational mobility after age 32 in Figure IIIa. We also show that summary statistics for the SOI sample are very similar to the core sample for the 1980-82 birth cohorts reported in Appendix Table III of this paper. Note that Chetty et al. (2014) compute parent income using the income of the parents in the single year of the parent-child match there, whereas we compute parent income as the five-year average over 1996-2000 here for consistency with results from the population data. Because we restrict to parents with positive income, this leads to a small difference in the SOI sample used across the two papers. For example, we have 4,383 children in the 1971 cohort, compared with 4,331 children in the sample used by Chetty et al. (2014).

Assignment of Children to Commuting Zones. Children are assigned ZIP codes of residence based on their parents' ZIP code on the form 1040 in which the parent is matched to the child. In 
the few cases where a parent files a F1040 claiming the child but does not report a valid ZIP code, we search information returns (such as W-2 and 1099-G forms) for a valid ZIP code in that year.

We map these ZIP codes to counties based on the 1999 Census crosswalk between ZIP codes and counties. We then aggregate counties into Commuting Zones using David Dorn's county-to-CZ crosswalk (download file E6). The counties in the U.S. Census Bureau crosswalk and in Dorn's crosswalk are not identical because they correspond to county definitions at different points in time; in particular the U.S. Census Bureau crosswalk includes changes between 1990 and 1999. We make manual adjustments for changes that affected 200 or more people. Using this procedure, we identify the $\mathrm{CZ}$ of 38,839 ZIP codes. To track individuals residing in ZIP codes that have been created since 1999, we add an additional 477 ZIP codes not valid in 1999 but appearing in the more up-to-date 2011 HUD-USPS crosswalk. For example, in 2007, Manhattan's ZIP code 10021 was split into three separate ZIP codes, resulting in the creation of new ZIP codes 10065 and 10075.

Of 9,864,965 children with non-missing ZIP codes in our core sample, 9,778,071 were assigned a childhood CZ using ZIP codes that existed in 1999; an additional 2,718 were assigned a CZ based on a ZIP code that existed in 2011 but not in 1999. For simplicity, we use the same crosswalk for all years of matching ZIP codes to CZs. We have verified that using year-specific crosswalks from ZIP codes to counties has a negligible effect on CZ assignments. All of the crosswalks we constructed are available on our project website.

Some of our specifications require tracking children's locations into adulthood using the ZIP code where they live as adults when we measure their income (e.g., for cost-of-living adjustments). We define a child's adult location using the latest non-missing ZIP code. We first search for a ZIP code in their 1040 form in 2012, followed by their information returns in 2012. We then repeat this procedure for 2011 if we do not find a zipcode in 2012. This yields 9,834,975 non-missing child ZIP codes in adulthood. Of these, we match 9,537,283 to a CZ from a ZIP code using the 1999 crosswalk (i.e. this ZIP code was in use in 1999) and an additional 198,317 using the later crosswalk because the ZIP code was created after 1999.

Construction of ZIP-Level Racial Shares. To construct Figure IXa and IXb, which condition on racial shares at the ZIP level, we need data on racial shares by ZIP code. The 2000 Census includes summary tables by ZIP code tabulation areas (ZCTAs) instead of ZIP code. ZCTAs are a U.S. Census Bureau geographical unit that in most cases correspond closely to ZIP codes, but sometimes do not. We use a ZCTA to ZIP Crosswalk from the John Snow Institute to assign each ZIP code a racial share based on Census 2000 ZCTA-level data from table P008.

CZ-Level Price Index. To measure real incomes, we first construct a CZ-level ACCRA price index using the 2010 ACCRA composite cost of living index (table 728) for "urbanized areas" in 2010, which we crosswalk to CZs as follows. First, we use the 2012Q1-2013Q1 correspondence (downloaded on 11/21/2013) to assign 298 out of the 325 urbanized areas to MSAs. Each county in an MSA was assigned the same value of the index. We then merge counties to CZs and calculate an unweighted mean of the index among non-missing values within the CZ. Some CZs had no counties within an MSA and were therefore assigned a missing value of the ACCRA index.

To construct a price index that covers all CZs, we regress the CZ-level ACCRA index on a quadratic in log population density (from the 2000 Census), a quadratic in log median housing values, the latitude and longitude of the $\mathrm{CZ}$ centroid, and state fixed effects. Housing values are the population-weighted mean of tract median housing values for owner-occupied units in the 1990 Census short form. Latitude and longitude are the mean latitude and longitude across counties within each CZ, obtained from the Census 2000 Gazetteer county-level data. The predicted values from this regression constitute our final price index that covers all CZs.

\section{B. Comparison to Survey Datasets}


In Appendix Table IV, we compare selected moments of income distributions and other variables in the tax data to data from two nationally representative surveys that have been used in prior work on the income distribution: the 2011-12 CPS and the 2011-12 ACS. We restrict the ACS and CPS samples to citizens in the same birth cohorts as our core sample (1980-82). To the extent possible, we define all income variables to match the concepts in the tax data.

To assess whether our method of linking children to parents based on dependent claiming creates selection bias, we compute statistics in the tax data both on the full sample of all children in the 1980-82 birth cohorts who are current U.S. citizens and the core sample of children linked to parents. Because most children are linked to parents, the differences between these two samples are small, though children who lack valid parent matches have slightly lower earnings on average.

Overall, the tax data are very similar to the CPS and ACS. The sum of the sampling weights in our survey-based samples provide estimates of the size of the target population being sampled. This population is very similar in the tax data and the two surveys. The mean and median earnings levels are very similar, as are the fractions with non-zero income. Perhaps more surprisingly, the interquartile range (P75-P25) of earnings is also similar across the three data sources. If survey data were reported with classical measurement error, we would expect the interquartile range to be larger in survey sources. However, survey reports of income exhibit "mean reverting" measurement error which has the effect of reducing variability (Bound and Krueger 1991, Bound, Brown and Mathiowetz 2001). Moreover, survey non-response tends to follow a U-shaped pattern (Kline and Santos 2013), with very high and low earning individuals being least likely to provide earnings responses, which can further reduce variability. The quantiles of family income also line up well across the three data sources, with the tax-based moments strongly resembling those from the ACS, perhaps because the ACS has a higher response rate for earnings than the CPS.

\section{Comparison to Mitnik et al. (2014)}

Mitnik et al. (2014) propose a new measure of the intergenerational elasticity that is more robust to the treatment of small incomes. In this appendix, we compare the traditional definition of the IGE (Solon 1999, Black and Devereux 2011) to the new measure proposed by Mitnik et al. We first show that the traditional IGE can be interpreted as the average elasticity of child income with respect to parent income in a model with heterogeneous elasticities, while Mitnik et al.'s new measure is a dollar-weighted (i.e., child-income-weighted) average of the same elasticity. We then compare estimates of the dollar-weighted IGE to estimates of the traditional IGE in our data and to the estimates of Mitnik et al.

Setup. Let $Y_{i}$ denote the level of child income and $X_{i}$ denote the level of parent income. Let $F_{Y \mid X=x}(y)$ denote the conditional distribution of $Y$ given $X$, which we assume is differentiable with respect to $x$ at all $(y, x)>0$. Define the conditional quantile function (CQF) as the inverse of the CDF:

$$
q(x, \tau)=F_{Y \mid X=x}^{-1}(\tau)
$$

for $\tau \in[0,1] .{ }^{52}$ The CQF gives the quantiles of the conditional distribution of $Y_{i}$ given $X_{i}$; for example, $q(x, .5)$ is the median of $Y_{i}$ when $X_{i}=x$.

We can use the CQF to represent $Y_{i}$ as:

$$
Y_{i}=q\left(X_{i}, U_{i}\right),
$$

where $U_{i} \mid X_{i} \sim$ Uniform $(0,1)$. Hence, the conditional mean of child income given parent income

\footnotetext{
${ }^{52}$ At mass points, we define $q(x, \tau) \equiv \inf \left\{y: F_{Y \mid X=x}(y) \geq \tau\right\}$.
} 
can be written as a function of the CQF:

$$
E\left[Y_{i} \mid X_{i}=x\right]=E\left[q\left(X_{i}, U_{i}\right) \mid X_{i}=x\right]=\int_{0}^{1} q(x, \tau) d \tau .
$$

Define the elasticity of a given quantile of the child's income distribution with respect to parent income around a parent income level $x$ as

$$
\sigma(x, \tau) \equiv \frac{d q(x, \tau)}{d x} \frac{x}{q(x, \tau)}=\frac{q_{x}(x, \tau) x}{q(x, \tau)} .
$$

In general, the elasticity will vary across quantiles $\tau .{ }^{53}$ We now show that traditional estimates of the intergenerational elasticity (e.g., Solon 1992) and the new estimator proposed by Mitnik et al. (2014) can be interpreted as different averages of the elasticities $\sigma(x, \tau)$.

Traditional IGE. The intergenerational elasticity at a given parent income level $x$, which we denote by $I G E(x)$, is defined as the impact of an increase in log parent income (starting from $x$ ) on expected log child income:

$$
\begin{aligned}
\operatorname{IGE}(x)=\frac{d E\left[\log Y_{i} \mid X_{i}=x\right]}{d \log x} & =\frac{d}{d \log x} \int_{0}^{1} \log q(x, \tau) d \tau \\
& =\int_{0}^{1} \frac{d}{d \log x} \log q(x, \tau) d \tau \\
& =\int_{0}^{1} \sigma(x, \tau) d \tau \\
& =\bar{\sigma}(x)
\end{aligned}
$$

where $\bar{\sigma}(x) \equiv E\left[\sigma\left(X_{i}, U_{i}\right) \mid X_{i}=x\right]$. If we interpret the IGE as the average of $\operatorname{IGE}(x)$ across levels of parent income $x$, we obtain

$$
I G E=E[\bar{\sigma}(x)]=\int_{-\infty}^{\infty} \int_{0}^{1} \sigma(x, \tau) d \tau d F_{X}(x),
$$

where $F_{X}($.$) is the marginal distribution of X_{i}$. Hence, the traditional IGE can be interpreted as the average elasticity of child income with respect to parent income across quantiles and parent income levels.

Mitnik et al. IGE. Mitnik et al. (2014) propose an alternative approach to estimating the IGE that switches the order of the log and the expectation relative to the traditional approach. They define the IGE as the impact of an increase in log parent income (starting from $x$ ) on the log of expected child income:

$$
I G E_{W}(x) \equiv \frac{d \log E\left[Y_{i} \mid X_{i}=x\right]}{d \log x} .
$$

\footnotetext{
${ }^{53}$ Naturally, this elasticity is only defined for quantiles where $q(x, \tau)>0$; the standard empirical practice in the prior literature (e.g., Solon 1992) has been to exclude children with zero income for this reason.
} 
To see how their estimand relates to the traditional IGE, observe that

$$
\begin{aligned}
I G E_{W}(x) & =\frac{d}{d \log x} \log \int_{0}^{1} q(x, \tau) d \tau \\
& =\frac{\int_{0}^{1} q_{x}(x, \tau) x d \tau}{\int_{0}^{1} q(x, \tau) d \tau} \\
& =\frac{\int_{0}^{1} q(x, \tau) \sigma(x, \tau) d \tau}{\int_{0}^{1} q(x, \tau) d \tau} \\
& =E\left[\omega\left(X_{i}, U_{i}\right) \sigma\left(X_{i}, U_{i}\right) \mid X_{i}=x\right]
\end{aligned}
$$

where $\omega\left(X_{i}, U_{i}\right) \equiv \frac{q\left(X_{i}, U_{i}\right)}{E\left[q\left(X_{i}, U_{i}\right) \mid X_{i}\right]}$ is a set of quantile specific weights which sum to one for each value of $X_{i}$. Averaging $I G E_{W}(x)$ across levels of parent income $x$, Mitnik et al.'s statistic can be written as $I G E_{W}=E\left[I G E_{W}(x)\right]$. The parameter $I G E_{W}(x)$ is a weighted average of the elasticity $\sigma(x, \tau)$ across quantiles $\tau$, with weights that are an increasing function of the child's income. Higher quantiles get larger weights, in proportion to their dollar value; the weights approach zero as the child's income approaches 0 . In this sense, the $I G E_{W}$ statistic defined by Mitnik et al. is a dollar-weighted mean of the IGE across quantiles.

The traditional $I G E$ and the dollar-weighted $I G E_{W}$ proposed by Mitnik et al. are two different parameters. The "correct" parameter depends on the question one seeks to answer. If one's goal is to estimate $I G E_{W}$, then the traditional $I G E$ estimate will in general yield a biased estimate of $I G E_{W}$. Conversely, if one's target is to estimate the traditional $I G E$ (e.g., for comparison to prior estimates in the literature), then $I G E_{W}$ will in general be biased.

As Mitnik et al. note, one statistical benefit of the dollar-weighted IGE is that it is not sensitive small changes in incomes at the bottom of the distribution, such as recoding zero income as $\$ 1$. Intuitively, dollar-weighted elasticities are not sensitive to the impacts of parent income on children's income at the bottom of the distribution. In contrast, person-weighted estimates are very sensitive to changes in incomes at the bottom of the distribution, because such changes can affect elasticities at the lowest quantiles substantially. The traditional IGE is unstable because the elasticity of child income with respect to parent income is ill-defined at quantiles with zero income.

Empirical Estimates. In large samples, we can estimate $E\left[Y_{i} \mid X_{i}=x\right]$ non-parametrically as shown in Figure Ia. It is therefore straightforward to estimate $I G E_{W}$ simply by regressing the non-parametric estimates of $\log E\left[Y_{i} \mid X_{i}=x\right]$ on $\log x .{ }^{54}$ The series in circles in Appendix Figure Ia plots $\log E\left[Y_{i} \mid X_{i}=x\right]$ vs. $\log x$ simply by taking $\operatorname{logs}$ of the data points shown in Figure Ia. ${ }^{55}$ As a reference, we also replicate the non-parametric plot of $E\left[\log Y_{i} \mid X_{i}=x\right]$ vs. $\log x$ from Figure Ib (excluding children with zero income) in the series in triangles.

The two series are very similar, implying that nonparametric estimates of $\frac{d \log E\left[Y_{i} \mid X_{i}=x\right]}{d \log x}$ and $\frac{d E\left[\log Y_{i} \mid X_{i}=x\right]}{d \log x}$ are very similar for most values of $x$. The dollar-weighted IGE estimate (including children with zero income) is $I G E_{W}=0.335$, virtually identical to the traditional IGE estimate of $I G E=0.344$ obtained when we exclude children with zero income. Between the 10th and 90 percentiles, the dollar-weighted IGE is 0.414, while the traditional IGE is 0.452 .

In Appendix Figure Ib, we report dollar-weighted IGE estimates by the age of the child to assess the extent of lifecycle bias in the dollar-weighted IGE estimates. We find that the dollar-weighted IGE also stabilizes around age 30: the estimated $I G E_{W}$ is $2.1 \%$ higher at age 32 than age 31 (0.343

\footnotetext{
${ }^{54}$ Mitnik et al. use a Poisson pseudo-maximum-likelihood (PPML) estimator to estimate $I G E_{W}$ in survey data, which approximates $\log E\left[Y_{i} \mid X_{i}=x\right]$ in large samples.

${ }^{55}$ Unlike in Figure Ia, we include the top bin (the top $1 \%$ of parents) in this figure.
} 
vs. 0.336$)$.

Mitnik et al. (2014) obtain larger estimates of the dollar-weighted IGE (around 0.5) in their SOI sample. Although both studies use similar data from tax records, there are several small methodological differences between Mitnik et al.'s approach and our approach. A useful direction for future work would be to investigate which of these differences in responsible for the differences in the IGE estimates.

\section{Comparison to Clark (2014)}

Clark (2014) presents estimates of mobility across generations using surname averages of income, representation in elite professions, and other related outcomes. He obtains implied IGE estimates around 0.8 , well above the estimates of intergenerational persistence obtained in our analysis and the prior literature (e.g., Solon 1999). In this appendix, we first show that in our data, estimates of mobility based on surname means are generally quite similar to our baseline individual-level estimates. We then present a simple hypothesis that may explain why Clark's focus on rare surnames leads to a much higher estimated IGE.

Surname-Based Estimates. In Chetty et al. (2014, Appendix B), we construct estimates of intergenerational mobility across surnames as follows. We begin with all the children in our core sample and restrict attention to those whose surnames in 2012 are the same as their parents' surnames. ${ }^{56}$ We then obtain a de-identified table of surname-level means of percentile ranks (using the baseline income definition) for both parents and children. Finally, we regress the surname-level mean ranks for children on surname-level mean ranks for parents (as suggested by Clark 2014, Appendix 2), weighting by the number of individuals with each surname, to obtain a surname-level rank-rank slope. We construct surname-level estimates of the log-log IGE analogously, computing surname level means of log income (excluding zeroes) for children and parents.

Appendix Table V reports the results of this analysis. Each row of the table shows the estimates for different subsets of names. The first row considers all names. Rows 2-4 restrict to rare surnames, i.e. names held by fewer that 25,50 , or 100 children. Rows 5-8 conversely limit the sample to common surnames, i.e. names held by more than 100, 1000, 10000, or 20000 people. In each row, we report the number of children in the sample (Column 1), the number of unique surnames in the sample (Column 2), surname-based estimates of the rank-rank slope (Column 3), individual-level estimates of the rank-rank slope (Column 4), surname-based estimates of the log-log IGE (Column 5), and individual-level estimates of the log-log IGE (Column 6).

Appendix Table $\mathrm{V}$ shows that surname-based averages of income generally do not imply much greater intergenerational persistence than individual-level regressions unless one uses specific subsets of names for the analysis. For example, when including all names (row 1), the individual-level rank-rank slope is 0.30 , compared with a surname-level rank-rank slope of 0.39. If we restrict to the rarest names (shared by fewer than 25 people), the individual-level rank-rank slope is 0.27 , compared with a surname-based rank-rank slope of 0.30. The IGE estimates at the individual level are also slightly smaller than those based on surname averages.

The only case in which the surname averages yield much larger implied IGEs and rank-rank slopes is in the last row of the table, where we restrict to the 7 most common names in the U.S. population. Here, the surname-based IGE is 0.81, compared with an individual-level IGE of 0.36. This implies that the rate of convergence in income across generations across these broad name groups - which likely capture broad differences in ethnicities or race - is much smaller than the

\footnotetext{
${ }^{56}$ As Clark (2014, Appendix 2) notes, surname-based analyses will yield attenuated estimates of the IGE if they include parents and children who do not actually have the same surname. Consistent with this hypothesis, we find smaller estimates of rank-rank correlations and IGEs when we use the full core sample, without limiting to children who have the same surname as their parents.
} 
rate of convergence within the groups, a point we return to below.

Interpretation of Clark (2014) Estimates. Why does Clark obtain much larger estimates of intergenerational persistence than we find in Appendix Table V? There are many methodological differences between Clark's analysis and our approach above. For example, Clark analyzes multiple generations and uses other proxies for status (such as professional occupation) rather than income. While a comprehensive analysis of the source of the difference is outside the scope of this study, we believe that one key difference is Clark's focus on distinctive surnames. For instance, one comparison Clark (2014, page 60, Figure 3.10) gives is of the surname "Katz" vs. "Washington." As he notes, Katz is a common Jewish surname, while Washington is a common black surname. The comparison of intergenerational convergence in income between these two names is thus analogous to using an indicator for race as an instrument in a traditional individual-level IGE regression. ${ }^{57}$

As is well known from prior work, using race to instrument for income yields much larger IGE estimates, presumably because race has direct effects on children's income independent of its impact on parent income, as shown e.g., by Borjas (1992). If one uses an indicator for being black as an instrument, the IGE estimate is equivalent to the proportional reduction in the black-white income gap across generations. In 1980, blacks' median earnings were $78.8 \%$ that of whites on average (Bureau of Labor Statistics 2011, Table 14, page 41). In 2010, blacks' median earnings were $79.9 \%$ that of whites. Hence, the implied between-group IGE is 78.8/79.9 $=0.986$, consistent with Clark's larger estimates. Importantly, even though there is very little convergence across racial groups during this time period, there is considerable social mobility within racial groups. This is why our estimates of the IGE based on individual-level data (or pooling all surnames) over the same period are much lower.

In sum, we believe that Clark's approach effectively identifies a parameter analogous to the degree of convergence in income across generations between racial or ethnic groups rather than across individuals. This is an interesting parameter, but one that differs from standard studies of intergenerational mobility that seek to measure the extent to which an individual's status is determined by his parents' idiosyncratic circumstances. ${ }^{58} \mathrm{~A}$ useful direction for future research would be to investigate why the rate of income convergence across certain ethnic groups is small even though intergenerational mobility within these groups is much higher.

\section{E. Comparison to Mazumder (2005)}

Mazumder (2005) reports that IGEs estimated using even 5-year averages of parent earnings exhibit substantial attenuation bias because of long-lasting transitory shocks to income. This appendix provides further details on why we find much less attenuation bias than Mazumder.

Mazumder (2005, Table 4, row 1, page 246) obtains IGE estimates as high as 0.6 when using 15-year averages of parent income matched SIPP-SSA administrative data, 54\% larger than his 4year pooled estimate of 0.388. In contrast, we find little difference between IGEs based on five-year vs. fifteen-year averages of parent income both using our preferred rank-rank specification (Figure IIIb) and using a log-log IGE specification similar to that estimated by Mazumder. For example, we obtain a log-log IGE of 0.366 using a 15-year average of parent family income, $6 \%$ larger than the estimate using a 5 year average reported in row 1 of Table I. ${ }^{59}$

\footnotetext{
${ }^{57}$ Clark reports many other surname comparisons that do not map as directly to racial or ethnic groups. However, it is possible that similar group-level persistence effects are picked up by other unique surname contrasts as well.

${ }^{58}$ This interpretation differs from that put forth by Clark, who argues that individual-level estimates do not capture latent "status" as well as surname-based averages. Our analysis of surname means suggests that the differences in the results are driven by differences in the rate of income convergence within vs. between ethnic groups rather than a downward bias in measures of intergenerational persistence based on individual data.

${ }^{59}$ When computing long time averages, we measure earnings of parents at older ages than Mazumder (2005) because
} 
We believe our results differ from Mazumder's findings because we directly observe income for all individuals in our data, whereas Mazumder imputes parent income based on race and education for up to $60 \%$ of the observations in his sample to account for top-coding in social security records. ${ }^{60}$ These imputations are analogous to instrumenting for parent income using race and education, an approach known to yield higher estimates of the IGE, perhaps because parents' education directly affects children's earnings (Solon 1992). Because the SSA earnings limit is lower in the early years of his sample, Mazumder imputes income for a larger fraction of observations when he averages parent income over more years (Mazumder 2005, Figure 3). As a result, Mazumder's estimates effectively converge toward IV estimates as he uses more years to calculate mean parent income, explaining why his estimates rise so sharply with the number of years used to measure parent income. Consistent with this explanation, when he drops imputed observations, his IGE estimates increase much less with the number of years used to measure parent income (Mazumder 2005, Table $6)$.

Mazumder also reports simulations of earnings processes showing that attenuation bias in the IGE should be substantial even when using five-year averages. However, he calibrates the parameters of the earnings process in his simulation based on estimates from survey data and his SIPP-SSA sample, both of which may have more noise than the population data we use here, which cover all workers and are not top-coded. If one replicates Mazumder's simulations using a smaller variance share for transitory shocks, one obtains results similar to ours in Figure IIIb, with little attenuation bias in estimates based on five-year averages.

To be clear, Mazumder acknowledges the potential bias due to imputation, as he recommends in his conclusion that "future research should attempt to verify the results here using long-term measures of permanent earnings from other sources that do not require the kind of imputations that were necessary in this study." We simply follows this recommendation.

\section{F. Robustness of Spatial Patterns}

In Appendix Table VII, we assess the robustness of the spatial patterns in mobility documented in Section V along four dimensions: (1) changes in sample definitions, (2) changes in income measures, (3) adjustments for differences in the cost-of-living and growth rates across areas, and (4) the use of alternative statistics to measure relative and upward mobility. The first number in each cell of this table reports the correlation across CZs of a baseline mobility measure (using child family income rank and parent family income rank in the core sample) with an alternative mobility measure described in each row. The second number in each cell reports the ratio of the standard deviation of the alternative measure to the baseline measure. Note that we do not report the ratio of standard deviations for statistics that are measured in different units relative to the corresponding baseline measure.

Column 1 reports the unweighted correlation (and SD ratio) across CZs between our baseline measure of absolute upward mobility $\left(\bar{r}_{25, c}\right)$ and the corresponding alternative measure of $\bar{r}_{25, c}$. Column 2 replicates Column 1 for relative mobility $\left(\beta_{c}\right)$. Columns 3 and 4 replicate Columns 1 and 2 weighting CZs by their population in the 2000 Census.

Sample Definitions. In the first section of Appendix Table VII, we assess the robustness of the

of the structure of our data. However, Appendix Figure IIb shows that our estimates of mobility are not sensitive to varying the age in which parent income is measured over the range observed in our dataset. Hence, the differences between the findings of the two papers cannot be explained by differences in the age at which parent income is measured.

${ }^{60}$ There are also other differences in Mazumder's specification, such as the imputation of income for children whose earnings are not covered by SSA. However, it is less obvious why these differences would produce sharp changes in the estimated IGE when using longer time averages of parent income. 
spatial patterns to changes in the sample definition, as we did at the national level in Table I. Rows 1 and 2 restrict the sample to male and female children, respectively. Rows 3 and 4 consider the subsamples of married parents and single parents. The correlations of both absolute and relative mobility in these subsamples with the corresponding baseline measures is typically above 0.9 .

In row 5, we replicate the baseline specifications using the 1983-85 birth cohorts (whose incomes are measured at age 27 on average in 2011-12). In row 6, we consider the 1986-88 birth cohorts instead. The intergenerational mobility estimates across CZs for these later birth cohorts are very highly correlated with the baseline estimates. This result has three implications. First, it demonstrates that the reliability of CZ-level estimates is quite high across cohorts; in particular, sampling error or cohort-specific shocks do not lead to much fluctuation in the CZ-level estimates. Second, because the later cohorts are linked to parents at earlier ages (as early as age 8), we conclude that the spatial patterns in intergenerational mobility are not sensitive to the precise age at which we link children to parents or measure their geographical location. Finally, because the earnings of later cohorts are measured at earlier ages, we conclude that one can detect the spatial differences in mobility even when measuring earnings quite early in children's careers.

In row 7 , we restrict the sample based on the age of parents at the birth of the child. We limit the sample to children whose mothers are between the ages of 24-28 and fathers are between 26-30 (a five year window around the median age of birth). The intergenerational mobility estimates in this subsample are very highly correlated with the baseline estimates, indicating that the cross-area differences in income mobility are not biased by differences in the age of child birth for low income individuals.

In row 8 , we assess the extent to which the variation in intergenerational mobility comes from children who succeed and move out of the $\mathrm{CZ}$ as adults vs. children who stay within the CZ. To do so, we restrict the sample to the $62 \%$ of children who live in the same $\mathrm{CZ}$ in 2012 as where they grew up. Despite the fact that this sample is endogenously selected on an ex-post outcome, the mobility estimates remain very highly correlated with those in the full sample. Apparently, areas such as Salt Lake City that generate high levels of upward income mobility do so not just by sending successful children to other CZs as adults but also by helping children move up in the income distribution within the area.

In row 9 , we restrict the sample to the $88 \%$ of children in the core sample who are not claimed as dependents by other individuals in subsequent years after they are linked to the parents we identify. We obtain very similar estimates for this "unique parent" subsample, indicating that the spatial pattern of our mobility estimates is not distorted by measurement error in linking children to their parents.

Income Definitions. In the second section of Appendix Table VII, we evaluate the sensitivity of the spatial patterns to alternative definitions of income. The definitions we consider match those in the robustness analysis in Table I; see Section IV.B for details on these definitions. In row 10 of Appendix Table VII, we define parent income as the income of the higher earner rather than total family income to evaluate potential biases from differences in parent marital status across areas. In row 11, we measure the child's income using individual income instead of family income to assess the effects of differences in the child's marital status. In row 12, we use the child's individual earnings (excluding capital and other non-labor income). In row 13, we replicate the specification in row 11 for male children, using individual income for the child and family income for the parent. Row 14 replicates row 13, but defines parent income as the income of the higher earner instead. In row 15, we define parent income using data from 1999-2003 (when we have data from W-2's) instead of 1996-2000. All of these definitions produce very similar spatial patterns in intergenerational mobility: correlations with the baseline measures exceed 0.9 in most cases.

Adjustments for Cost-of-Living and Growth Rates. The third section of Appendix Table VII 
considers a set of other factors that could bias comparisons of intergenerational mobility across areas. One natural concern is that our estimates of upward mobility may be affected by differences in prices across areas. To evaluate the importance of differences in cost of living, we construct a CZ-level price index using the American Chamber of Commerce Research Association (ACCRA) price index for urban areas combined with information on housing values, population density, and CZ location (see Appendix A for details). We then divide parents' income by the price index for the CZ where their child grew up and the child's income by the price index for the CZ where he lives as an adult (in 2012) to obtain real income measures.

Row 16 of Appendix Table VII shows that the measures of intergenerational mobility based on real incomes are very highly correlated with our baseline measures (see also Appendix Figure VIa). The reason that cost-of-living adjustments have little effect is that prices affect both the parent and the child. Intuitively, in high-priced areas such as New York City, adjusting for prices reduces the child's absolute rank in the national real income distribution. But adjusting for prices also lowers the real income rank of parents living in New York City. As a result, the degree of upward mobility - i.e., the difference between the child's rank and the parent's rank - is essentially unaffected by adjusting for local prices.

The preceding logic assumes that children always live in the same cities as their parents. In practice, some children move to areas with higher prices (e.g. from rural Iowa to New York City). Our measures of upward mobility are affected by the cost of living adjustment in such cases, but they are not sufficiently frequent to have a large impact on our estimates. The correlation between the cost of living in the child's CZ at age 30 and the parent's CZ is 0.77, and the correlation between a child's nominal percentile rank and the local price index is only 0.10. As a result, cost of living adjustments end up having a minor impact on the difference between child and parent income and thus have little effect on our mobility statistics.

Next, we assess the extent to which economic growth is responsible for the spatial variation in upward mobility. In row 17, we define parent income as mean family income in 2011-12, the same years in which we measure child income. Insofar as local economic growth raises the incomes of both parents and children, this measure nets out the effects of growth on mobility. Both the upward and relative mobility measures remain very highly correlated with the baseline measures, suggesting that differences in local economic growth drive relatively little of the spatial variation in mobility.

As an alternative approach to accounting for growth shocks, we regress our measures of mobility on the CZ-level growth rate from 2000-2010 and calculate residuals. ${ }^{61}$ Row 18 of Appendix Table VII shows that the correlation of the growth-adjusted relative mobility measures with the baseline measures exceeds 0.9 ; the correlations for absolute mobility exceed 0.8 . Note that these growth-adjusted measures over-control for exogenous growth shocks insofar as growth is partly a consequence of factors that generate upward income mobility in an area. Hence, the finding that even controlling for growth rates directly does not significantly change the spatial pattern of intergenerational mobility supports the view that most of the variation in mobility across areas is not due to exogenous growth shocks in the 2000's. ${ }^{62}$

\footnotetext{
${ }^{61}$ We measure income in 2000 using the Census and in 2008 using the 5-year American Community Survey, averaged over 2006-2010. We calculate household income per working age adult as aggregate income in a CZ divided by the number of individuals aged 16-64 in that CZ. Annualized income growth is calculated as the annual growth rate implied by the change in income over the 8 year period; we use 8 years because 2008 is the midpoint of 2006-2010.

${ }^{62}$ The fact that college and teenage birth gradients are similar to income mobility gradients provides further evidence that growth shocks in the 2000s do not generate the differences in mobility across areas, as college and teenage birth are measured around 2000. These results also show that the spatial patterns are unlikely to be driven by differences in reporting of taxable income.
} 
Alternative Statistics for Mobility. One potential concern with our approach is that using national ranks may misrepresent the degree of relative mobility within the local income distribution, which may better reflect a child's opportunities. To address this concern, in row 19 of Appendix Table VII, we measure relative mobility using local ranks. We rank parents relative to other parents living in the same $\mathrm{CZ}$ and children relative to other children who grew up in the same CZ (no matter where they live as adults). We define relative mobility as the slope of the local rank-rank relationship. ${ }^{63}$ Relative mobility based on local ranks is very highly correlated with relative mobility based on national ranks. This is because local ranks are approximately a linear transformation of national ranks.

Finally, we consider two alternative measures of absolute upward mobility. In row 20, we measure absolute upward mobility based on the probability that the child rises from the bottom quintile of parent income to the top quintile of child income, as in Column 5 of Table III. In row 21, we measure absolute upward mobility as the probability that a child has family income above the poverty line conditional on having parents at the 25th percentile. To construct this statistic, we first regress an indicator for having family income above the federal poverty line in 2012 on parent rank in the national income distribution in each CZ. ${ }^{64}$ We then calculate the predicted fraction of children above the poverty line for parents at the 25th percentile based on the slope and intercept in each CZ. The spatial patterns in both of these measures - which are also shown in the maps in Appendix Figure VI - are very similar to those in our mean-rank based measure of upward mobility, with correlations across CZs above 0.9 in both cases.

\section{G. Construction of CZ-Level Covariates}

This appendix provides definitions and sources for the CZ-level covariates used in Section VO. Online Data Table IX contains detailed descriptions of each covariate and briefly describes the source of data for each variable. Here, we provide additional details on each data source along with links to original sources. As a reference, we provide Stata code on our website that constructs the final CZ-level covariates (data available in Online Data Table VIII) from the raw data downloaded from the links below.

Our source data are primarily at the ZIP code and county level. We map ZIP codes and counties to CZs using the procedure described in Appendix A. We compute CZ-level means of the ZIP- and county-level data using population-weighted averages, with population counts from the 2000 Census.

Racial Demographics. Racial shares are calculated from the 2000 census short form (SF1) table P008. Note that all Census data can be obtained by searching for the relevant census table on the U.S. Census Bureau's American FactFinder. The black share is defined as the number of people in a $\mathrm{CZ}$ who are black alone divided by the $\mathrm{CZ}$ population; the white share is calculated similarly. For the Hispanic share, the numerator is the number of people of any race who are Hispanic. We also calculate a residual category where the numerator is the number of people that are neither black alone nor white alone nor Hispanic.

Segregation. We measure racial and income segregation using Theil indices as described in the text. ${ }^{65}$ We compute the racial segregation index using the census tract level data on racial

\footnotetext{
${ }^{63}$ We cannot study absolute mobility with local ranks because both child and parent ranks have a mean of 50 by definition: if one child moves up in the local distribution, another must move down.

${ }^{64}$ We define household size as the maximum household size in $2010-11$, where household size is defined as 1 plus an indicator for being married plus the number of dependents claimed. The poverty line threshold is defined as $\$ 11,170+($ household size - 1) $\times \$ 3,960$.

${ }^{65}$ As Iceland (2004) argues, the Theil index is an attractive measure conceptually because it captures segregation across multiple racial groups. However, we obtain similar results using alternative two-group measures of black-white
} 
shares from table P008 from the 2000 Census. ${ }^{66}$ For segregation of affluence and poverty, we use the sample data from the 2000 census long form (SF3) on the income distribution of households in 1999 by census tract contained in table P052. Our formulas for the three income segregation measures are taken directly from Reardon (2011). We compute $H\left(p_{k}\right)$ for each of the 16 income groups given in table P052. We then estimate $H\left(p_{25}\right)$ and $H\left(p_{75}\right)$ in each $\mathrm{CZ}$ using the 4 th order polynomial version of the weighted linear regression in equation 12 on page 23 of Reardon (2011). The overall segregation of income index is Reardon's rank-order index, which we compute from equation 13, where the $\delta$ vector is given in Appendix A4 of Reardon (2011).

To compute the commute time variable, we divide the number of workers that commute for less than 15 minutes by the total number of workers. The sample for both of these counts is restricted to workers that are at least 16 years old and do not work from home. Travel time data is from the 2000 census table P031.

Income Distributions. We compute mean income per working age adult by dividing aggregate household income in a CZ by the total number of people aged 16-64 in that CZ. These data come from the 2000 census table P054 and P008. The Gini coefficient, fraction middle class, and top 1\% income share are computed using our sample of parents and the family income definitions used for the main analysis in this paper, but with family income top coded at $\$ 100$ million in all years.

K-12 Education. We use the National Center for Education Statistics' Common Core of Data data for public schools for several of our K-12 covariates. School expenditures per student is taken from school-district data for the 1996-1997 fiscal year. We drop 8 CZs that are in the top 1\% of the distribution of expenditures per student to reduce the influence of outliers. While we would ideally measure school spending in the 1980s and early 1990s, when the students in our core sample were in school, such data are not readily available for earlier years. However, the correlation in school spending per capita across states in 1982 and 1992 is 0.86, suggesting that using earlier data would not substantially affect our findings.

We use school-level data on student-teacher ratios for the 1996-1997 school year. We drop the top $0.1 \%$ of observations, which have student-teacher ratios that exceed 100 . We also drop approximately $10 \%$ of schools whose student-teacher ratios are recorded as being 0 .

High school dropout rates are obtained from school-district data for the 2000-2001 school year. We code the dropout rate as missing in CZs in which more than $25 \%$ of school districts have missing data on dropout rates. We construct an income-adjusted measure of dropout rates using residuals from a CZ-level regression of the dropout rate on mean parent family income (from 1996-2000) in the core sample.

We obtain a standardized measure of grade 3-8 test scores from the National Math Percentile and National Reading Percentile series in the Global Report Card. We calculate the studentweighted mean of the math and reading rankings over 2004, 2005, and 2007 in each CZ to arrive at our measure of mean test scores. We then construct a measure of income-adjusted test scores using the residual from a CZ-level regression of mean test scores on mean parent family income (from 1996-2000) in the core sample.

segregation such as isolation indices or dissimilarity indices because alternative measures of segregation are highly correlated at the level of metro areas (Cutler, Glaeser and Vigdor 1999). The segregation patterns are sufficiently stark that one can directly see the differences in segregation between the least and most upwardly mobile cities using the color-coded dot maps produced by Cable (2013) using Census data. For instance, compare Atlanta - one of the most segregated cities and one of the lowest-mobility cities in our data - to Sacramento - one of the most integrated and highest-mobility cities.

${ }^{66}$ We also replicated the analysis using measures of segregation from the 1990 Census and find very similar results. For example, the correlation between upward mobility and the Theil racial segregation index measured using the 1990 Census is -0.357 , compared with -0.361 when measured using the 2000 Census. The correlation between upward mobility and income segregation is -0.393 using both the 1990 and 2000 Census. 
We construct enrollment-weighted means at the ZIP code level of all the school and school district level variables using the school and district ZIP codes provided in each of the data sources. We then take enrollment-weighted means across ZIP codes to construct CZ-level estimates using the ZIP to CZ crosswalk discussed in Appendix A.

Social Capital. For social capital, we use the 1990 county-level social capital index from Rupasingha and Goetz (2008). For religious affiliation, we use data on the self-reported number of religious adherents from the Association of Religion Data Archives at Pennsylvania State University. Data on crime rates are from the FBI's Uniform Crime Reporting program. We downloaded county-level data from the ICPSR and use the number of arrests for serious (part 1 index) violent crimes divided by the total covered population.

Family Structure. We define the share of single mothers in each county as the number of households with female heads (and no husband present) with own children present divided by the total number of households with own children present. These data from from the 2000 census long form (SF3) in table P018. We calculate the fraction married and fraction divorced in each county using the number of people that are married or divorced (in the sample of people that are 15 years and older) using data from the 2000 census in table P018.

Taxes and Government Expenditures. We estimate local tax rates using data on tax revenue by county from the U.S. Census Bureau's 1992 Census of Government county-level summaries, which we downloaded from the ICPSR. In particular, Part 2 of the ICPSR download contains the county-level summaries. We define the tax rate in each $\mathrm{CZ}$ as follows. First, we calculate county tax revenue divided by the county population estimate for each county in the CZ. We then take a population-weighted mean across these counties to obtain a CZ-level mean per-person taxes. Finally, we divide mean per-person taxes by the Census 1990 estimate of nominal income per household, which we downloaded from the National Historical Geographic Information System (NHGIS). We code the tax rate as missing for one CZ (Barrow, Alaska), which has a calculated tax rate of $90 \%$.

We compute total government spending per capita in each county using Census data on government expenditures by aggregating all county-level total expenditure categories and dividing by the 1992 county population estimates. We then construct a CZ-level measure by taking populationweighted means of expenditures per capita in the counties in each CZ. We code local government expenditures as missing for two CZs (Barrow, Alaska and Kotzebue, Alaska), which have unusually high expenditures per capita that exceed $50 \%$ of per capita income.

We measure state income tax progressivity as the difference between 2008 state income tax rates for incomes above $\$ 100,000$ and incomes in the bottom tax bracket using data from the Tax Foundation. We obtain data on State EITC rates by year from Hotz and Scholz (2003). We calculate mean EITC rate for the years 1980-2001, setting the rate to zero for state-year pairs where there was no state EITC. Note that Wisconsin's state EITC rate depends on the number of children in a household; we use the rate for households with two children.

Higher Education. We use the Integrated Postsecondary Education Data System (IPEDS) to construct our three measures of college access and quality. We restrict the sample to Title IV institutions that have undergraduate students, and are degree offering. The number of colleges per capita in each CZ is the number of institutions in the 2000 IPEDS in each CZ divided by the CZ population. We define college tuition as the mean in-state tuition and fees for first-time, full-time undergraduates for the institutions in each CZ. We define the enrollment-weighted mean graduation rate based on the $150 \%$ of normal time college graduation rate from IPEDS 2009, the first year for which this data is available. We construct a measure of income-adjusted graduation rates using the residual from a CZ-level regression of graduation rates on mean parent income in the core sample.

Local Labor Market Conditions. The labor force participation rate is defined as the number of 
people in the labor force by the total population in the sample of people that are at least 16 years old. These data are from the 2000 Census long form (SF3) in table P043. We compute the share of workers in manufacturing from the 2000 census in table P049; we divide the number of people working in manufacturing by the total number of workers.

The exposure to Chinese trade variable is the percentage change in imports per worker from China between 1990 and 2000. It is measured as the growth in imports allocated to a CZ, divided by the CZ work force in 1990 (with the growth rate defined as 10 times the annualized change). This variable was constructed by Autor et al. (2013) and provided to us by David Dorn.

The teenage labor force participation rate is defined in each $\mathrm{CZ}$ as the share of individuals who received one or more W-2's between the ages of 14 and 16 . We calculate the teenage LFP rate using W-2 data for the 1985-1987 birth cohorts, the earliest cohorts for which we have W-2 data at age 14 .

Migration Rates. For inflow and outflow migration data, we use the county-to-county migration data from the Internal Revenue Service's Statistics of Income for 2004-2005. Inflow migration is the number of people moving into a $\mathrm{CZ}$ from counties in other $\mathrm{CZs}$ divided by the total $\mathrm{CZ}$ population; outflow migration is calculated similarly. We compute the share of each CZ's population that is foreign born using sample data from the 2000 census (table P021) on the number of foreign born inhabitants divided by total CZ population. In both cases, total CZ population is the sum of county populations from the 2000 Census (table P008) over counties in the CZ.

\section{H. Correlates of Intergenerational Mobility: Other Factors}

In this appendix, we first discuss correlations between absolute upward mobility and the four factors in Figure VIII that were not discussed in Section VI: local tax policies, higher education, labor market conditions, and migration. We then summarize the methodology used to estimate the correlations in Appendix Table VIII and the binned scatter plots in Appendix Figures X-XII.

Local Public Goods and Tax Policies. We assess correlations between local tax and expenditure policies and intergenerational mobility in the seventh panel of Figure VIII and Appendix Table VIII. We begin by correlating upward mobility with local tax rates. We measure the average local tax rate in each $\mathrm{CZ}$ as total tax revenue collected at the county or lower level in the CZ (based on the 1992 Census of Governments) divided by total household income in the CZ based on the 1990 Census. ${ }^{67}$ Note that $75 \%$ of local tax revenue comes from property taxes; hence, this measure largely captures variation in property tax rates. In the baseline unweighted specification pooling all $\mathrm{CZs}$, the correlation between absolute upward mobility and the average local tax rates is 0.33 . We find a robust positive correlation between tax rates and upward mobility across the specifications in Appendix Table VIII.

An alternative measure of local public good provision is local government expenditure. Tax revenue differs from local government expenditure because of inter-governmental transfers. We define local government expenditure as mean local govt. expenditure per capita at the county or lower level in the CZ (based on the 1992 Census of Governments). The correlation between government expenditure and upward mobility is also positive, but it is smaller than that between local tax rates and upward mobility. This could potentially be because local tax rates are used

\footnotetext{
${ }^{67}$ Government expenditures in the neighborhoods where low-income families live within the CZ (rather than average government expenditures) may be more relevant for upward mobility. To evaluate this possibility, we reconstructed each of the measures of public goods and school quality analyzed in this and the next subsection, weighting by the number of below-median income families living in each county or school district. The correlations between upward mobility and these measures of public goods for low-income individuals are very similar to those reported in Appendix Table VIII because expenditures in low-income areas are very highly correlated with mean expenditures at the CZ level.
} 
primarily to finance schools, which may have a larger impact on upward mobility than expenditures funded by other sources of revenue.

Next, we evaluate whether areas that provide more transfers to low-income families through the tax system exhibit greater upward mobility. We use two state-level proxies for the progressivity of local tax policy. The first is the size of the state Earned Income Tax Credit. State EITC programs are the largest state-level cash transfer for low income earners. Because state EITC policies changed significantly over the period when children in our sample were growing up, we define a measure of mean exposure to the state EITC as the mean state EITC rate between 1981 and 2001, when the children in our sample were between the ages of 0 and $20 .{ }^{68}$ The mean state EITC rate is positively correlated with upward mobility, with a correlation of approximately 0.25 that is fairly robust across specifications. Our second proxy for the progressivity of the local tax code is the difference between the top state income tax rate and the state income tax rate for individuals with taxable income of $\$ 20,000$ in 2008 based on data from the Tax Foundation. There is a weak positive correlation between local tax progressivity and upward mobility across the various specifications in Appendix Table VIII, but the correlation is not statistically significant.

In summary, we find that areas that provide more local public goods and larger tax credits for low income families tend to have higher levels of upward mobility. However, factors such as segregation and inequality are much stronger and more robust predictors of the variation in intergenerational mobility than differences in local tax and expenditure policies.

Access to Higher Education. We construct three measures of local access to higher education using data from the Integrated Postsecondary Education Data System (IPEDS). The first measure is the number of Title IV, degree-granting colleges per capita in the CZ in 2000, which is similar to the distance-based instrument used by Card (1995). The second measure is the mean (enrollmentweighted) tuition sticker price for in-state, full-time undergraduates for colleges in the CZ, which reflects the affordability of local higher education. The third measure is the residual from an OLS regression of the mean (enrollment-weighted) graduation rate from colleges in the $\mathrm{CZ}$ on mean parent family income in the $\mathrm{CZ}$, a rough proxy for the output of local higher education.

The correlations between all three of these measures - shown in the eighth panel of Figure VIII and Appendix Table VIII - are small and typically statistically insignificant. We also evaluated several additional measures of access to higher education, including the mean value of institutional grants to students enrolled in colleges in the $\mathrm{CZ}$, the number of low-cost (below the national median) colleges per capita in the $\mathrm{CZ}$, and the mean distance to the nearest low-cost college. We found no significant relationship between any of these measures and our measures of intergenerational mobility (not reported).

We conclude that very little of the spatial variation in intergenerational mobility is explained by differences in local access to higher education. Of course, this finding does not imply that college does not play a role in upward mobility. Indeed, areas with greater upward mobility tend to have high college attendance rates for children from low-income families (Appendix Figure VIIIa), suggesting that attending college is an important pathway for moving up in the income distribution. The point here is simply that the characteristics of local colleges are not a strong predictor of children's success, perhaps because the marginal impact of improving local access to higher education on college attendance and later outcomes is small.

Labor Market Structure. Some analysts have suggested that the availability of certain types of jobs (e.g., manufacturing) may provide ladders for lower-skilled workers to move up in the income distribution (e.g., Wilson 1996). To explore this possibility, we measure various characteristics of

\footnotetext{
${ }^{68}$ We assign state-years without a state EITC a rate of 0 when computing this mean. See Appendix G for further details on the computation of state EITC rates.
} 
the local labor market: (1) the overall employment rate in the local labor market in 2000, (2) the fraction of workers employed in the manufacturing industry, and (3) a measure of exposure to import competition based on the growth in Chinese imports per worker from Autor, Dorn and Hanson (2013). As shown in the ninth panel of Figure VIII and Appendix Table VIII, all of these characteristics are weakly correlated with the variation in upward mobility, with little evidence of a clear, robust relationship across specifications. We also find no significant correlation with other indicators such as the fraction of workers employed in management or professional occupations or industry establishment shares (not reported).

One labor market indicator that is strongly correlated with upward mobility is the teenage labor force participation rate. We measure the teenage labor force participation rate as the fraction of children who have a W-2 between the ages of 14-16 in the 1985-87 birth cohorts, the earliest cohorts for which W-2 data are available at age 14 in the tax data. The unweighted correlation between the teenage labor force participation rate and absolute upward mobility is 0.631 . This could be because formal jobs help disadvantaged teenagers directly or because areas with good schools and other characteristics tend to have more teenagers who work. In either case, this finding mirrors the general pattern documented above: the strongest predictors of upward mobility are factors that affect children before they enter the labor force as adults.

Migration Rates. We evaluate whether there is a correlation between migration rates and intergenerational mobility using three measures: (1) the migration inflow rate, defined as the number of people who move into the CZ between 2004 and 2005 based on IRS Statistics of Income migration data divided by the CZ population in 2000 based on Census data, (2) the migration outflow rate, defined as the number of people who move out of the CZ between 2004 and 2005 divided by population in 2000, and (3) the fraction of foreign-born individuals living in the CZ based on the 2000 Census.

The correlations between all three of these measures - shown in the last panel of Figure VIII and Appendix Table VIII - are generally quite low and statistically insignificant. In the first two specifications, migration rates are negatively correlated with upward mobility, but in the populationweighted and urban-area specifications, there are no significant relationships.

Empirical Methodology: Appendix Table VIII. Appendix Table VIII reports each of the correlations corresponding to Figure VIII in Column 1. The remaining columns evaluate the robustness of these estimates to alternative specifications. In Column 2, we report estimates based on withinstate variation by including state fixed effects in a regression specification analogous to that in Column 1 of Table IV. Column 3 replicates Column 1, weighting each CZ by its population as recorded in the 2000 Census. ${ }^{69}$ Column 4 restricts the sample to urban areas (CZs that intersect MSAs) and replicates Column 1. Column 5 replicates Column 1, controlling for the fraction of black individuals in the $\mathrm{CZ}$ and the local income growth rate from 2000-2010 (calculated as in Appendix G) using regression specifications of the form used in Table IV. Finally, in Column 6, we correlate each covariate with relative mobility $\beta_{c}$.

Empirical Methodology: Appendix Figures X-XII. Appendix Figures X-XII present binned scatter plots of absolute upward mobility $\left(\bar{r}_{25, c}\right)$ in each $\mathrm{CZ}$ vs. various characteristics. Each figure is constructed using one observation for each $\mathrm{CZ}$ in which we have more than 250 parent-child pairs. To construct the binned scatter plots, we divide the variable plotted on the x-axis into 20 equally sized bins (vingtiles) and plot the mean value of the variable plotted on the y-axis (absolute upward mobility) vs. the mean value of the $\mathrm{x}$ variable within each bin. We also report the unweighted correlation between the $\mathrm{x}$ and $\mathrm{y}$ variables (estimated using the underlying CZ-level

\footnotetext{
${ }^{69}$ We normalize all variables by their weighted standard deviations in this and all other specifications that use weights, so that univariate regression coefficients can be interpreted as weighted correlations.
} 
data), with standard errors clustered at the state level to correct for spatial correlation across CZs. To facilitate comparisons across figures that plot the relationship between upward mobility and different factors, we always use a fixed y scale ranging from 35 to 55, approximately the 5th to 95th percentile of the distribution of $\bar{r}_{25, c}$ across CZs.

\section{Construction of Predicted Time Trends}

This appendix describes the construction of Appendix Figure XIII. The series in circles is taken directly from Chetty et al. (2014, Figure 2). The solid circles show estimates of national rank-rank slopes by birth cohort using the SOI $0.1 \%$ sample. The open circles show forecasts of the rank-rank slope based on income measured at age 26 and the college attendance rates using the population data. The remaining series in the figure show predicted changes in relative mobility based on trends in the five factors that are most strongly correlated with the variation in intergenerational mobility across CZs (see Section VI). We choose proxies for the five factors that are strongly correlated with mobility in the cross section and are consistently measured over time.

We begin by describing how we construct the prediction based on changes in racial segregation, shown by the series in solid triangles. This series is constructed in four steps. (1) We regress the rank-rank slope on the Theil index of racial segregation, with one observation per CZ. This regression corresponds to the correlation reported in Row 2, Column 6 of Appendix Table VIII, except that we do not use normalized variables in this regression. (2) Using Census data from the NHGIS, we compute the Theil index of racial segregation across census tracts in each CZ in 1980, 1990, and 2000, following the method described in Appendix G. We then compute the predicted value from the regression in step (1) using the population-weighted national mean of the racial segregation index in 1980,1990 , and $2000 .^{70}$ (3) We assign each birth cohort the predicted value when they were age 10, the mid-point of their childhood. For instance, the 1990 birth cohort is assigned the fitted value based on racial segregation in 2000. (4) We add a constant to the series to make the mean predicted values in 1970, 1980, and 1990 match the mean observed rank-rank slope (from Chetty et al. 2014) between 1971-1990. This final step normalizes the levels of the fitted values and allows us to focus on the predicted time trends.

The remaining series are constructed similarly; however, due to limitations in historical data availability, we cannot always use the same data source as the one used to estimate cross-sectional correlations. For the bottom 99\% Gini coefficient, we follow Chetty et al. (2014) and use the U.S. Census Bureau's time series (Table F-4) on the Gini coefficient for families, which we interpret as a measure of the bottom $99 \%$ Gini because of top-coding in survey data. ${ }^{71}$ For the religious share, we use a time series compiled by the Association of Religion Data Archives using data from the General Social Survey. We define the religious share as the share of people that attend a religious service at least once per month, the closest analog of the CZ-level definition of religious adherents that we use for the cross-sectional correlations. For the share of single mothers, we use data for the 1980, 1990, and 2000 Censuses obtained from the NHGIS. For all three of these variables, we assign each birth cohort predicted values at age 10, as for racial segregation.

For the high school dropout rate, we use the same CCD data that we use for the CZ-level cross-sectional correlations. We assign each birth cohort the predicted value corresponding to the national high school dropout rate when they were 17. For simplicity, we do not residualize the HS dropout rate by income both in the cross-sectional regression and the prediction. For example, the 1997 high school dropout rate is assigned to the 1980 birth cohort. Analogous high school dropout

\footnotetext{
${ }^{70}$ Tract-level data on racial shares are not available for all Census tracts in 1980; we compute the national mean using the tracts for which data are available.

${ }^{71}$ Chetty et al. (2014) note that there is a break in this series in 1993 . We address this issue in the same manner as that paper by subtracting 0.021 from the Gini coefficient from 1993 onward.
} 
rate data are unavailable in 1987, and hence we have no prediction for the 1970 birth cohort.

The predicted changes in the rank-rank slope from the 1970 to 1990 birth cohorts based on each of these factors are -0.024 (racial segregation), +0.026 (Gini), +0.003 (religious share), and +0.038 (fraction single mothers). The predicted change from the 1980 to 1990 birth cohort based on high school dropout rates is -0.010. Using a multivariable cross-sectional regression specification combining all five factors yields a predicted increase in the rank-rank slope from 1980 to 1990 of 0.010, or 0.001 per year. An analogous prediction for the change from 1970 to 1980 based on four factors (excluding the high school dropout rate) yields a predicted increase from 1970 to 1980 of approximately 0.014 . 


\section{References}

Autor, David H., David Dorn, and Gordon H. Hanson. 2013. "The Geography of Trade and Technology Shocks in the United States." American Economic Review, 103 (3): 220-25.

Bailey, Martha J. and Susan M. Dynarski. 2011. "Gains and Gaps: Changing Inequality in U.S. College Entry and Completion." NBER Working Paper 17633, National Bureau of Economic Research, Inc.

Becker, Gary S. 1991. A Treatise on the Family, Cambridge, Mass.: Harvard University Press.

Bhattacharya, Debopam and Bhashkar Mazumder. 2011. "A nonparametric analysis of black-white differences in intergenerational income mobility in the United States." Quantitative Economics, 2 (3): 335-379.

Bjorklund, Anders and Markus Jäntti. 1997. "Intergenerational Income Mobility in Sweden Compared to the United States." American Economic Review, 87 (5): 1009-18.

Black, Dan, Seth Sanders, Evan Taylor, and Lowell Taylor. 2011. "The Impact of the Great Migration on Mortality of African Americans: Evidence from the Deep South." Unpublished Univ. of Chicago mimeo.

Black, Sandra E. and Paul J. Devereux. 2011. "Recent Developments in Intergenerational Mobility." in O. Ashenfelter and D. Card, eds., Handbook of Labor Economics, Vol. 4, Elsevier, chapter 16, pp. 1487-1541.

Borjas, George J. 1992. "Ethnic Capital and Intergenerational Mobility." The Quarterly Journal of Economics, 107 (1): 123-50.

Boserup, Simon, Wojciech Kopczuk, and Claus Kreiner. 2013. "Intergenerational Wealth Mobility: Evidence from Danish Wealth Records of Three Generations." Univ. of Copenhagen mimeo.

Bound, John and Alan B Krueger. 1991. "The Extent of Measurement Error in Longitudinal Earnings Data: Do Two Wrongs Make a Right?" Journal of Labor Economics, 9 (1): 1-24.

Bound, John, Charles Brown, and Nancy Mathiowetz. 2001. "Measurement error in survey data." in J.J. Heckman and E.E. Leamer, eds., Handbook of Econometrics, Vol. 5, Elsevier, chapter 59, pp. 3705-3843.

Cameron, Stephen V. and James J. Heckman. 2001. "The Dynamics of Educational Attainment for Black, Hispanic, and White Males." Journal of Political Economy, 109 (3): 455-499.

Card, David. 1995. "Using Geographic Variation in College Proximity to Estimate the Return to Schooling." in Louis N. Christofides, Kenneth E. Grant, and Robert Swidinsky, eds., Aspects of Labour Market Behaviour: Essays in Honour of John Vanderkamp, Toronto: University of Toronto Press.

Chadwick, Laura and Gary Solon. 2002. "Intergenerational Income Mobility Among Daughters." American Economic Review, 92 (1): 335-344.

Chetty, Raj and Nathan Hendren. 2014. "The Value-Added of Neighborhoods: QuasiExperimental Estimates of Neighborhood Effects on Children's Long-Term Outcomes" Harvard Univ. mimeo (in preparation). 
Chetty, Raj, John N. Friedman, and Jonah E. Rockoff. 2014 forthcoming. "Measuring the Impacts of Teachers II: Teacher Value-Added and Student Outcomes in Adulthood." American Economic Review.

Chetty, Raj, Nathaniel Hendren, Patrick Kline, Emmanuel Saez, and Nicholas Turner. 2014. "Is the United States Still a Land of Opportunity? Recent Trends in Intergenerational Mobility." American Economic Review Papers and Proceedings, 104 (5): 141-147.

Cilke, James. 1998. "A Profile of Non-Filers." U.S. Department of the Treasury, Office of Tax Analysis Working Paper No. 78.

Clark, Gregory. 2014. The Son Also Rises: Surnames and the History of Social Mobility.

Coleman, James S. 1988. "Social Capital in the Creation of Human Capital." American Journal of Sociology, 94, pp. S95-S120.

Corak, Miles. 2013. "Income Inequality, Equality of Opportunity, and Intergenerational Mobility." Journal of Economic Perspectives, 27 (3): 79-102.

Corak, Miles and Andrew Heisz. 1999. "The Intergenerational Earnings and Income Mobility of Canadian Men: Evidence from Longitudinal Income Tax Data." Journal of Human Resources, 34 (3): 504-533.

Cutler, David M. and Edward L. Glaeser. 1997. "Are Ghettos Good or Bad?" The Quarterly Journal of Economics, 112 (3): 827-72.

Cutler, David M., Edward L. Glaeser, and Jacob L. Vigdor. 1999. "The Rise and Decline of the American Ghetto." Journal of Political Economy, 107 (3): 455-506.

Dahl, Molly W. and Thomas DeLeire. 2008. The association between children's earnings and fathers' lifetime earnings: estimates using administrative data, University of Wisconsin-Madison, Institute for Research on Poverty.

Dorn, David. "Essays on Inequality, Spatial Interaction, and the Demand for Skills." PhD dissertation, University of St. Gallen no. 3613, 2009.

Duncan, Greg J., Kathleen M. Ziol-Guest, and Ariel Kalil. 2010. "Early-Childhood Poverty and Adult Attainment, Behavior, and Health." Child Development, 81 (1): 306-325.

Fields, Gary S. and Efe A. Ok. 1999. "The Measurement of Income Mobility: An Introduction to the Literature." in Jacques Silber, ed., Handbook of Income Inequality Measurement, Vol. 71, Springer Netherlands, pp. 557-598.

Graham, Bryan and Patrick Sharkey. 2013. "Mobility and the Metropolis: How Communities Factor Into Economic Mobility." Washington D.C.: Economic Mobility Project, The Pew Charitable Trusts.

Grawe, Nathan D. 2006. "Lifecycle bias in estimates of intergenerational earnings persistence." Labour Economics, 13 (5): 551-570.

Haider, Steven and Gary Solon. 2006. "Life-Cycle Variation in the Association between Current and Lifetime Earnings." American Economic Review, 96 (4): 1308-1320.

Hanushek, Eric A. 2003. "The Failure of Input-Based Schooling Policies." Economic Journal, 113 (485): F64-F98. 
Heckman, James J. 2006. "Skill Formation and the Economics of Investing in Disadvantaged Children." Science, 312 (5782): 1900-1902.

Hertz, Tom. 2006. "Understanding mobility in America." Center for American Progress Discussion Paper.

Hotz, Joseph V. and John K. Scholz. "The Earned Income Tax Credit." in Rober A. Moffitt, ed., Means-Tested Transfer Programs in the United States, University of Chicago Press 2003. pp. 141-197.

Iceland, John. 2004. "Beyond Black and White: Metropolitan residential segregation in multiethnic America." Social Science Research, 33 (2): 248-271.

Internal Revenue Service. 2013. "Statistics of Income: Individual Income Tax Returns, 2012." Technical Report, Washington, DC: government printing press.

Jencks, Christopher and Susan E. Mayer. 1990. "The Social Consequences of Growing Up in a Poor Neighborhood." in L. Lynn and M. G. H. McGeary, eds., Inner City Poverty in the United States, Washington D.C.: National Academy Press, p. 111-186.

Jäntti, Markus, Bernt Bratsberg, Knut Røed, Oddbjørn Raaum, Robin Naylor, Eva Österbacka, Anders Björklund, and Tor Eriksson. 2006. "American Exceptionalism in a New Light: A Comparison of Intergenerational Earnings Mobility in the Nordic Countries, the United Kingdom and the United States." IZA Discussion Paper 1938, Institute for the Study of Labor (IZA).

Kain, John F. 1968. "Housing Segregation, Negro Employment, and Metropolitan Decentralization." The Quarterly Journal of Economics, 82 (2): 175-197.

Kasarda, John D. 1989. "Urban Industrial Transition and the Underclass." Annals of the American Academy of Political and Social Science, 501, pp. 26-47.

Katz, Lawrence F., Jeffrey R. Kling, and Jeffrey B. Liebman. 2001. "Moving To Opportunity In Boston: Early Results Of A Randomized Mobility Experiment." The Quarterly Journal of Economics, 116 (2): 607-654.

Kline, Patrick and Andres Santos. 2013. "Sensitivity to missing data assumptions: Theory and an evaluation of the U.S. wage structure." Quantitative Economics, 4 (2): 231-267.

Kline, Patrick and Enrico Moretti. 2014. "People, Places and Public Policy: Some Simple Welfare Economics of Local Economic Development Programs." Annual Review of Economics, 6 (1): forthcoming.

Krueger, Alan. "The Rise and Consequences of Inequality in the United States." Speech at the Center for American Progress, Washington D.C. on January 12, 2012.

Lamb, Michael E. 2004. The Role of the Father in Child Development, Hoboken, N.J.: Wiley.

Lee, Chul-In and Gary Solon. 2009. "Trends in Intergenerational Income Mobility." The Review of Economics and Statistics, 91 (4): 766-772.

Massey, Douglas S and Nancy A Denton. 1993. American Apartheid: Segregation and the Making of the Underclass, Cambridge, Mass.: Harvard University Press. 
Mazumder, Bhashkar. 2005. "Fortunate Sons: New Estimates of Intergenerational Mobility in the United States Using Social Security Earnings Data." The Review of Economics and Statistics, $87(2): 235-255$.

Mazumder, Bhashkar. 2011. "Black-white differences in intergenerational economic mobility in the US." Working Paper Series WP-2011-10, Federal Reserve Bank of Chicago.

Mitnik, Pablo, Victoria Bryant, David B. Grusky, and Michael Weber. 2014. "New Estimates of Intergnerational Income Mobility Using Administrative Data." Statistics of Income, Internal Revenue Service. mimeo (in preparation).

Murray, Charles A. 1984. Losing ground: American social policy, 1950-1980, New York: Basic Books.

Murray, Charles A. 2012. Coming apart: the state of white America, 1960-2010, New York, N.Y.: Crown Forum.

Neal, Derek A and William R Johnson. 1996. "The Role of Premarket Factors in Black-White Wage Differences." Journal of Political Economy, 104 (5): 869-95.

Oreopoulos, Philip. 2003. "The Long-Run Consequences of Living in a Poor Neighborhood." The Quarterly Journal of Economics, 118 (4): 1533-1575.

Piketty, Thomas and Emmanuel Saez. 2003. "Income Inequality in the United States, 1913-1998." The Quarterly Journal of Economics, 118 (1): 1-41.

Putnam, Robert D. 1995. "Bowling Alone: America's Declining Social Capital." Journal of Democracy, 6 (1): 65-78.

Ray, Debraj. 2010. "Uneven Growth: A Framework for Research in Development Economics." Journal of Economic Perspectives, 24 (3): 45-60.

Reardon, Sean and Kendra Bischoff. 2011. "Growth in the residential segregation of families by income, 1970-2009." US 2010 Project.

Reardon, Sean F. 2011. "Measures of income segregation." CEPA Working Papers. Stanford, CA: Stanford Center for Education Policy Analysis.

Reardon, Sean F. and Glenn Firebaugh. 2002. "Measures of Multigroup Segregation." Sociological Methodology, 32 (1): 33-67.

Rupasingha, Anil and Stephan J. Goetz. 2008. "US County-Level Social Capital Data, 19902005." The Northeast Regional Center for Rural Development, Penn State University, University Park, PA.

Sampson, Robert J., Jeffrey D. Morenoff, and Thomas Gannon-Rowley. 2002. "Assessing "Neighborhood Effects": Social Processes and New Directions in Research." Annual Review of Sociology, 28 (1): 443-478.

Solon, Gary. 1992. "Intergenerational Income Mobility in the United States." American Economic Review, 82 (3): 393-408.

Solon, Gary. 1999. "Intergenerational Mobility in the Labor Market." in O. Ashenfelter and D. Card, eds., Handbook of Labor Economics, Vol. 3, Elsevier, pp. 1761-1800. 
Solon, Gary. 2002. "Cross-Country Differences in Intergenerational Earnings Mobility." Journal of Economic Perspectives, 16 (3): 59-66.

Solon, Gary, Marianne E. Page, and Greg J. Duncan. 2000. "Correlations Between Neighboring Children In Their Subsequent Educational Attainment." The Review of Economics and Statistics, 82 (3): 383-392.

Theil, Henri. 1972. Statistical decomposition analysis. With applications in the social and administrative sciences number v. 14. In 'Studies in mathematical and managerial economics.', Amsterdam, New York: North-Holland Pub. Co.; American Elsevier Pub. Co.

Thomas, Adam and Isabel Sawhill. 2002. "For richer or for poorer: Marriage as an antipoverty strategy." Journal of Policy Analysis and Management, 21 (4): 587-599.

Tolbert, Charles M. and Molly Sizer. 1996. "U.S. Commuting Zones and Labor Market Areas: A 1990 update." Economic Research Service Staff Paper, 9614.

Trivedi, Pravin K. and David M. Zimmer. 2007. "Copula Modeling: An Introduction for Practitioners." Foundations and Trends in Econometrics, 1 (1): 1-111.

Wilson, William J. 1987. The truly disadvantaged: the inner city, the underclass, and public policy, Chicago: University of Chicago Press.

Wilson, William J. 1996. When work disappears: the world of the new urban poor, New York: Knopf: Distributed by Random House, Inc.

Zimmerman, David J. 1992. "Regression toward Mediocrity in Economic Stature." American Economic Review, 82 (3): 409-29. 
TABLE I

Intergenerational Mobility Estimates at the National Level

\begin{tabular}{|c|c|c|c|c|c|c|c|c|}
\hline \multirow[b]{2}{*}{ Child's outcome } & \multirow[b]{2}{*}{ Parent's Income Def. } & \multicolumn{6}{|c|}{ Sample } & \multirow[b]{2}{*}{$\begin{array}{c}\text { Fixed Age at } \\
\text { Child Birth } \\
(7)\end{array}$} \\
\hline & & $\begin{array}{c}\text { Core } \\
\text { sample } \\
(1)\end{array}$ & $\begin{array}{c}\text { Male } \\
\text { children } \\
(2) \\
\end{array}$ & $\begin{array}{c}\text { Female } \\
\text { children } \\
(3)\end{array}$ & $\begin{array}{c}\text { Married } \\
\text { parents } \\
(4) \\
\end{array}$ & $\begin{array}{c}\text { Single } \\
\text { parents } \\
(5)\end{array}$ & $\begin{array}{c}1980-1985 \\
\text { cohorts } \\
(6) \\
\end{array}$ & \\
\hline $\begin{array}{l}\text { 1. Log family income } \\
\text { (excluding zeros) }\end{array}$ & Log family income & $\begin{array}{c}0.344 \\
(0.0004)\end{array}$ & $\begin{array}{c}0.349 \\
(0.0006)\end{array}$ & $\begin{array}{c}0.342 \\
(0.0005)\end{array}$ & $\begin{array}{c}0.303 \\
(0.0005)\end{array}$ & $\begin{array}{c}0.264 \\
(0.0008)\end{array}$ & $\begin{array}{c}0.316 \\
(0.0003)\end{array}$ & $\begin{array}{c}0.361 \\
(0.0008)\end{array}$ \\
\hline $\begin{array}{l}\text { 2. Log family income } \\
\text { (recoding zeros to } \$ 1 \text { ) }\end{array}$ & Log family income & $\begin{array}{c}0.618 \\
(0.0009)\end{array}$ & $\begin{array}{c}0.697 \\
(0.0013)\end{array}$ & $\begin{array}{c}0.540 \\
(0.0011)\end{array}$ & $\begin{array}{c}0.509 \\
(0.0011)\end{array}$ & $\begin{array}{c}0.528 \\
(0.0020)\end{array}$ & $\begin{array}{c}0.580 \\
(0.0006)\end{array}$ & $\begin{array}{c}0.642 \\
(0.0018)\end{array}$ \\
\hline $\begin{array}{l}\text { 3. Log family income } \\
\text { (recoding zeros to } \$ 1000 \text { ) }\end{array}$ & Log family income & $\begin{array}{c}0.413 \\
(0.0004)\end{array}$ & $\begin{array}{c}0.435 \\
(0.0007)\end{array}$ & $\begin{array}{c}0.392 \\
(0.0006)\end{array}$ & $\begin{array}{c}0.358 \\
(0.0006)\end{array}$ & $\begin{array}{c}0.322 \\
(0.0009)\end{array}$ & $\begin{array}{c}0.380 \\
(0.0003)\end{array}$ & $\begin{array}{c}0.434 \\
(0.0009)\end{array}$ \\
\hline 4. Family income rank & Family income rank & $\begin{array}{c}0.341 \\
(0.0003)\end{array}$ & $\begin{array}{c}0.336 \\
(0.0004)\end{array}$ & $\begin{array}{c}0.346 \\
(0.0004)\end{array}$ & $\begin{array}{c}0.289 \\
(0.0004)\end{array}$ & $\begin{array}{c}0.311 \\
(0.0007)\end{array}$ & $\begin{array}{c}0.323 \\
(0.0002)\end{array}$ & $\begin{array}{c}0.359 \\
(0.0006)\end{array}$ \\
\hline 5. Family income rank & $\begin{array}{l}\text { Family income rank } \\
(1999-2003)\end{array}$ & $\begin{array}{c}0.339 \\
(0.0003)\end{array}$ & $\begin{array}{c}0.333 \\
(0.0004)\end{array}$ & $\begin{array}{c}0.344 \\
(0.0004)\end{array}$ & $\begin{array}{l}0.287 \\
(0.0004)\end{array}$ & $\begin{array}{l}0.294 \\
(0.0007)\end{array}$ & $\begin{array}{c}0.323 \\
(0.0002)\end{array}$ & $\begin{array}{c}0.357 \\
(0.0006)\end{array}$ \\
\hline 6. Family income rank & Top par. income rank & $\begin{array}{c}0.312 \\
(0.0003)\end{array}$ & $\begin{array}{c}0.307 \\
(0.0004)\end{array}$ & $\begin{array}{c}0.317 \\
(0.0004)\end{array}$ & $\begin{array}{c}0.256 \\
(0.0004)\end{array}$ & $\begin{array}{c}0.253 \\
(0.0006)\end{array}$ & $\begin{array}{c}0.296 \\
(0.0002)\end{array}$ & $\begin{array}{c}0.327 \\
(0.0006)\end{array}$ \\
\hline 7. Individual income rank & Family income rank & $\begin{array}{c}0.287 \\
(0.0003)\end{array}$ & $\begin{array}{c}0.317 \\
(0.0004)\end{array}$ & $\begin{array}{c}0.257 \\
(0.0004)\end{array}$ & $\begin{array}{c}0.265 \\
(0.0004)\end{array}$ & $\begin{array}{c}0.279 \\
(0.0007)\end{array}$ & $\begin{array}{c}0.286 \\
(0.0002)\end{array}$ & $\begin{array}{c}0.292 \\
(0.0006)\end{array}$ \\
\hline 8. Individual earnings rank & Family income rank & $\begin{array}{c}0.282 \\
(0.0003)\end{array}$ & $\begin{array}{c}0.313 \\
(0.0004)\end{array}$ & $\begin{array}{c}0.249 \\
(0.0004)\end{array}$ & $\begin{array}{c}0.259 \\
(0.0004)\end{array}$ & $\begin{array}{c}0.272 \\
(0.0007)\end{array}$ & $\begin{array}{c}0.283 \\
(0.0002)\end{array}$ & $\begin{array}{c}0.287 \\
(0.0006)\end{array}$ \\
\hline 9. College attendance & Family income rank & $\begin{array}{c}0.675 \\
(0.0005)\end{array}$ & $\begin{array}{c}0.708 \\
(0.0007)\end{array}$ & $\begin{array}{c}0.644 \\
(0.0007)\end{array}$ & $\begin{array}{c}0.641 \\
(0.0006)\end{array}$ & $\begin{array}{c}0.663 \\
(0.0013)\end{array}$ & $\begin{array}{c}0.678 \\
(0.0003)\end{array}$ & $\begin{array}{c}0.661 \\
(0.0010)\end{array}$ \\
\hline $\begin{array}{l}\text { 10. College quality rank } \\
\text { (P75-P25 gradient) }\end{array}$ & Family income rank & $\begin{array}{c}0.191 \\
(0.0010)\end{array}$ & $\begin{array}{c}0.188 \\
(0.0014)\end{array}$ & $\begin{array}{c}0.195 \\
(0.0015)\end{array}$ & $\begin{array}{c}0.174 \\
(0.0014)\end{array}$ & $\begin{array}{c}0.172 \\
(0.0020)\end{array}$ & $\begin{array}{c}0.198 \\
(0.0007)\end{array}$ & $\begin{array}{c}0.189 \\
(0.0022)\end{array}$ \\
\hline $\begin{array}{l}\text { 11. Teenage birth } \\
\text { (females only) }\end{array}$ & Family income rank & $\begin{array}{c}-0.298 \\
(0.0006)\end{array}$ & & & $\begin{array}{c}-0.231 \\
(0.0007)\end{array}$ & $\begin{array}{c}-0.322 \\
(0.0016)\end{array}$ & $\begin{array}{c}-0.285 \\
(0.0004)\end{array}$ & $\begin{array}{c}-0.290 \\
(0.0011)\end{array}$ \\
\hline Number of observations & & $9,867,736$ & $4,935,804$ & $4,931,066$ & $6,854,588$ & $3,013,148$ & $20,520,588$ & $2,250,380$ \\
\hline
\end{tabular}

Notes: Each cell in this table reports the coefficient from a univariate OLS regression of an outcome for children on a measure of their parents' incomes with standard errors in parentheses. All rows report estimates of slope coefficients from linear regressions of the child outcome on the parent income measure except row 10, in which we regress college quality rank on a quadratic in parent income rank (as in Figure IVa). In this row, we report the difference between the fitted values for children with parents at the 75th percentile and parents at the 25th percentile using the quadratic specification. Column 1 uses the core sample of children, which includes all current U.S. citizens with a valid SSN or ITIN who are (1) born in birth cohorts 1980-82, (2) for whom we are able to identify parents based on dependent claiming, and (3) whose mean parent income over the years 1996-2000 is strictly positive. Columns 2 and 3 limit the sample used in column 1 to males or females. Columns 4 and 5 limit the sample to children whose parents were married or unmarried in the year the child was linked to the parent. Column 6 uses all children in the 1980-85 birth cohorts. Column 7 restricts the core sample to children whose parents both fall within a 5 year window of median parent age at time of child birth (age 26-30 for fathers; $24-28$ for mothers); we impose only one of these restrictions for single parents. Child family income is the mean of 2011-12 family income, while parent family income is the mean from 1996-2000. Parent top earner income is the mean income of the higher-earning spouse between 1999-2003 (when W-2 data are available). Child's individual income is the sum of W-2 wage earnings, Ul benefits, and SSDI benefits, and half of any remaining income reported on the 1040 form. Individual earnings includes W-2 wage earnings, UI benefits, SSDI income, and self-employment income. College attendance is defined as ever attending college from age 18 to 21 , where attending college is defined as presence of a 1098-T form. College quality rank is defined as the percentile rank of the college that the child attends at age 20 based on the mean earnings at age 31 of children who attended the same college (children who do not attend college are included in a separate "no college" group); see Section III.B for further details. Teenage birth is defined as having a child while between age 13 and 19 . In Columns 1-5 and 7, income percentile ranks are constructed by ranking all children relative to others in their birth cohort based on the relevant income definition and ranking all parents relative to other parents in the core sample. Ranks are always defined on the full sample of all children; that is, they are not re-defined within the subsamples in Columns $2-5$ or 7 . In Column 6 , parents are ranked relative to other parents with children in the 1980-85 birth cohorts. The number of observations corresponds to the specification in row 4 . The number of observations is approximately $7 \%$ lower in row 1 because we exclude children with zero income. The number of observations is approximately $50 \%$ lower in row 11 because we restrict to the sample of female children. There are 866 children in the core sample with unknown sex, which is why the number of observations in the core sample is not equal to the sum of the observations in the male and female samples. 
TABLE II

National Quintile Transition Matrix

\begin{tabular}{ccccccc}
\hline \hline & \multicolumn{5}{c}{ Parent Quintile } \\
\cline { 3 - 7 } & 1 & 1 & 2 & 3 & 4 & 5 \\
\cline { 3 - 7 } & 1 & $33.7 \%$ & $24.2 \%$ & $17.8 \%$ & $13.4 \%$ & $10.9 \%$ \\
Child & 2 & $28.0 \%$ & $24.2 \%$ & $19.8 \%$ & $16.0 \%$ & $11.9 \%$ \\
Quintile & 3 & $18.4 \%$ & $21.7 \%$ & $22.1 \%$ & $20.9 \%$ & $17.0 \%$ \\
& 4 & $12.3 \%$ & $17.6 \%$ & $22.0 \%$ & $24.4 \%$ & $23.6 \%$ \\
& 5 & $7.5 \%$ & $12.3 \%$ & $18.3 \%$ & $25.4 \%$ & $36.5 \%$ \\
\hline \hline
\end{tabular}

Notes. Each cell reports the percentage of children with family income in the quintile given by the row conditional on having parents with family income in the quintile given by the column for the 9,867,736 children in the core sample (1980-82 birth cohorts). See notes to Table I for income and sample definitions. See Online Appendix Table VI for an analogous transition matrix constructed using the $1980-85$ cohorts. 
TABLE III

Intergenerational Mobility in the 50 Largest Commuting Zones

\begin{tabular}{|c|c|c|c|c|c|c|}
\hline $\begin{array}{c}\text { Upward } \\
\text { Mob. Rank } \\
\text { (1) } \\
\end{array}$ & $\begin{array}{c}\text { CZ Name } \\
(2)\end{array}$ & $\begin{array}{c}\text { Population } \\
(3) \\
\end{array}$ & $\begin{array}{c}\text { Absolute } \\
\text { Upward Mobility } \\
(4) \\
\end{array}$ & $\begin{array}{c}\text { P(Child in Q5 | } \\
\text { Parent in Q1) } \\
(5) \\
\end{array}$ & $\begin{array}{c}\text { Pct. Above } \\
\text { Poverty Line } \\
(6) \\
\end{array}$ & $\begin{array}{c}\text { Relative Mobility } \\
\text { Rank-Rank Slope } \\
(7)\end{array}$ \\
\hline 1 & Salt Lake City, Utah & $1,426,729$ & 46.2 & 10.8 & 77.3 & 0.264 \\
\hline 2 & Pittsburgh, Pennsylvania & $2,561,364$ & 45.2 & 9.5 & 74.9 & 0.359 \\
\hline 3 & San Jose, California & $2,393,183$ & 44.7 & 12.9 & 73.5 & 0.235 \\
\hline 4 & Boston, Massachusetts & $4,974,945$ & 44.6 & 10.5 & 73.7 & 0.322 \\
\hline 5 & San Francisco, California & $4,642,561$ & 44.4 & 12.2 & 72.5 & 0.250 \\
\hline 6 & San Diego, California & $2,813,833$ & 44.3 & 10.4 & 74.3 & 0.237 \\
\hline 7 & Manchester, New Hampshire & $1,193,391$ & 44.2 & 10.0 & 75.0 & 0.296 \\
\hline 8 & Minneapolis, Minnesota & $2,904,389$ & 44.2 & 8.5 & 75.2 & 0.338 \\
\hline 9 & Newark, New Jersey & $5,822,286$ & 44.1 & 10.2 & 73.7 & 0.350 \\
\hline 10 & New York, New York & $11,781,395$ & 43.8 & 10.5 & 72.2 & 0.330 \\
\hline 11 & Los Angeles, California & $16,393,360$ & 43.4 & 9.6 & 73.8 & 0.231 \\
\hline 12 & Providence, Rhode Island & $1,582,997$ & 43.4 & 8.2 & 73.6 & 0.333 \\
\hline 13 & Washington DC & $4,632,415$ & 43.2 & 11.0 & 72.2 & 0.330 \\
\hline 14 & Seattle, Washington & $3,775,744$ & 43.2 & 10.9 & 72.0 & 0.273 \\
\hline 15 & Houston, Texas & $4,504,013$ & 42.8 & 9.3 & 74.7 & 0.325 \\
\hline 16 & Sacramento, California & $2,570,609$ & 42.7 & 9.7 & 71.3 & 0.257 \\
\hline 17 & Bridgeport, Connecticut & $3,405,565$ & 42.4 & 7.9 & 72.4 & 0.359 \\
\hline 18 & Fort Worth, Texas & $1,804,370$ & 42.3 & 9.1 & 73.6 & 0.320 \\
\hline 19 & Denver, Colorado & $2,449,044$ & 42.2 & 8.7 & 73.3 & 0.294 \\
\hline 20 & Buffalo, New York & $2,369,699$ & 42.0 & 6.7 & 73.1 & 0.368 \\
\hline 21 & Miami, Florida & $3,955,969$ & 41.5 & 7.3 & 76.3 & 0.267 \\
\hline 22 & Fresno, California & $1,419,998$ & 41.3 & 7.5 & 71.3 & 0.295 \\
\hline 23 & Portland, Oregon & $1,842,889$ & 41.3 & 9.3 & 70.5 & 0.277 \\
\hline 24 & San Antonio, Texas & $1,724,863$ & 41.1 & 6.4 & 74.3 & 0.320 \\
\hline 25 & Philadelphia, Pennsylvania & $5,602,247$ & 40.8 & 7.4 & 69.6 & 0.393 \\
\hline 26 & Austin, Texas & $1,298,076$ & 40.4 & 6.9 & 71.9 & 0.323 \\
\hline 27 & Dallas, Texas & $3,405,666$ & 40.4 & 7.1 & 72.6 & 0.347 \\
\hline 28 & Phoenix, Arizona & $3,303,211$ & 40.3 & 7.5 & 70.6 & 0.294 \\
\hline 29 & Grand Rapids, Michigan & $1,286,045$ & 40.1 & 6.4 & 71.3 & 0.378 \\
\hline 30 & Kansas City, Missouri & $1,762,873$ & 40.1 & 7.0 & 70.4 & 0.365 \\
\hline 31 & Las Vegas, Nevada & $1,568,418$ & 40.0 & 8.0 & 71.1 & 0.259 \\
\hline 32 & Chicago, Illinois & $8,183,799$ & 39.4 & 6.5 & 70.8 & 0.393 \\
\hline 33 & Milwaukee, Wisconsin & $1,660,659$ & 39.3 & 4.5 & 70.3 & 0.424 \\
\hline 34 & Tampa, Florida & $2,395,997$ & 39.1 & 6.0 & 71.3 & 0.335 \\
\hline 35 & Orlando, Florida & $1,697,906$ & 39.1 & 5.8 & 71.5 & 0.326 \\
\hline 36 & Port St. Lucie, Florida & $1,533,306$ & 39.0 & 6.2 & 71.2 & 0.303 \\
\hline 37 & Baltimore, Maryland & $2,512,431$ & 38.8 & 6.4 & 67.7 & 0.412 \\
\hline 38 & St. Louis, Missouri & $2,325,609$ & 38.4 & 5.1 & 69.0 & 0.413 \\
\hline 39 & Dayton, Ohio & $1,179,009$ & 38.3 & 4.9 & 68.2 & 0.397 \\
\hline 40 & Cleveland, Ohio & $2,661,167$ & 38.2 & 5.1 & 68.7 & 0.405 \\
\hline 41 & Nashville, Tennessee & $1,246,338$ & 38.2 & 5.7 & 67.9 & 0.357 \\
\hline 42 & New Orleans, Louisiana & $1,381,652$ & 38.2 & 5.1 & 69.5 & 0.397 \\
\hline 43 & Cincinnati, Ohio & $1,954,800$ & 37.9 & 5.1 & 66.4 & 0.429 \\
\hline 44 & Columbus, Ohio & $1,663,807$ & 37.7 & 4.9 & 67.1 & 0.406 \\
\hline 45 & Jacksonville, Florida & $1,176,696$ & 37.5 & 4.9 & 68.9 & 0.361 \\
\hline 46 & Detroit, Michigan & $5,327,827$ & 37.3 & 5.5 & 68.5 & 0.358 \\
\hline 47 & Indianapolis, Indiana & $1,507,346$ & 37.2 & 4.9 & 67.5 & 0.398 \\
\hline 48 & Raleigh, North Carolina & $1,412,127$ & 36.9 & 5.0 & 67.3 & 0.389 \\
\hline 49 & Atlanta, Georgia & $3,798,017$ & 36.0 & 4.5 & 69.4 & 0.366 \\
\hline 50 & Charlotte, North Carolina & $1,423,942$ & 35.8 & 4.4 & 67.0 & 0.397 \\
\hline
\end{tabular}

Notes: This table reports estimates of intergenerational mobility for the 50 largest commuting zones (CZs) according to their populations in the 2000 Census. The CZs are sorted in descending order by absolute upward mobility (Column 4 ). The mobility measures are calculated using the core sample (1980-82 birth cohorts) and the baseline family income definitions described in Table I (except for Column 5, which uses the 1980-85 birth cohorts). The measures in Columns 4 and 7 are both derived from within-CZ OLS regressions of child income rank against parent income rank. Column 7 reports the slope coefficient from this regression, which is equal to the difference in mean child income rank between children with parents in the 100th percentile and children with parents in the 0th percentile (divided by 100). Column 4 reports the predicted value at parent income rank equal to 25. Column 5 reports the percentage of children whose family income is in the top quintile of the national distribution of child family income conditional on having parent family income in the bottom quintile of the parental national income distribution. These probabilities are taken directly from Online Data Table VII. Column 6 reports the fitted values at parent rank 25 from a regression of an indicator for child family income being above the poverty line on parent income rank (see Appendix F for details). . See Online Data Table V for estimates for all CZs as well as estimates using alternative samples and income definitions. 
TABLE IV

Segregation and Intergenerational Mobility

\begin{tabular}{|c|c|c|c|c|c|c|c|}
\hline \multirow[t]{2}{*}{ Dep. Var.: } & \multicolumn{7}{|c|}{ Absolute Upward Mobility } \\
\hline & $(1)$ & $(2)$ & $(3)$ & $(4)$ & $(5)$ & $(6)$ & $(7)$ \\
\hline Racial Segregation & $\begin{array}{l}-0.361 \\
(0.045)\end{array}$ & $\begin{array}{c}-0.360 \\
(0.068)\end{array}$ & & & & & \\
\hline Income Segregation & & & $\begin{array}{l}-0.393 \\
(0.065)\end{array}$ & & & & $\begin{array}{l}-0.058 \\
(0.090)\end{array}$ \\
\hline Segregation of Poverty $(<\mathrm{p} 25)$ & & & & $\begin{array}{l}-0.508 \\
(0.155)\end{array}$ & $\begin{array}{c}-0.408 \\
(0.166)\end{array}$ & & \\
\hline Segregation of Affluence (>p75) & & & & $\begin{array}{c}0.108 \\
(0.140)\end{array}$ & $\begin{array}{c}0.216 \\
(0.171)\end{array}$ & & \\
\hline Share with Commute $<15$ Mins & & & & & & $\begin{array}{c}0.605 \\
(0.126)\end{array}$ & $\begin{array}{c}0.571 \\
(0.165)\end{array}$ \\
\hline Urban Areas Only & & $x$ & & & $x$ & & \\
\hline R-Squared & 0.131 & 0.130 & 0.154 & 0.167 & 0.052 & 0.366 & 0.368 \\
\hline Observations & 709 & 325 & 709 & 709 & 325 & 709 & 709 \\
\hline
\end{tabular}

Notes: Each column reports coefficients from an OLS regression with standard errors clustered at the state level reported in parentheses. All independent and dependent variables are normalized (in the relevant estimation sample) to have mean 0 and standard deviation 1 , so univariate regression coefficients equal correlation coefficients. The regressions are run using data for the $709 \mathrm{CZs}$ with at least 250 children in the core sample. The dependent variable in all columns is our baseline measure of absolute upward mobility, the expected rank of children whose parents are at the 25th national percentile. Column 2 and 5 restrict to the sample of CZs that intersect an MSA. Racial segregation is measured by the Theil index defined in Section VI.B using racial shares at the census tract level. Income segregation is measured by a weighted average of two-group Theil indices, as in Reardon (2011). Segregation of poverty is a two-group Theil index, where the groups are defined as being above vs. below the 25th percentile of the local household income distribution. Segregation of affluence is defined analogously at the 75th percentile. Share with commute $<15$ minutes is the fraction of working individuals in each $C Z$ who commute less than 15 minutes to work. See Appendix $\mathrm{G}$ for details on the definitions of the independent variables. 
TABLE V

Income Inequality and Intergenerational Mobility: The "Great Gatsby" Curve

\begin{tabular}{|c|c|c|c|c|c|c|c|c|}
\hline \multirow{3}{*}{ Dep. Var. } & \multicolumn{5}{|c|}{ Across CZs within the U.S. } & \multicolumn{3}{|c|}{ Across Countries } \\
\hline & \multicolumn{4}{|c|}{ Absolute Upward Mobility } & \multirow{2}{*}{$\begin{array}{c}\text { Relative } \\
\text { Mobility } \\
(5)\end{array}$} & \multicolumn{2}{|c|}{$\begin{array}{c}\text { Log-Log } \\
\text { Elasticity } \\
1985 \text { Inequality }\end{array}$} & \multirow{2}{*}{$\begin{array}{c}\text { Log-Log } \\
\text { Elasticity } \\
2005 \text { Inequality } \\
(8) \\
\end{array}$} \\
\hline & $(1)$ & $(2)$ & $(3)$ & $(4)$ & & $(6)$ & $(7)$ & \\
\hline Gini Coefficient & $\begin{array}{l}-0.578 \\
(0.093)\end{array}$ & & & & & & & \\
\hline Gini Bottom 99\% & & $\begin{array}{l}-0.634 \\
(0.090)\end{array}$ & $\begin{array}{c}-0.624 \\
(0.113)\end{array}$ & & $\begin{array}{c}0.476 \\
(0.088)\end{array}$ & $\begin{array}{c}0.72 \\
(0.21)\end{array}$ & $\begin{array}{c}0.62 \\
(0.27)\end{array}$ & $\begin{array}{c}0.78 \\
(0.27)\end{array}$ \\
\hline Top 1\% Income Share & & $\begin{array}{l}-0.123 \\
(0.035)\end{array}$ & $\begin{array}{c}0.029 \\
(0.039)\end{array}$ & & $\begin{array}{l}-0.032 \\
(0.032)\end{array}$ & & $\begin{array}{c}0.17 \\
(0.27)\end{array}$ & $\begin{array}{l}-0.11 \\
(0.28)\end{array}$ \\
\hline Frac. Between p25 and p75 & & & & $\begin{array}{c}0.679 \\
(0.111)\end{array}$ & & & & \\
\hline Urban Areas Only & & & $x$ & & & & & \\
\hline R-Squared & 0.334 & 0.433 & 0.380 & 0.462 & 0.224 & 0.518 & 0.536 & 0.531 \\
\hline Observations & 709 & 709 & 325 & 709 & 709 & 13 & 13 & 12 \\
\hline
\end{tabular}

Notes: Each column reports regression coefficients from an OLS regression with all variables normalized to have mean 0 and standard deviation 1 in the estimation sample, so univariate regression coefficients are equal to correlation coefficients. Columns 1-5 are estimated using data for the $709 \mathrm{CZs}$ with at least 250 children in the core sample. The dependent variable in Columns 1-4 is our baseline CZ-level measure of absolute upward mobility, the expected rank of children whose parents are at the 25th national percentile in the core sample. In Column 5 , the dependent variable is relative mobility, the rank-rank slope within each $\mathrm{CZ}$. In Column 3 , we restrict to CZs that intersect MSAs. In Columns 1-5, the Gini coefficient is defined as the Gini coefficient of family income for parents in the core sample in each CZ; the top $1 \%$ income share is defined as the fraction of total parent family income in each $\mathrm{CZ}$ accruing to the richest $1 \%$ of parents in that $\mathrm{CZ}$; the Gini Bottom $99 \%$ is defined as the Gini coefficient minus the top 1\% income share; and the fraction between p25 and p 75 is the fraction of parents in each CZ whose family income is between the 25th and 75th percentile of the national distribution of parent family income for those in the core sample. In Columns 6-8, the dependent variable is the log-log IGE estimate by country from Corak (2013, Figure 1). The Gini coefficients across countries are obtained from the OECD Income Distribution Database (series "Income Distribution and Poverty: by country"). We interpret these coefficients as applying to the bottom $99 \%$ because the surveys on which they are based are typically topcoded. The top $1 \%$ income share across countries is from the World Top Income Database (series "Top 1\% Income Share"). The independent variables are measured in 1985 in Columns 6 and 7 and in 2005 in Column 8. 
TABLE VI

Correlates of Intergenerational Mobility: Comparing Alternative Hypotheses

\begin{tabular}{|c|c|c|c|c|c|c|c|c|}
\hline \multirow[t]{2}{*}{ Dep. Var. } & \multicolumn{3}{|c|}{ Absolute Upward Mobility } & \multicolumn{2}{|c|}{$\underline{\text { Relative Mobility }}$} & \multicolumn{3}{|c|}{ Absolute Upward Mobility } \\
\hline & $(1)$ & $(2)$ & $(3)$ & $(4)$ & $(5)$ & $(6)$ & $(7)$ & $(8)$ \\
\hline Fraction Short Commute & $\begin{array}{c}0.302 \\
(0.065)\end{array}$ & $\begin{array}{c}0.227 \\
(0.077)\end{array}$ & $\begin{array}{c}0.314 \\
(0.052)\end{array}$ & $\begin{array}{l}-0.290 \\
(0.061)\end{array}$ & $\begin{array}{l}-0.325 \\
(0.064)\end{array}$ & $\begin{array}{c}0.331 \\
(0.070)\end{array}$ & & $\begin{array}{c}0.319 \\
(0.065)\end{array}$ \\
\hline Gini Bottom 99\% & $\begin{array}{c}-0.009 \\
(0.053)\end{array}$ & $\begin{array}{l}-0.017 \\
(0.043)\end{array}$ & $\begin{array}{c}0.060 \\
(0.097)\end{array}$ & $\begin{array}{c}0.006 \\
(0.071)\end{array}$ & $\begin{array}{c}0.343 \\
(0.095)\end{array}$ & $\begin{array}{l}-0.287 \\
(0.059)\end{array}$ & & $\begin{array}{l}-0.021 \\
(0.054)\end{array}$ \\
\hline High School Dropout Rate & $\begin{array}{l}-0.147 \\
(0.055)\end{array}$ & $\begin{array}{l}-0.120 \\
(0.038)\end{array}$ & $\begin{array}{c}-0.109 \\
(0.085)\end{array}$ & $\begin{array}{c}0.010 \\
(0.064)\end{array}$ & $\begin{array}{c}0.181 \\
(0.056)\end{array}$ & $\begin{array}{l}-0.288 \\
(0.059)\end{array}$ & & $\begin{array}{c}-0.140 \\
(0.055)\end{array}$ \\
\hline Social Capital Index & $\begin{array}{c}0.169 \\
(0.047)\end{array}$ & $\begin{array}{c}0.065 \\
(0.050)\end{array}$ & $\begin{array}{c}0.173 \\
(0.060)\end{array}$ & $\begin{array}{c}0.154 \\
(0.060)\end{array}$ & $\begin{array}{c}0.154 \\
(0.070)\end{array}$ & $\begin{array}{c}0.168 \\
(0.059)\end{array}$ & & $\begin{array}{c}0.168 \\
(0.045)\end{array}$ \\
\hline Fraction Single Mothers & $\begin{array}{c}-0.487 \\
(0.062)\end{array}$ & $\begin{array}{c}-0.477 \\
(0.071)\end{array}$ & $\begin{array}{l}-0.555 \\
(0.089)\end{array}$ & $\begin{array}{c}0.591 \\
(0.049)\end{array}$ & & & $\begin{array}{l}-0.808 \\
(0.085)\end{array}$ & $\begin{array}{l}-0.579 \\
(0.061)\end{array}$ \\
\hline Fraction Black & & & & & & & $\begin{array}{c}0.056 \\
(0.073)\end{array}$ & $\begin{array}{l}0.132 \\
(0.051)\end{array}$ \\
\hline State Fixed Effects & & $x$ & & & & & & \\
\hline Urban Areas Only & & & $x$ & & & & & \\
\hline R-Squared & 0.757 & 0.859 & 0.671 & 0.48 & 0.324 & 0.651 & 0.584 & 0.763 \\
\hline Observations & 709 & 709 & 325 & 709 & 709 & 709 & 709 & 709 \\
\hline
\end{tabular}

Notes: Each column reports coefficients from an OLS regression with standard errors clustered at the state level reported in parentheses. The regressions are run using data for the $709 \mathrm{CZs}$ with at least 250 children in the core sample. The dependent variable in Columns 1-3 and 6-8 is our baseline measure of absolute upward mobility, the expected rank of children whose parents are at the 25th national percentile. The dependent variable in columns 4 and 5 is relative mobility, the rank-rank slope within each CZ. All independent and dependent variables are normalized (in the relevant estimation sample) to have mean 0 and standard deviation 1. Column 1 reports unweighted estimates across all CZs. Column 2 includes state fixed effects. In Column 3 , we restrict to CZs that intersect MSAs. Columns 4-8 replicate the unweighted specification in Column 1 with different dependent and independent variables. The fraction with short commutes is the share of workers that commute to work in less than 15 minutes calculated using data for the 2000 Census. Gini bottom $99 \%$ is the Gini coefficient minus the top $1 \%$ income share within each CZ, computed using the distribution of parent family income within each CZ for parents in the core sample. Incomeresidualized high school dropout rate is the residual from a regression of the fraction of children who drop out of high school in the CZ, estimated using data from the NCES Common Core of Data for the 2000-01 school year, on mean household income in 2000. Social capital index is the standardized index of social capital constructed by Rupasingha and Goetz (2008). Fraction single mothers is the fraction of children being raised by single mothers in each $\mathrm{CZ}$. Fraction black is the number of people in the CZ who are black alone divided by the CZ population. We code the high school dropout rate as 0 for $116 \mathrm{CZs}$ in which dropout rate data are missing for more than $25 \%$ of the districts in the $\mathrm{CZ}$, and include an indicator for having a missing high school dropout rate. We do the same for $16 \mathrm{CZs}$ with missing data on social capital. See Section VI, Online Data Table IX, and Online Appendix $G$ for additional details on the definitions of each of these variables. 


\begin{tabular}{|c|c|c|c|c|c|}
\hline & & & & $\begin{array}{c}\text { Base national } \\
\text { dataset }\end{array}$ & $\begin{array}{c}\text { Base CZ- } \\
\text { level dataset }\end{array}$ \\
\hline & $\begin{array}{l}\text { Size of Birth } \\
\text { Cohort } \\
\text { (in '000s) }\end{array}$ & $\begin{array}{l}\text { Percentage in } \\
\text { DM1 database, } \\
\text { US citizens, } \\
\text { alive }\end{array}$ & $\begin{array}{c}\text { and matched } \\
\text { to a parent }\end{array}$ & $\begin{array}{l}\text { with positive } \\
\text { parent income } \\
\text { in } 1996-2000\end{array}$ & $\begin{array}{l}\text { and with valid } \\
\text { parental geo } \\
\text { information }\end{array}$ \\
\hline & $(1)$ & $(2)$ & $(3)$ & $(4)$ & $(5)$ \\
\hline 1977 & 3,327 & $95.9 \%$ & $55.0 \%$ & & \\
\hline 1978 & 3,333 & $97.0 \%$ & $72.4 \%$ & & \\
\hline 1979 & 3,494 & $97.6 \%$ & $80.9 \%$ & & \\
\hline 1980 & 3,612 & $99.2 \%$ & $85.6 \%$ & $85.2 \%$ & $84.4 \%$ \\
\hline 1981 & 3,629 & $104.6 \%$ & $91.6 \%$ & $91.1 \%$ & $90.3 \%$ \\
\hline 1982 & 3,681 & $105.5 \%$ & $93.8 \%$ & $93.2 \%$ & $92.4 \%$ \\
\hline 1983 & 3,639 & $105.4 \%$ & $95.4 \%$ & $94.7 \%$ & $93.8 \%$ \\
\hline 1984 & 3,669 & $105.1 \%$ & $96.7 \%$ & $95.8 \%$ & $94.9 \%$ \\
\hline 1985 & 3,761 & $104.8 \%$ & $97.5 \%$ & $96.4 \%$ & $95.4 \%$ \\
\hline 1986 & 3,757 & $104.7 \%$ & $98.0 \%$ & $96.6 \%$ & $95.6 \%$ \\
\hline 1987 & 3,809 & $104.7 \%$ & $98.4 \%$ & $96.8 \%$ & $95.8 \%$ \\
\hline 1988 & 3,910 & $104.5 \%$ & $98.5 \%$ & $96.8 \%$ & $95.7 \%$ \\
\hline 1989 & 4,041 & $105.0 \%$ & $98.5 \%$ & $96.7 \%$ & $95.6 \%$ \\
\hline 1990 & 4,158 & $104.7 \%$ & $98.6 \%$ & $96.7 \%$ & $95.6 \%$ \\
\hline 1991 & 4,111 & $104.5 \%$ & $98.5 \%$ & $96.6 \%$ & $95.5 \%$ \\
\hline 1980-1991 & 45,776 & $104.4 \%$ & $96.0 \%$ & $94.8 \%$ & $93.8 \%$ \\
\hline
\end{tabular}

Notes: Column 1 reports the size of each birth cohort from 1987-1991, based on data from vital statistics obtained from the US Statistical Abstract 2012, Table 78. The remaining columns report the number of individuals in the population tax data as a percentage of the total number in the birth cohort, imposing the additional restrictions listed in the header of each column. Column 2 reports the number of individuals born in each cohort who are in the DM1 tax database, are current US citizens, and are alive in 2013. This column can differ from the birth cohort due to immigration and naturalization, emigration, and deaths before 2012. The percentage of citizens in the DM1 data rises in 1981 because citizenship status is missing for some individuals born before 1981. Column 3 further requires the individuals to be matched to parents (i.e., claimed as children dependents on individual income tax returns by a person aged 15-40 at the time of the birth of the child) in 1996 or after. Column 4, which requires in addition that parents have positive mean income between 1996-2000, is our key sample of interest for all national level statistics. Column 5 further requires valid geographical information (ZIP code) for parents. Column 5 is our key sample of interest for all local area statistics. The core sample includes the 1980-2 cohorts. The extended sample includes the 1980-91 cohorts. 
ONLINE APPENDIX TABLE II

SOI Sample Counts by Birth Cohort

\begin{tabular}{ccc}
\hline \hline & Number of Observations & Number of Unique Children \\
\cline { 2 - 3 } Cohort & $(1)$ & $(2)$ \\
\hline 1971 & 4,383 & 4,383 \\
1972 & 7,787 & 5,569 \\
1973 & 10,831 & 6,154 \\
1974 & 14,330 & 7,065 \\
1975 & 17,736 & 8,207 \\
1976 & 17,938 & 8,246 \\
1977 & 18,459 & 8,156 \\
1978 & 17,756 & 7,958 \\
1979 & 18,375 & 7,614 \\
1980 & 19,545 & 7,732 \\
1981 & 19,916 & 8,155 \\
1982 & 22,331 & 9,929 \\
1983 & 24,599 & 10,927 \\
1984 & 28,221 & 12,390 \\
1985 & 31,711 & 13,476 \\
1986 & 33,221 & 13,540 \\
1987 & 35,382 & 14,234 \\
1988 & 38,139 & 15,362 \\
1989 & 42,450 & 18,162 \\
1990 & 47,768 & 19,805 \\
1991 & 52,821 & 21,231 \\
Total & 523,699 & 228,295 \\
\hline \hline
\end{tabular}

Notes: This table reports the sample size for the Statistics of Income stratified random sample by birth cohort. Column 1 reports the total number of observations per cohort. Column 2 reports the number of unique children per cohort. See Appendix A for details on the construction of the SOI sample. 
ONLINE APPENDIX TABLE III

Summary Statistics for Core Sample: Children Born in 1980-82

\begin{tabular}{lccc}
\hline \hline \multicolumn{1}{c}{ Variable } & $\begin{array}{c}\text { Mean } \\
(1)\end{array}$ & $\begin{array}{c}\text { Std. Dev. } \\
(2)\end{array}$ & $\begin{array}{c}\text { Median } \\
(3)\end{array}$ \\
\cline { 2 - 4 } & & & \\
Parents: & 87,219 & 353,430 & 60,129 \\
\hline Family Income (1996-2000 average) & 68,854 & 830,487 & 48,134 \\
Top Earner's Income (1999-2003 average) & $30.6 \%$ & $46.1 \%$ & \\
Fraction Single Parents & $72.0 \%$ & $44.9 \%$ & \\
Fraction Female among Single Parents & 28.5 & 6.2 & 28 \\
Father's Age at Child Birth & 26.1 & 5.2 & 26 \\
Mother's Age at Child Birth & 43.5 & 6.3 & 43 \\
Father's Age in 1996 & 41.1 & 5.2 & 41 \\
Mother's Age in 1996 & & & \\
Children: & 48,050 & 93,182 & 34,975 \\
Family Income (2011-12 average) & $6.1 \%$ & $23.9 \%$ & \\
Fraction with Zero Family Income & 31,441 & 112,394 & 24,931 \\
Individual Income & 30,345 & 98,692 & 23,811 \\
Individual Earnings & $50.0 \%$ & $50.0 \%$ & \\
Fraction Female & $44.3 \%$ & $49.7 \%$ & \\
Fraction Single & $58.9 \%$ & $49.2 \%$ & \\
Attend College between 18-21 & $15.8 \%$ & $36.5 \%$ & \multirow{2}{*}{0.8} \\
Fraction of Females with Teen Birth & 30.0 & 0.8 & \\
Child's Age in 2011 & & $9,867,736$ & \\
& & \\
Number of Children & & & \\
\hline \hline
\end{tabular}

Notes: The table presents summary statistics for the core sample (1980-82 birth cohorts); see notes to Table I for further details on the definition of the core sample. Child income is mean income in 2011-12 (when the child is approximately 30 years old), while parent family income is mean income from 19962000. Family income is total pre-tax household income. Top earner's income is the income of the higherearning parent from 1999-2003 (when W-2's are available). Parents' marital status is measured in the year the parent is matched to the child. Child's individual income is the sum of W-2 wage earnings, UI benefits, and SSDI benefits, and half of any remaining income reported on the 1040 form. Individual earnings includes W-2 wage earnings, UI benefits, SSDI income, and self-employment income. A child is defined as single if he/she does not file with a spouse in 2011 and 2012. College attendance is defined as ever attending college from age 18 to 21 , where attending college is defined as presence of a 1098-T form. Teenage birth is defined (for females only) as having a child while being aged 19 or less. See Section III.B and Online Appendix A for additional details on sample and variable definitions. All dollar values are reported in 2012 dollars, deflated using the CPI-U. 
ONLINE APPENDIX TABLE IV

Comparison of Administrative Tax Data to CPS and ACS Survey Datasets

\begin{tabular}{|c|c|c|c|c|c|c|c|c|}
\hline & $\begin{array}{c}\text { Tax Data } \\
\text { Full Sample } \\
(1)\end{array}$ & $\begin{array}{c}\text { Tax Data } \\
\text { Core Sample } \\
(2) \\
\end{array}$ & $\begin{array}{c}2011-2012 \\
\text { CPS } \\
(3) \\
\end{array}$ & $\begin{array}{c}2011-2012 \\
\text { ACS } \\
(4) \\
\end{array}$ & $\begin{array}{c}\text { Tax Data } \\
\text { Full Sample } \\
(5)\end{array}$ & $\begin{array}{c}\text { Tax Data } \\
\text { Core Sample } \\
(6) \\
\end{array}$ & $\begin{array}{c}2011-2012 \\
\text { CPS } \\
(7) \\
\end{array}$ & $\begin{array}{c}2011-2012 \\
\text { ACS } \\
(8) \\
\end{array}$ \\
\hline Income Distribution: & \multicolumn{4}{|c|}{ Earned Family Income } & \multicolumn{4}{|c|}{ Total Family Income } \\
\hline$\%$ Zero & $9.74 \%$ & $7.32 \%$ & $9.23 \%$ & $12.64 \%$ & $8.54 \%$ & $6.11 \%$ & $5.44 \%$ & $8.00 \%$ \\
\hline$\%$ Negative & $0.00 \%$ & $0.00 \%$ & $0.00 \%$ & $0.00 \%$ & $0.33 \%$ & $0.34 \%$ & $0.04 \%$ & $0.05 \%$ \\
\hline Mean & 44,278 & 46,805 & 54,313 & 42,382 & 45,406 & 48,050 & 56,438 & 44,845 \\
\hline Std. Deviation & 104,528 & 109,667 & 58,556 & 47,879 & 90,594 & 93,182 & 59,145 & 50,072 \\
\hline P10 & 63 & 1,624 & 1,307 & 0 & 521 & 2,810 & 6,431 & 1,500 \\
\hline P25 & 12,724 & 14,984 & 18,843 & 12,000 & 12,842 & 14,919 & 20,414 & 14,000 \\
\hline P50 & 32,165 & 34,737 & 40,829 & 31,642 & 32,273 & 34,975 & 42,768 & 33,000 \\
\hline P75 & 62,095 & 65,148 & 75,000 & 57,000 & 62,992 & 66,169 & 76,554 & 60,000 \\
\hline P90 & 96,995 & 99,911 & 115,000 & 91,865 & 98,802 & 101,770 & 118,050 & 96,243 \\
\hline \multicolumn{9}{|l|}{ Demographics: } \\
\hline \% Married & $42.43 \%$ & $44.31 \%$ & $49.32 \%$ & $46.17 \%$ & & & & \\
\hline$\%$ Female & $50.03 \%$ & $49.97 \%$ & $50.43 \%$ & $49.98 \%$ & & & & \\
\hline$\%$ Live in South & $36.83 \%$ & $37.94 \%$ & $38.33 \%$ & $37.56 \%$ & & & & \\
\hline$\%$ College & $54.62 \%$ & $58.93 \%$ & $66.20 \%$ & $61.34 \%$ & & & & \\
\hline Observations & $11,262,459$ & $9,867,736$ & 14,246 & 190,561 & $11,262,459$ & $9,867,736$ & 14,246 & 194,501 \\
\hline Sum of Samp. Weights & $11,262,459$ & $9,867,736$ & $10,845,147$ & $11,043,039$ & $11,262,459$ & $9,867,736$ & $10,845,147$ & $11,043,039$ \\
\hline
\end{tabular}

Notes: Columns (1) and (5) include all individuals in the Data Master-1 file from the SSA who were born in 1980-1982, are current U.S. citizens, and lived through 2012. In Columns (2) and (6), we impose the additional restriction that an individual was claimed as a dependent on a tax return in the years $1996-2012$ by parents with positive income as described in the text. CPS sample consists of civilian, non-institutionalized citizens age $29-31$ in the 2011 wave and 30-32 in 2012 waves of the Current Population Survey. ACS sample consists of civilian, non-institutionalized citizens born between 1980-1982 in the 2011 and 2012 American Community Surveys. Earned income refers to wages and salary plus social security and unemployment insurance plus positive self-employment income, except for the ACS measure, which does not include unemployment insurance. IRS wages and salary income is defined as the amount of all wages, tips, and other compensation before any payroll deductions (total of all amounts reported on all Forms W-2, Box 1). IRS unemployment compensation is defined as the amount of Unemployment Compensation and Railroad Retirement Board payments prior to tax withholding as reported on Form 1099-G, Box 1. IRS social security income is defined as total Social Security Administration benefits, as reported on Form SSA-1099 (as well as any Railroad Retirement Board benefits paid, as reported on Form RRB-1099, Box 3). IRS selfemployment income is defined as the profit reported on Form 1040 Schedule C. In the CPS, self-employment income is business income; in the ACS, it is both farm and non-farm business income. In the tax data, total income is the sum of Adjusted Gross Income, social security, and tax exempt interest. Total income in CPS and ACS is all reported income including negative business and investment income. All dollar amounts are in 2012 dollars. Married refers to filing of joint return in 2011-2012 period for the tax data, and self-report of currently married in CPS/ACS samples. College means attended a degree granting institution between the ages of 18 and 21 in the tax data and self-report of more than high school attainment in CPS/ACS samples. South refers to filing a federal tax return in (for tax data) or being surveyed in (for ACS/CPS) one of the following states: DE, DC, FL, GA, MD, NC, SC, VA, WV, AL, KY, MS, TN, AR, LA, OK, TX. ACS and CPS moments computed using sampling weights (inverse probability of inclusion in sample). For the ACS and CPS, the sum of the sample weights is the average of the sum of the sample weights in 2011 and in 2012. 
ONLINE APPENDIX TABLE V

Estimates of Intergenerational Mobility Using Surname Means vs. Individual Incomes

\begin{tabular}{|c|c|c|c|c|c|c|}
\hline \multirow{2}{*}{$\begin{array}{l}\text { Name Freq. } \\
\text { Restriction }\end{array}$} & \multirow{2}{*}{$\begin{array}{c}\text { Number of } \\
\text { Children } \\
\text { (1) }\end{array}$} & \multirow{2}{*}{$\begin{array}{c}\text { Number } \\
\text { of Names } \\
(2)\end{array}$} & \multicolumn{2}{|c|}{ Rank-Rank Slope } & \multicolumn{2}{|c|}{ Log-Log IGE } \\
\hline & & & $\begin{array}{c}\text { Surname } \\
\text { (3) }\end{array}$ & $\begin{array}{c}\text { Individual } \\
\text { (4) }\end{array}$ & $\begin{array}{c}\text { Surname } \\
(5)\end{array}$ & $\begin{array}{c}\text { Individual } \\
(6)\end{array}$ \\
\hline 1. No restriction & $4,843,629$ & 395,439 & 0.39 & 0.30 & 0.42 & 0.33 \\
\hline 2. $<25$ & $1,135,624$ & 375,753 & 0.30 & 0.27 & 0.33 & 0.30 \\
\hline 3. $<50$ & $1,437,280$ & 384,576 & 0.31 & 0.27 & 0.34 & 0.30 \\
\hline 4. $<100$ & $1,784,635$ & 389,611 & 0.33 & 0.28 & 0.36 & 0.31 \\
\hline 5. $>100$ & $3,053,494$ & 5,773 & 0.46 & 0.31 & 0.50 & 0.33 \\
\hline 6. $>1,000$ & $1,650,583$ & 546 & 0.41 & 0.31 & 0.43 & 0.34 \\
\hline 7. $>10,000$ & 390,187 & 22 & 0.41 & 0.33 & 0.45 & 0.35 \\
\hline 8. $>20,000$ & 202,734 & 7 & 0.75 & 0.34 & 0.81 & 0.36 \\
\hline
\end{tabular}

Notes: This table compares estimates of rank-rank slopes and log-log IGEs based on individual-level data to estimates based on surname means, as in Clark (2014). In this table, we restrict the core sample to children who have the same surname (in 2012) as their parents. The first row uses all children who satisfy this restriction. Rows $2-4$ limit the sample to rare surnames: those that occur less than 25 times, 50 times, and 100 times in the sample. Conversely, rows 5-8 limit the sample to common surnames: those that occur more than 100,1000, 10,000, and 20,000 times. Column 1 shows the number of children in each subsample (i.e., the number of observations used to estimate the rank-rank slope). Column 2 shows the number of distinct surnames in each sample. We estimate the individual-level rank-rank slopes and log-log IGE's (Columns 4 and 6) using OLS regressions on the microdata as in Table I. In Columns 3 and 5, we estimate the rankrank slopes and log-log IGE's using OLS regressions on a dataset collapsed to surname-level means, weighting by the number of observations for each name. See Appendix D for further details. 
ONLINE APPENDIX TABLE VI

National Quintile Transition Matrix: 1980-85 Cohorts

\begin{tabular}{ccccccc}
\hline \hline \multicolumn{1}{c}{} & \multicolumn{5}{c}{ Parent Quintile } \\
\cline { 3 - 7 } & 1 & 1st & 2nd & 3rd & 4th & 5th \\
\cline { 3 - 7 } Child & $23.1 \%$ & $24.1 \%$ & $17.7 \%$ & $13.5 \%$ & $11.7 \%$ \\
Quintile & $27.7 \%$ & $24.0 \%$ & $19.6 \%$ & $16.1 \%$ & $12.6 \%$ \\
& 3 & $18.7 \%$ & $21.6 \%$ & $21.9 \%$ & $20.7 \%$ & $17.0 \%$ \\
& 4 & $12.7 \%$ & $17.7 \%$ & $21.8 \%$ & $24.1 \%$ & $23.7 \%$ \\
\hline \hline
\end{tabular}

Notes. Each cell reports the percentage of children with family income in the quintile given by the row conditional on having parents with family income in the quintile given by the column for children in the 1980-85 birth cohorts. See notes to Table I for income and sample definitions. See Table II for an analogous transition matrix constructed using the 1980-82 birth cohorts. 
ONLINE APPENDIX TABLE VII

Robustness of Spatial Variation in Intergenerational Mobility to Alternative Specifications

\begin{tabular}{|c|c|c|c|c|}
\hline \multirow[b]{2}{*}{ Change from Baseline Specification } & \multicolumn{4}{|c|}{ Correlation with Baseline Mobility Estimates and Ratio of Std. Dev. } \\
\hline & $\begin{array}{l}\text { Upward mobility } \\
\text { Unweighted } \\
\text { (1) }\end{array}$ & $\begin{array}{l}\text { Relative mobility } \\
\text { Unweighted } \\
(2) \\
\end{array}$ & $\begin{array}{l}\text { Upward mobility } \\
\text { Pop. Weighted } \\
\text { (3) }\end{array}$ & $\begin{array}{c}\text { Relative mobility } \\
\text { Pop. Weighted } \\
(4)\end{array}$ \\
\hline \multicolumn{5}{|c|}{ A. Alternative Samples } \\
\hline $\begin{array}{l}\text { 1. Male children } \\
\text { 2. Female children } \\
\text { 3. Children of married parents } \\
\text { 4. Children of single parents } \\
\text { 5. Birth cohorts } 1983-85 \\
\text { 6. Birth cohorts } 1986-88 \\
\text { 7. Parent age at child birth within } 5 \text { years of median } \\
\text { 8. Children who stay within CZ } \\
\text { 9. Children matched to unique parents }\end{array}$ & $\begin{array}{ll}0.99, & 1.07 \\
0.98, & 0.96 \\
0.97, & 0.96 \\
0.97, & 0.97 \\
0.97, & 1.00 \\
0.94, & 0.95 \\
0.98, & 1.06 \\
0.94, & 1.02 \\
0.99, & 0.93\end{array}$ & 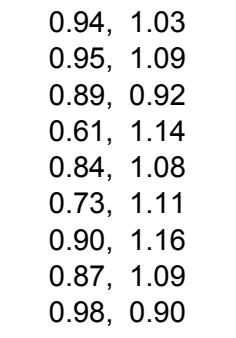 & $\begin{array}{ll}0.98, & 1.07 \\
0.97, & 0.98 \\
0.91, & 1.02 \\
0.97, & 0.96 \\
0.96, & 0.93 \\
0.82, & 0.91 \\
0.98, & 1.05 \\
0.93, & 1.12 \\
0.98, & 0.93\end{array}$ & $\begin{array}{ll}0.98, & 1.01 \\
0.98, & 1.02 \\
0.93, & 0.89 \\
0.83, & 1.02 \\
0.96, & 1.05 \\
0.88, & 0.98 \\
0.96, & 1.02 \\
0.95, & 1.04 \\
0.99, & 0.93\end{array}$ \\
\hline \multicolumn{5}{|c|}{ B. Alternative Income Definitions } \\
\hline $\begin{array}{l}\text { 10. Top parent income } \\
\text { 11. Individual child income } \\
\text { 12. Individual child earnings } \\
\text { 13. Individual child income (males only) } \\
\text { 14. Indiv child income and top parent income (males only) } \\
\text { 15. Parent Income } 1999-2003\end{array}$ & $\begin{array}{ll}1.00, & 1.05 \\
0.94, & 0.74 \\
0.93, & 0.72 \\
0.96, & 1.03 \\
0.97, & 1.07 \\
1.00, & 0.99\end{array}$ & $\begin{array}{ll}0.97, & 1.00 \\
0.89, & 0.80 \\
0.86, & 0.82 \\
0.90, & 1.01 \\
0.87, & 1.02 \\
0.98, & 0.99\end{array}$ & $\begin{array}{ll}0.99, & 1.04 \\
0.83, & 0.97 \\
0.82, & 0.93 \\
0.96, & 1.14 \\
0.97, & 1.15 \\
1.00, & 0.98\end{array}$ & $\begin{array}{ll}0.99, & 0.99 \\
0.95, & 0.81 \\
0.93, & 0.82 \\
0.95, & 0.97 \\
0.94, & 0.95 \\
1.00, & 0.99\end{array}$ \\
\hline \multicolumn{5}{|c|}{ C. Adjustments for Cost of Living and Growth Rates } \\
\hline $\begin{array}{l}\text { 16. Cost of living adjusted income } \\
\text { 17. Parent income measured in } 2011 / 12 \\
\text { 18. Controlling for growth }\end{array}$ & $\begin{array}{ll}0.98, & 1.06 \\
0.97, & 0.90 \\
0.83, & 0.83\end{array}$ & $\begin{array}{ll}0.99, & 0.99 \\
0.92, & 0.89 \\
0.92, & 0.92\end{array}$ & $\begin{array}{ll}0.86, & 1.01 \\
0.94, & 0.95 \\
0.81, & 0.83\end{array}$ & $\begin{array}{ll}0.99, & 0.97 \\
0.98, & 0.93 \\
0.96, & 0.97\end{array}$ \\
\hline \multicolumn{5}{|c|}{ D. Alternative Measures of Mobility } \\
\hline $\begin{array}{l}\text { 19. Within-CZ ranks } \\
\text { 20. Prob. Child in Q5 | Parent in Q1 } \\
\text { 21. Child income > poverty line }\end{array}$ & $\begin{array}{l}0.91 \\
0.94\end{array}$ & $0.95,0.94$ & $\begin{array}{l}0.92 \\
0.89\end{array}$ & $0.96,0.98$ \\
\hline \multicolumn{5}{|c|}{ E. Alternative Child Outcomes } \\
\hline $\begin{array}{l}\text { 22. College Attendance (age 18-21) } \\
\text { 23. College Quality (age } 20 \text { ) } \\
\text { 24. Teenage Birth, females only }\end{array}$ & $\begin{array}{r}0.71 \\
0.71 \\
-0.61\end{array}$ & $\begin{array}{r}0.68 \\
0.51 \\
-0.58\end{array}$ & $\begin{array}{r}0.53 \\
0.55 \\
-0.64\end{array}$ & $\begin{array}{r}0.72 \\
0.65 \\
-0.68\end{array}$ \\
\hline
\end{tabular}

Notes: The first number in each cell of this table reports the correlation across CZs of a baseline mobility measure (using child family income rank and parent family income rank in the core sample) with an alternative mobility measure. The second number in each cell reports the ratio of the standard deviation of the alternative measure to the baseline measure. We do not report the ratio of standard deviations for statistics that are measured in different units relative to the corresponding baseline measure. The alternative mobility measures are defined either using a different sample (Panel A), a different income measure for parents or children (Panel B), adjusting for cost of living or local growth (Panel C), using alternative statistics for mobility (Panel D), or using earlier outcomes (Panel E). Column (1) reports the unweighted correlation (and SD ratio) between the alternative and baseline measure of absolute upward mobility, the expected rank of children whose parents are at the 25th national percentile in the core sample. Column (2) reports the unweighted correlation (and SD ratio) between the alternative and baseline measure of relative mobility, the slope of the rank-rank relationship in the core sample. Columns (3) and (4) repeat Columns (1) and (2), weighting the correlations and standard deviations by $C Z$ population as recorded in the 2000 Census. With the exception of the transition probability in row 20 , all absolute and relative mobility measures are constructed using OLS regressions of child outcomes on parent ranks as described in the text. Ranks are always defined in the full sample, prior to defining specific subsamples, except in row 19. See Appendix F for details on the definition of each measure. 
ONLINE APPENDIX TABLE VIII

Correlates of Intergenerational Mobility Across Commuting Zones

\begin{tabular}{|c|c|c|c|c|c|c|c|c|c|c|c|c|c|}
\hline \multirow{3}{*}{\multicolumn{2}{|c|}{ Dep. Var.: }} & \multicolumn{10}{|c|}{ Absolute Upward Mobility } & \multicolumn{2}{|c|}{ Relative Mobility } \\
\hline & & \multirow{2}{*}{\multicolumn{2}{|c|}{$\frac{\text { Baseline }}{(1)}$}} & \multicolumn{2}{|c|}{ State FEs } & \multirow{2}{*}{\multicolumn{2}{|c|}{$\begin{array}{c}\text { Pop. Weighted } \\
(3)\end{array}$}} & \multirow{2}{*}{\multicolumn{2}{|c|}{$\begin{array}{c}\text { Urban Areas Only } \\
(4)\end{array}$}} & \multicolumn{2}{|c|}{ Controls } & & \\
\hline & & & & & & & & & & & & \multicolumn{2}{|c|}{$(6)$} \\
\hline Race & Fraction Black Residents & -0.580 & $(0.066)$ & -0.353 & $(0.048)$ & -0.616 & $(0.074)$ & -0.673 & $(0.063)$ & & & 0.631 & $(0.048)$ \\
\hline Segregation & $\begin{array}{l}\text { Racial Segregation Theil Index } \\
\text { Income Segregation Theil Index } \\
\text { Segregation of Poverty }(<\mathrm{p} 25) \\
\text { Segregation of Affluence }(>\mathrm{p} 75) \\
\text { Share with Commute }<15 \text { Mins }\end{array}$ & $\begin{array}{c}-0.361 \\
-0.393 \\
-0.407 \\
-0.369 \\
0.605\end{array}$ & $\begin{array}{l}(0.045) \\
(0.065) \\
(0.066) \\
(0.064) \\
(0.126)\end{array}$ & $\begin{array}{c}-0.274 \\
-0.260 \\
-0.261 \\
-0.250 \\
0.342\end{array}$ & $\begin{array}{l}(0.027) \\
(0.036) \\
(0.038) \\
(0.035) \\
(0.092)\end{array}$ & $\begin{array}{c}-0.311 \\
-0.169 \\
-0.216 \\
-0.142 \\
0.335\end{array}$ & $\begin{array}{l}(0.092) \\
(0.105) \\
(0.098) \\
(0.106) \\
(0.115)\end{array}$ & $\begin{array}{c}-0.360 \\
-0.184 \\
-0.210 \\
-0.155 \\
0.548\end{array}$ & $\begin{array}{l}(0.068) \\
(0.068) \\
(0.066) \\
(0.070) \\
(0.080)\end{array}$ & $\begin{array}{c}-0.273 \\
-0.267 \\
-0.274 \\
-0.250 \\
0.415\end{array}$ & $\begin{array}{l}(0.046) \\
(0.054) \\
(0.054) \\
(0.052) \\
(0.131)\end{array}$ & $\begin{array}{l}0.406 \\
0.183 \\
0.218 \\
0.146 \\
-0.447\end{array}$ & $\begin{array}{l}(0.048) \\
(0.063) \\
(0.059) \\
(0.063) \\
(0.074)\end{array}$ \\
\hline $\begin{array}{l}\text { Income } \\
\text { Distribution }\end{array}$ & $\begin{array}{l}\text { Household Income per Capita for Working-Age Adults } \\
\text { Gini coefficient for Parent Income } \\
\text { Top } 1 \% \text { Income Share for Parents } \\
\text { Gini Bottom } 99 \% \\
\text { Fraction Middle Class (Between National p25 and p75) }\end{array}$ & $\begin{array}{r}0.050 \\
-0.578 \\
-0.190 \\
-0.647 \\
0.679\end{array}$ & $\begin{array}{l}(0.071) \\
(0.093) \\
(0.072) \\
(0.092) \\
(0.111)\end{array}$ & $\begin{array}{c}-0.013 \\
-0.281 \\
-0.065 \\
-0.433 \\
0.500\end{array}$ & $\begin{array}{l}(0.075) \\
(0.050) \\
(0.031) \\
(0.063) \\
(0.102)\end{array}$ & $\begin{array}{c}0.046 \\
-0.236 \\
0.059 \\
-0.416 \\
0.293\end{array}$ & $\begin{array}{l}(0.092) \\
(0.162) \\
(0.094) \\
(0.123) \\
(0.129)\end{array}$ & $\begin{array}{c}0.043 \\
-0.537 \\
-0.144 \\
-0.616 \\
0.551\end{array}$ & $\begin{array}{l}(0.076) \\
(0.120) \\
(0.069) \\
(0.114) \\
(0.126)\end{array}$ & $\begin{array}{c}0.064 \\
-0.362 \\
-0.072 \\
-0.470 \\
0.458\end{array}$ & $\begin{array}{l}(0.080) \\
(0.086) \\
(0.065) \\
(0.104) \\
(0.145)\end{array}$ & $\begin{array}{l}-0.145 \\
0.346 \\
0.019 \\
0.473 \\
-0.451\end{array}$ & $\begin{array}{l}(0.081) \\
(0.089) \\
(0.063) \\
(0.090) \\
(0.109)\end{array}$ \\
\hline $\begin{array}{c}\mathrm{K}-12 \\
\text { Education }\end{array}$ & $\begin{array}{l}\text { School Expenditure per Student } \\
\text { Teacher-Student Ratio } \\
\text { Test Score Percentile (Controlling for Parent Income) } \\
\text { High School Dropout Rate (Controlling for Parent Income) }\end{array}$ & $\begin{array}{c}0.246 \\
-0.328 \\
0.588 \\
-0.574\end{array}$ & $\begin{array}{l}(0.095) \\
(0.100) \\
(0.087) \\
(0.089)\end{array}$ & $\begin{array}{c}0.026 \\
-0.213 \\
0.466 \\
-0.413\end{array}$ & $\begin{array}{l}(0.099) \\
(0.128) \\
(0.074) \\
(0.060)\end{array}$ & $\begin{array}{c}0.219 \\
0.062 \\
0.176 \\
-0.433\end{array}$ & $\begin{array}{l}(0.088) \\
(0.139) \\
(0.220) \\
(0.100)\end{array}$ & $\begin{array}{r}0.236 \\
0.024 \\
0.413 \\
-0.441\end{array}$ & $\begin{array}{l}(0.092) \\
(0.104) \\
(0.147) \\
(0.108)\end{array}$ & $\begin{array}{c}0.053 \\
-0.249 \\
0.393 \\
-0.440\end{array}$ & $\begin{array}{l}(0.082) \\
(0.088) \\
(0.093) \\
(0.086)\end{array}$ & $\begin{array}{c}-0.279 \\
0.009 \\
-0.317 \\
0.328\end{array}$ & $\begin{array}{l}(0.092) \\
(0.108) \\
(0.122) \\
(0.099)\end{array}$ \\
\hline $\begin{array}{l}\text { Social } \\
\text { Capital }\end{array}$ & $\begin{array}{l}\text { Social Capital Index (Rupasingha and Goetz 2008) } \\
\text { Fraction Religious } \\
\text { Violent Crime Rate }\end{array}$ & $\begin{array}{r}0.641 \\
0.521 \\
-0.380\end{array}$ & $\begin{array}{l}(0.091) \\
(0.085) \\
(0.146)\end{array}$ & $\begin{array}{r}0.349 \\
0.357 \\
-0.163\end{array}$ & $\begin{array}{l}(0.092) \\
(0.061) \\
(0.058)\end{array}$ & $\begin{array}{r}0.299 \\
0.410 \\
-0.149\end{array}$ & $\begin{array}{l}(0.131) \\
(0.096) \\
(0.166)\end{array}$ & $\begin{array}{r}0.517 \\
0.417 \\
-0.367\end{array}$ & $\begin{array}{l}(0.116) \\
(0.096) \\
(0.145)\end{array}$ & $\begin{array}{r}0.478 \\
0.484 \\
-0.244\end{array}$ & $\begin{array}{l}(0.097) \\
(0.065) \\
(0.062)\end{array}$ & $\begin{array}{l}-0.327 \\
-0.101 \\
0.217\end{array}$ & $\begin{array}{l}(0.085) \\
(0.090) \\
(0.140)\end{array}$ \\
\hline $\begin{array}{c}\text { Family } \\
\text { Structure }\end{array}$ & $\begin{array}{l}\text { Fraction of Children with Single Mothers } \\
\text { Fraction of Adults Divorced } \\
\text { Fraction of Adults Married }\end{array}$ & $\begin{array}{l}-0.764 \\
-0.486 \\
0.571\end{array}$ & $\begin{array}{l}(0.074) \\
(0.100) \\
(0.062)\end{array}$ & $\begin{array}{l}-0.571 \\
-0.333 \\
0.417\end{array}$ & $\begin{array}{l}(0.085) \\
(0.085) \\
(0.063)\end{array}$ & $\begin{array}{c}-0.613 \\
-0.389 \\
0.221\end{array}$ & $\begin{array}{l}(0.129) \\
(0.074) \\
(0.127)\end{array}$ & $\begin{array}{l}-0.719 \\
-0.346 \\
0.377\end{array}$ & $\begin{array}{l}(0.063) \\
(0.103) \\
(0.069)\end{array}$ & $\begin{array}{l}-0.611 \\
-0.569 \\
0.365\end{array}$ & $\begin{array}{l}(0.066) \\
(0.086) \\
(0.089)\end{array}$ & $\begin{array}{l}0.641 \\
0.158 \\
-0.370\end{array}$ & $\begin{array}{l}(0.046) \\
(0.088) \\
(0.078)\end{array}$ \\
\hline $\operatorname{Tax}$ & $\begin{array}{l}\text { Local Tax Rate } \\
\text { Local Government Expenditures per Capita } \\
\text { State EITC Exposure } \\
\text { State Income Tax Progressivity }\end{array}$ & $\begin{array}{l}0.325 \\
0.186 \\
0.245 \\
0.207\end{array}$ & $\begin{array}{l}(0.070) \\
(0.083) \\
(0.064) \\
(0.146)\end{array}$ & $\begin{array}{l}0.135 \\
0.074\end{array}$ & $\begin{array}{l}(0.073) \\
(0.028)\end{array}$ & $\begin{array}{l}0.155 \\
0.192 \\
0.279 \\
0.265\end{array}$ & $\begin{array}{l}0.092) \\
(0.087) \\
(0.076) \\
(0.070)\end{array}$ & $\begin{array}{l}0.182 \\
0.085 \\
0.355 \\
0.198\end{array}$ & $\begin{array}{l}(0.073) \\
(0.079) \\
(0.073) \\
(0.098)\end{array}$ & $\begin{array}{l}0.207 \\
0.107 \\
0.163 \\
0.155\end{array}$ & $\begin{array}{l}(0.071) \\
(0.083) \\
(0.073) \\
(0.133)\end{array}$ & $\begin{array}{l}-0.328 \\
-0.301 \\
-0.144 \\
-0.150\end{array}$ & $\begin{array}{l}(0.061) \\
(0.080) \\
(0.047) \\
(0.106)\end{array}$ \\
\hline College & $\begin{array}{l}\text { Number of Colleges per Capita } \\
\text { Mean College Tuition } \\
\text { College Graduation Rate (Controlling for Parent Income) }\end{array}$ & $\begin{array}{c}0.200 \\
-0.018 \\
0.155\end{array}$ & $\begin{array}{l}(0.114) \\
(0.067) \\
(0.062)\end{array}$ & $\begin{array}{c}-0.015 \\
-0.044 \\
0.141\end{array}$ & $\begin{array}{l}(0.118) \\
(0.039) \\
(0.052)\end{array}$ & $\begin{array}{l}0.108 \\
0.058 \\
0.107\end{array}$ & $\begin{array}{l}(0.088) \\
(0.096) \\
(0.089)\end{array}$ & $\begin{array}{l}-0.045 \\
-0.015 \\
0.120\end{array}$ & $\begin{array}{l}(0.076) \\
(0.087) \\
(0.095)\end{array}$ & $\begin{array}{c}0.060 \\
-0.029 \\
0.173\end{array}$ & $\begin{array}{l}(0.142) \\
(0.066) \\
(0.073)\end{array}$ & $\begin{array}{l}-0.125 \\
0.109 \\
-0.025\end{array}$ & $\begin{array}{l}(0.052) \\
(0.064) \\
(0.057)\end{array}$ \\
\hline $\begin{array}{l}\text { Local Labor } \\
\text { Market }\end{array}$ & $\begin{array}{l}\text { Labor Force Participation Rate } \\
\text { Fraction Working in Manufacturing } \\
\text { Growth in Chinese Imports 1990-2000 (Autor and Dorn 2013) } \\
\text { Teenage (14-16) Labor Force Participation Rate }\end{array}$ & $\begin{array}{c}0.212 \\
-0.261 \\
-0.175 \\
0.631\end{array}$ & $\begin{array}{l}(0.086) \\
(0.091) \\
(0.078) \\
(0.087)\end{array}$ & $\begin{array}{c}-0.045 \\
0.007 \\
0.006 \\
0.358\end{array}$ & $\begin{array}{l}(0.052) \\
(0.079) \\
(0.023) \\
(0.098)\end{array}$ & $\begin{array}{c}0.022 \\
-0.158 \\
0.001 \\
0.299\end{array}$ & $\begin{array}{l}(0.090) \\
(0.090) \\
(0.070) \\
(0.153)\end{array}$ & $\begin{array}{c}0.267 \\
-0.128 \\
0.008 \\
0.540\end{array}$ & $\begin{array}{l}(0.113) \\
(0.096) \\
(0.102) \\
(0.109)\end{array}$ & $\begin{array}{c}0.146 \\
0.002 \\
-0.107 \\
0.388\end{array}$ & $\begin{array}{l}(0.073) \\
(0.085) \\
(0.048) \\
(0.090)\end{array}$ & $\begin{array}{c}-0.237 \\
0.393 \\
0.171 \\
-0.516\end{array}$ & $\begin{array}{l}(0.082) \\
(0.070) \\
(0.083) \\
(0.084)\end{array}$ \\
\hline Migration & $\begin{array}{l}\text { Migration Inflow Rate } \\
\text { Migration Outflow Rate } \\
\text { Fraction of Foreign Born Residents }\end{array}$ & $\begin{array}{l}-0.258 \\
-0.163 \\
-0.027\end{array}$ & $\begin{array}{l}(0.074) \\
(0.070) \\
(0.064)\end{array}$ & $\begin{array}{l}-0.186 \\
-0.162 \\
-0.014\end{array}$ & $\begin{array}{l}(0.049) \\
(0.048) \\
(0.039)\end{array}$ & $\begin{array}{l}-0.146 \\
0.062 \\
0.237\end{array}$ & $\begin{array}{l}(0.076) \\
(0.094) \\
(0.083)\end{array}$ & $\begin{array}{l}-0.040 \\
0.013 \\
0.092\end{array}$ & $\begin{array}{l}(0.078) \\
(0.076) \\
(0.064)\end{array}$ & $\begin{array}{l}-0.285 \\
-0.145 \\
-0.004\end{array}$ & $\begin{array}{l}(0.069) \\
(0.071) \\
(0.051)\end{array}$ & $\begin{array}{l}-0.084 \\
-0.150 \\
-0.247\end{array}$ & $\begin{array}{l}(0.067) \\
(0.070) \\
(0.055)\end{array}$ \\
\hline
\end{tabular}




\section{FIGURE I: Association between Children's and Parents' Incomes}

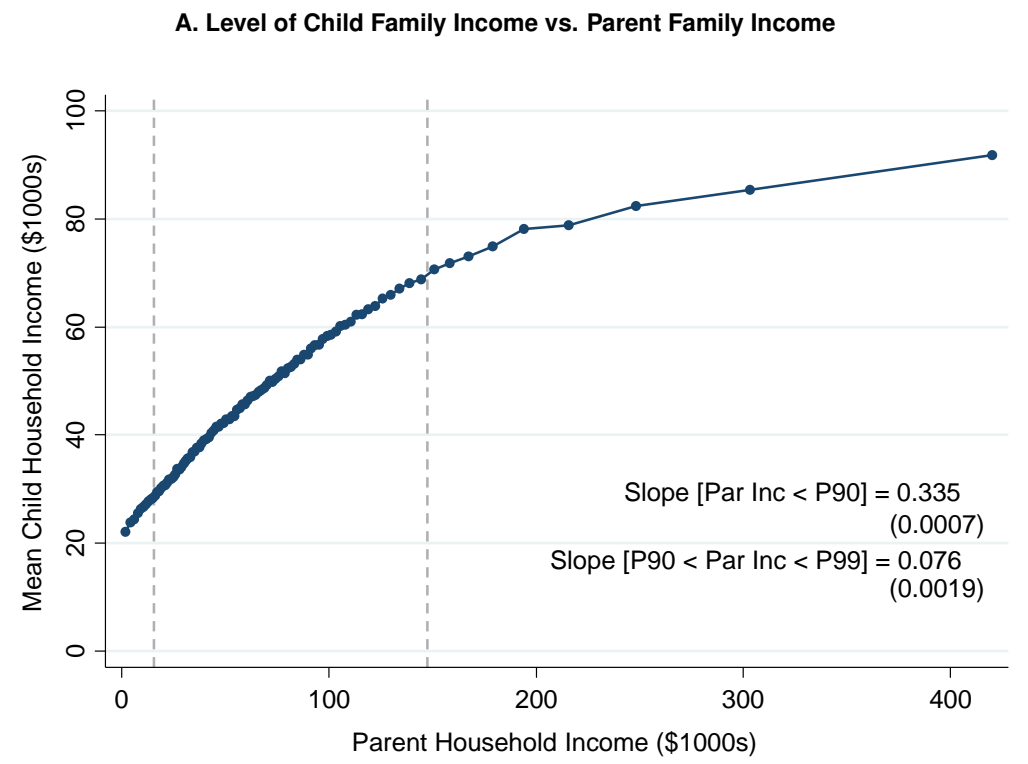

B. Log Child Family Income vs. Log Parent Family Income

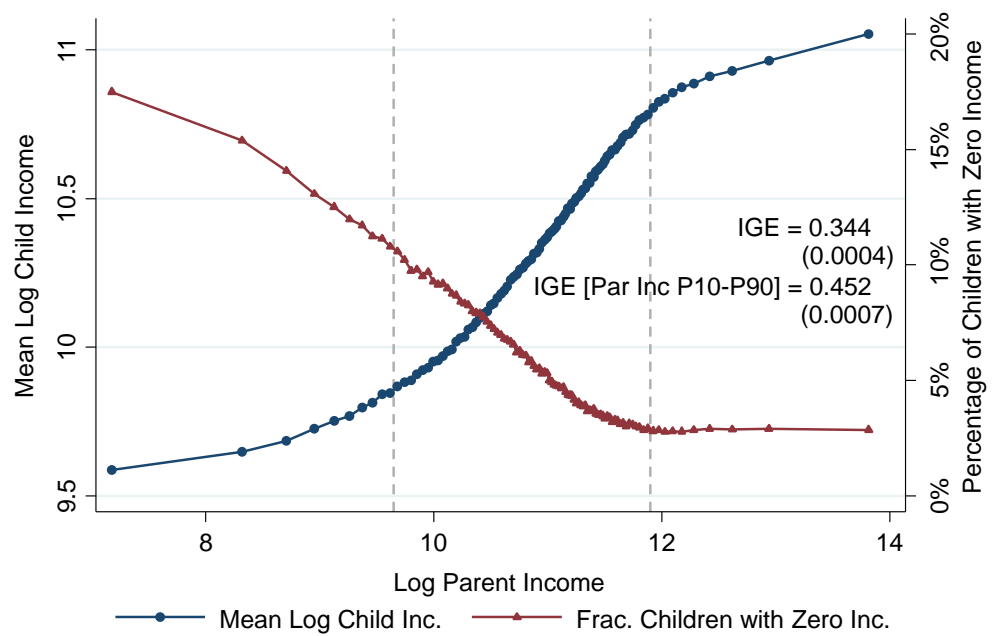

Notes: These figures present non-parametric binned scatter plots of the relationship between child income and parent income. Both figures are based on the core sample (1980-82 birth cohorts) and baseline family income definitions for parents and children. Child income is the mean of 2011-2012 family income (when the child is approximately 30 years old), while parent income is mean family income from 1996-2000. Incomes are in 2012 dollars. To construct Panel A, we bin parent family income into 100 equal-sized (centile) bins and plot the mean level of child income vs. mean level of parent income within each bin. For scaling purposes, we do not show the point for the top $1 \%$ in Panel A. In the top $1 \%$ bin, mean parent income is $\$ 1.4$ million and mean child income is $\$ 114,000$. In Panel B, we again bin parent family income into 100 bins and plot mean log income for children (left y-axis) and the fraction of children with zero family income (right y-axis) vs. mean parents' log income. Children with zero family income are excluded from the log income series. In both panels, the 10th and 90th percentile of parents' income are depicted in dashed vertical lines. The coefficient estimates and standard errors (in parentheses) reported on the figures are obtained from OLS regressions on the microdata. In Panel A, we report separate slopes for parents below the 90th percentile and parents between the 90th and 99th percentile. In panel B, we report slopes of the log-log regression (i.e., the intergenerational elasticity of income or IGE) in the full sample and for parents between the 10th and 90th percentiles. 


\section{FIGURE II: Association between Children's and Parents' Percentile Ranks}

A. Mean Child Income Rank vs. Parent Income Rank in the U.S.

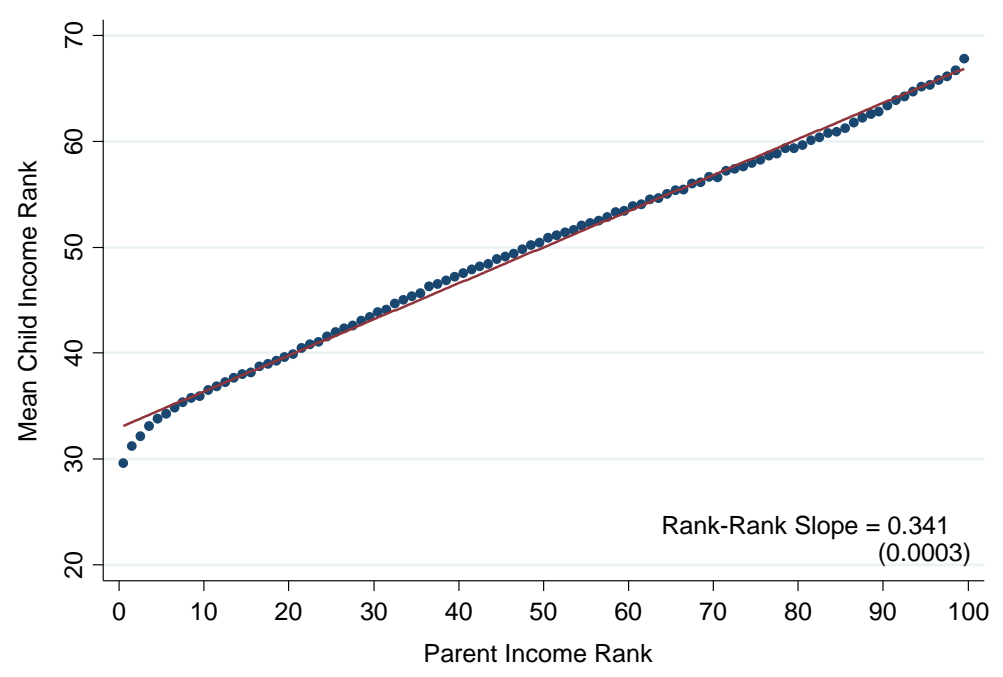

B. Cross-Country Comparisons

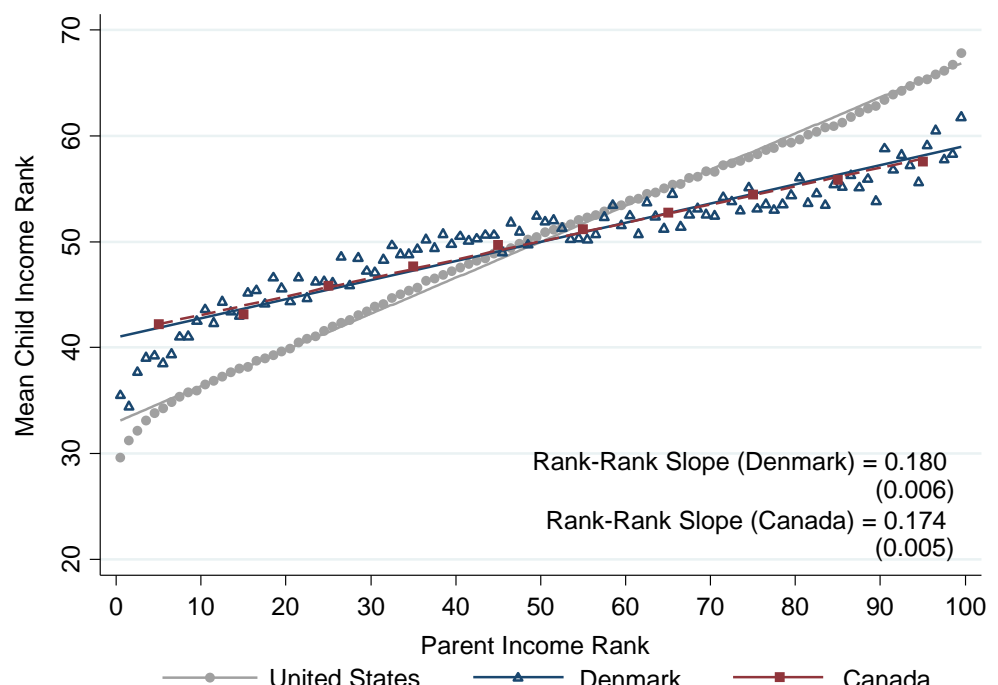

Notes: These figures present non-parametric binned scatter plots of the relationship between children's and parent's percentile income ranks. Both figures are based on the core sample (1980-82 birth cohorts) and baseline family income definitions for parents and children. Child income is the mean of 2011-2012 family income (when the child is approximately 30 years old), while parent income is mean family income from 1996-2000. Children are ranked relative to other children in their birth cohort, while parents are ranked relative to all other parents in the core sample. Panel A plots the mean child percentile rank within each parent percentile rank bin. The series in triangles in Panel B plots the analogous series for Denmark, computed by Boserup, Kopczuk, and Kreiner (2013) using a similar sample and income definitions. The series in squares plots estimates of the rank-rank series using the decile-decile transition matrix from Corak and Heisz (1999). The series in circles in Panel $\mathrm{B}$ reproduces the rank-rank relationship in the U.S. from Panel A as a reference. The slopes and best-fit lines are estimated using an OLS regression on the microdata for the U.S. and on the binned series (as we do not have access to the microdata) for Denmark and Canada. Standard errors are reported in parentheses. 


\section{FIGURE III: Robustness of Intergenerational Mobility Estimates}

\section{A. Lifecycle Bias: Rank-Rank Slopes by Age of Child}

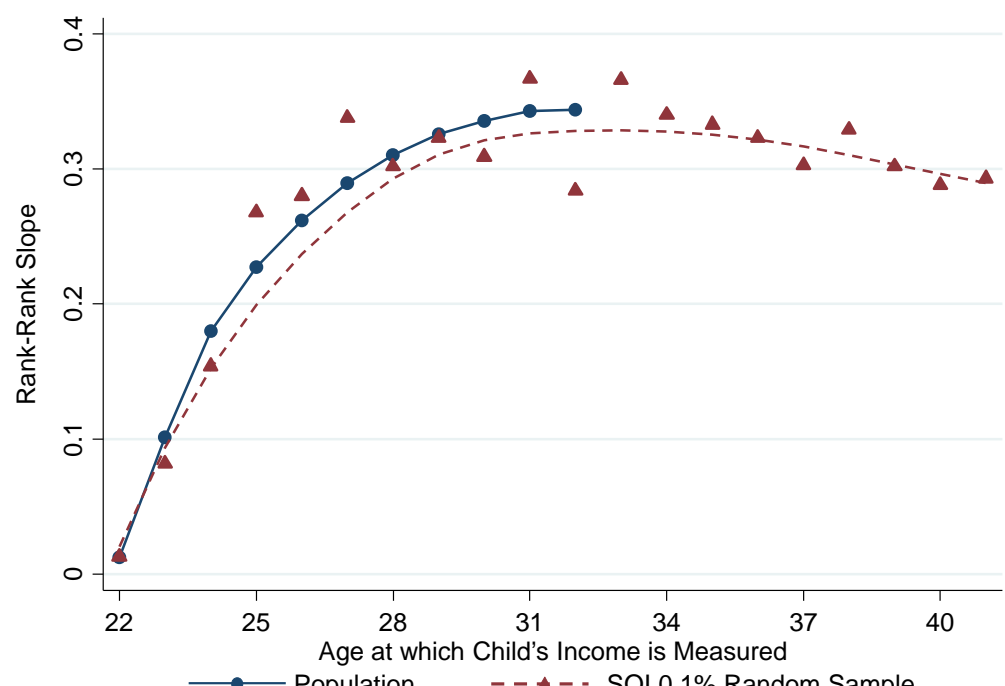

B. Attenuation Bias: Rank-Rank Slopes by Number of Years Used to Measure Parent Income

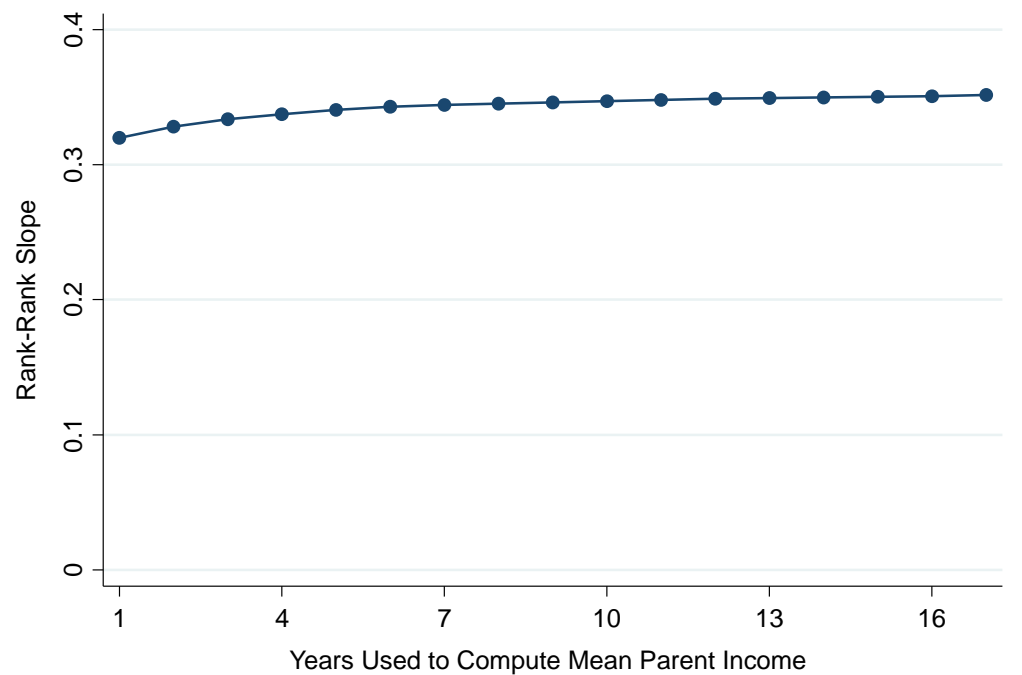

Notes: This figure evaluates the robustness of the rank-rank slope estimated in Figure IIa to changes in the age at which child income is measured (Panel A) and the number of years used to measure parents' income (Panel B). In both panels, child income is defined as mean family income in 2011-2012. In Panel A, parent income is defined as mean family income from 1996-2000. Each point in Panel A shows the slope coefficient from a separate OLS regression of child income rank on parent income rank, varying the child's birth cohort and hence the child's age in 2011-12 when the child's income is measured. The circles use the extended sample in the population data, while the triangles use the $0.1 \%$ Statistics of Income stratified random sample. The first point in Panel A corresponds to the children in the 1990 birth cohort, who are 21-22 when their incomes are measured in 2011-12 (denoted by age 22 on the figure). The last point for which we have population-wide estimates corresponds to the 1980 cohort, who are 31-32 (denoted by 32) when their incomes are measured. The last point in the SOI sample corresponds to the 1971 cohort, who are 40-41 (denoted by 41) when their incomes are measured. The dashed line is a lowess curve fit through the SOI $0.1 \%$ sample rank-rank slope estimates. In Panel B, we focus on children in the core sample (1980-82 birth cohorts) in the population data. Each point in this figure shows the coefficient from the same rank-rank regression as in Figure IIa, varying the number of years used to compute mean parent income. The first point uses parent income data for 1996 only to define parent ranks. The second point uses mean parent income from 1996-1997. The last point uses mean parent income from 1996-2012, a 17 year average. 


\section{FIGURE IV: Gradients of College Attendance and Teenage Birth by Parent Rank}

\section{A. Children's College Attendance Rate and Quality vs. Parent Income Rank}

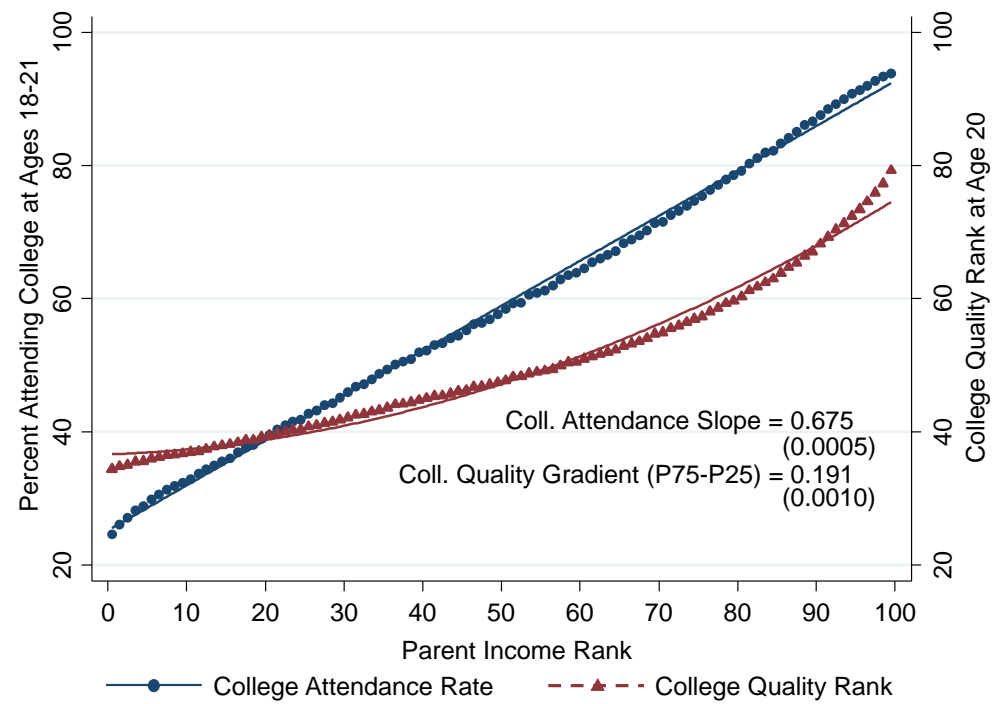

B. Female Children's Teenage Birth Rate vs. Parent Income Rank

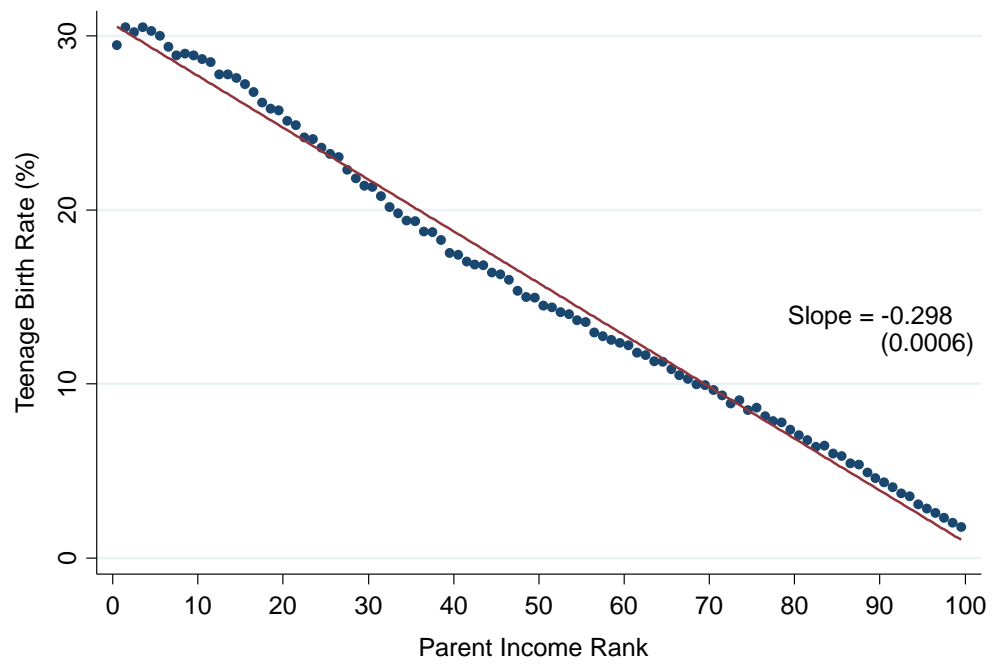

Notes: These figures present non-parametric binned scatter plots of the relationship between children's college attendance rates (Panel A, circles), college quality rank (Panel A, triangles), and teenage birth rates (Panel B) vs. parents' percentile rank. Both figures are based on the core sample (1980-82 birth cohorts). Parent rank is defined based on mean family income from 1996-2000. In Panel A, the circles plot the fraction of children ever attending college between age 18-21 within each parent-income percentile bin; the triangles plot the average college quality rank at age 20 within each parent-income percentile bin. College attendance is defined as the presence of a 1098-T form filed by a college on behalf of the student. College quality rank is defined as the percentile rank of the college that the child attends at age 20 based on the mean earnings at age 31 of children who attended the same college (children who do not attend college are included in a separate "no college" group); see Section III.B for further details. Panel B plots the fraction of female children who give birth while teenagers within each parental percentile bin. Having a teenage birth is defined as ever claiming a dependent child who was born while the mother was aged 13-19. The slopes and best-fit lines for college attendance and teenage birth are estimated using linear regressions of the outcome of interest on parent income rank in the microdata. We regress college quality rank on a quadratic in parent rank to match the non-linearity of the relationship. The college quality gradient is defined as the difference between the fitted values for children with parents at the 75 th percentile and parents at the 25 th percentile using this quadratic specification. 


\section{FIGURE V: Intergenerational Mobility in Selected Commuting Zones}

\section{A. Salt Lake City vs. Charlotte}

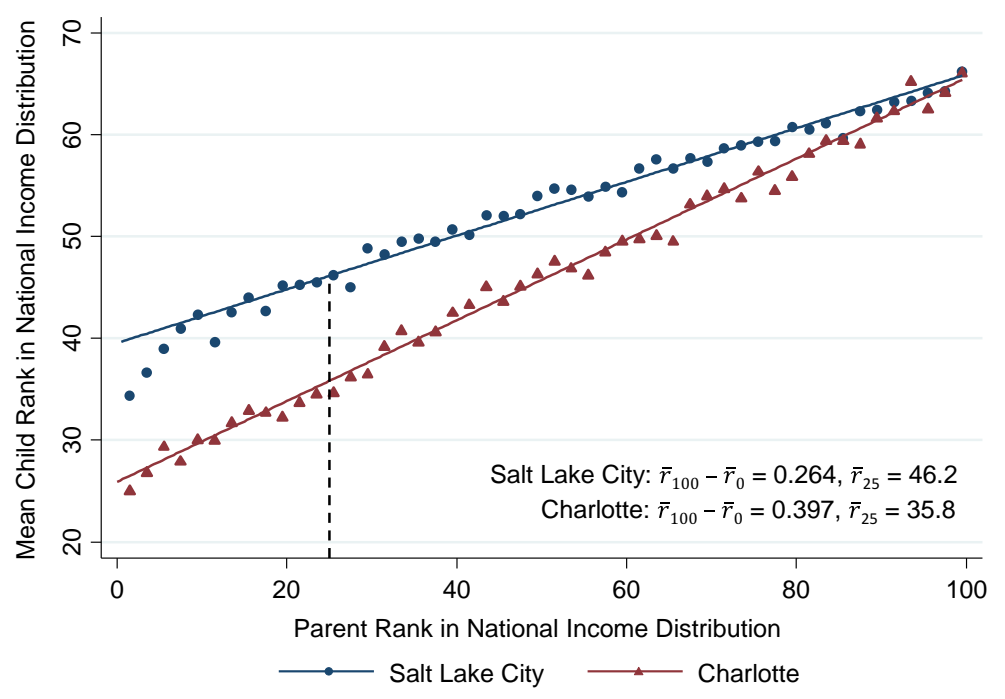

B. San Francisco vs. Chicago

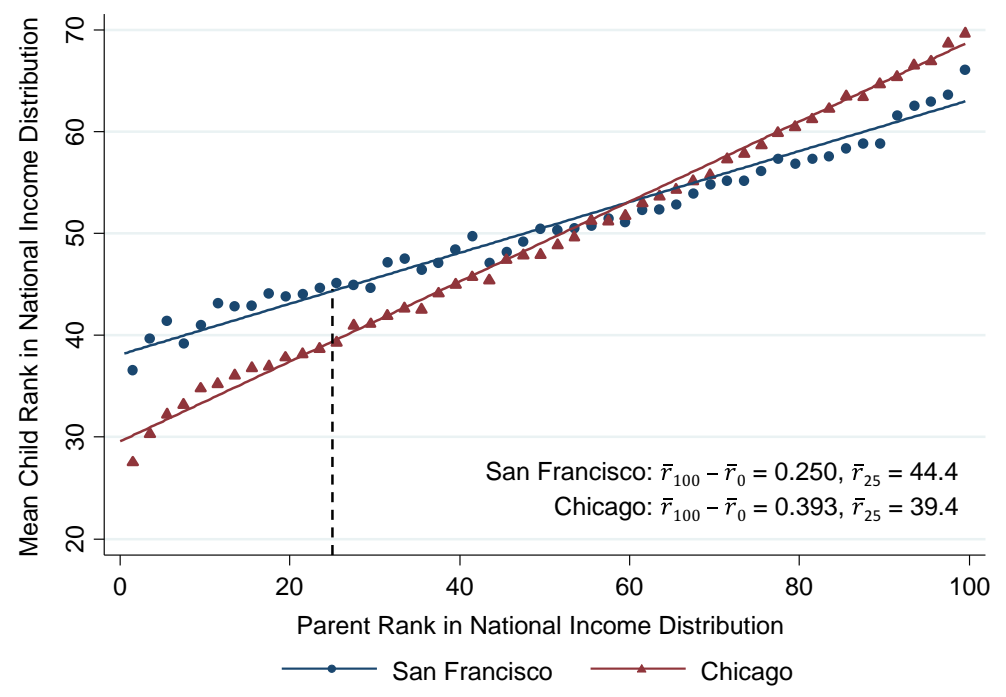

Notes: These figures present non-parametric binned scatter plots of the relationship between child and parent income ranks in selected CZs. Both figures are based on the core sample (1980-82 birth cohorts) and baseline family income definitions for parents and children. Children are assigned to commuting zones based on the location of their parents (when the child was claimed as a dependent), irrespective of where they live as adults. Parent and child percentile ranks are always defined at the national level, not the CZ level. To construct each series, we group parents into 50 equally sized (two percentile point) bins and plot the mean child percentile rank vs. the mean parent percentile rank within each bin. We report two measures of mobility based on the rank-rank relationships in each CZ. The first is relative mobility $\left(\bar{r}_{100}-\bar{r}_{0}\right)$, which is 100 times the rank-rank slope estimate. The second is absolute upward mobility $\left(\bar{r}_{25}\right)$, the predicted child income rank at the 25 th percentile of parent income distribution, depicted by the dashed vertical line in the figures. All mobility statistics and best-fit lines are estimated on the underlying microdata (not the binned means). 


\section{FIGURE VI: The Geography of Intergenerational Mobility}

\section{A. Absolute Upward Mobility: Mean Child Rank for Parents at 25th Percentile $\left(\bar{r}_{25}\right)$ by CZ}

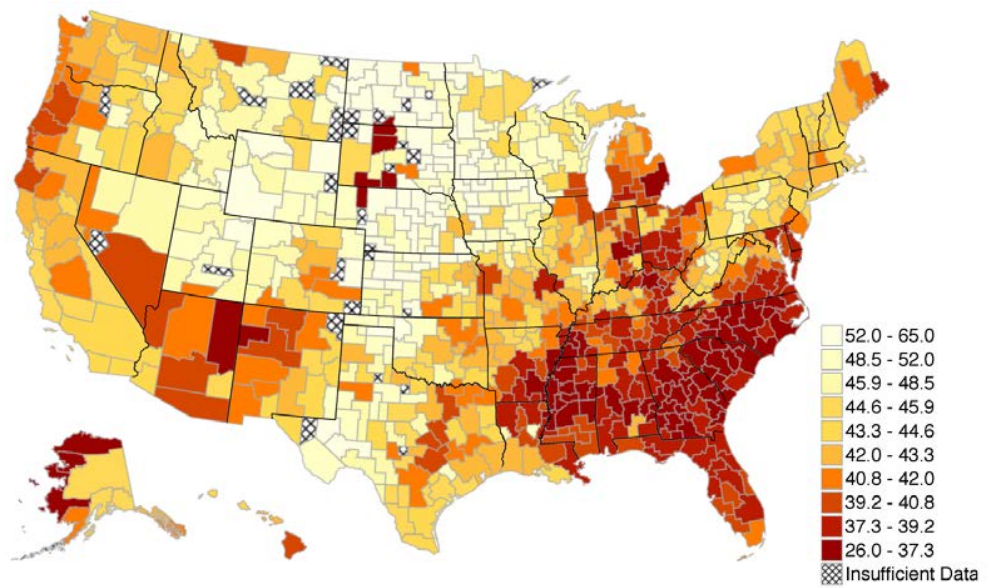

B. Relative Mobility: Rank-Rank Slopes $\left(\bar{r}_{100}-\bar{r}_{0}\right) / 100$ by CZ

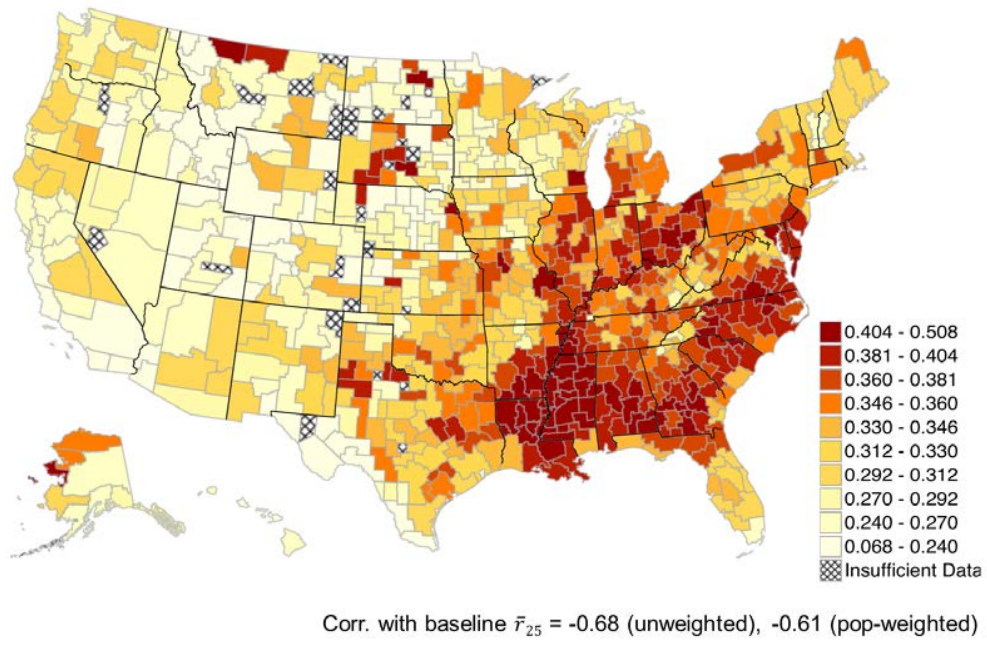

Notes: These figures present heat maps of our two baseline measures of intergenerational mobility by commuting zone (CZ). Both figures are based on the core sample (1980-82 birth cohorts) and baseline family income definitions for parents and children. Children are assigned to commuting zones based on the location of their parents (when the child was claimed as a dependent), irrespective of where they live as adults. In each CZ, we regress child income rank on a constant and parent income rank. Using the regression estimates, we define absolute upward mobility $\left(\bar{r}_{25}\right)$ as the intercept $+25 \times($ rank-rank slope), which corresponds to the predicted child rank given parent income at the 25th percentile (see Figure V). We define relative mobility as the rank-rank slope; the difference between the outcomes of the child from the richest and poorest family is 100 times this coefficient $\left(\bar{r}_{100}-\bar{r}_{0}\right)$. The maps are constructed by grouping CZs into ten deciles and shading the areas so that lighter colors correspond to higher absolute mobility (Panel A) and lower rank-rank slopes (Panel B). Areas with fewer than 250 children in the core sample, for which we have inadequate data to estimate mobility, are shaded with the cross-hatch pattern. In Panel B, we report the unweighted and population-weighted correlation coefficients between relative mobility and absolute mobility across CZs. The CZ-level statistics underlying these figures are reported in Online Data Table V. 


\section{FIGURE VII: Relationship Between Absolute and Relative Mobility}

A. Association Between Absolute and Relative Mobility by Parent Income Rank

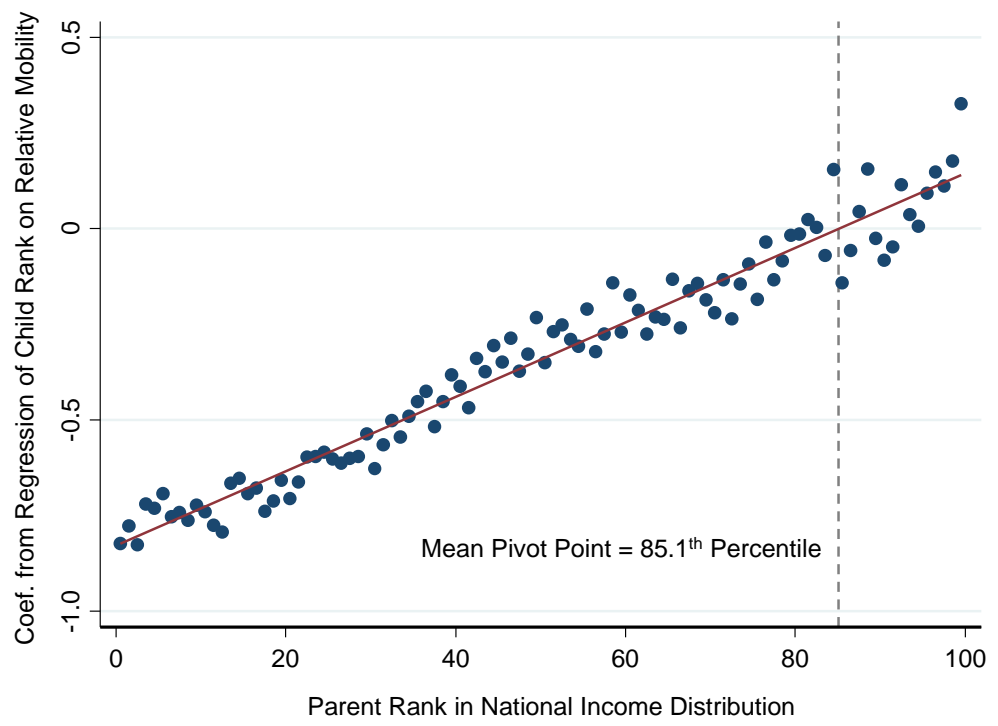

B. Illustrative Schematic of Pivot in Rank-Rank Relationship

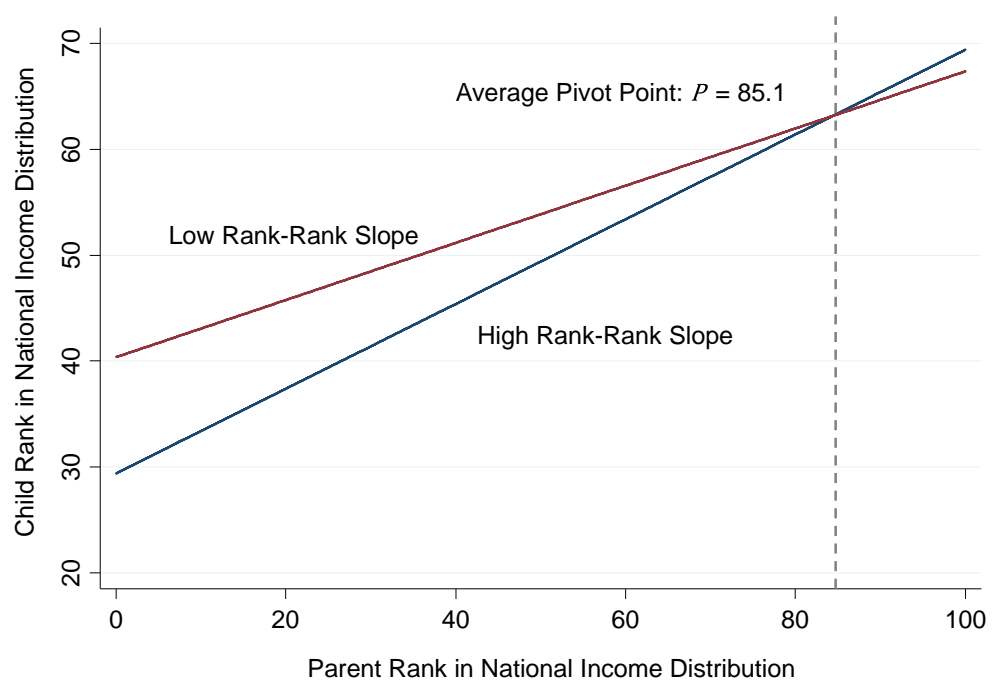

Notes: These figures illustrate the correlation between relative mobility and absolute mobility at various percentiles of the income distribution. To construct Panel A, we first calculate the mean income rank of children in CZ $c$ with parents in (national) percentile $p$, denoted by $\bar{\mu}_{p c}$. We then run a CZ-level regression of $\bar{\mu}_{p c}$ on relative mobility $\left(\bar{r}_{100 c}-\bar{r}_{0 c}\right)$ at each percentile $p$ separately. Panel A plots the resulting regression coefficients $\gamma_{p}$ vs. the percentile $p$. The coefficient $\gamma_{p}$ can be interpreted as the mean impact of a 1 unit increase in relative mobility on the absolute outcomes of children whose parents are at percentile $p$. We also plot the best linear fit across the 100 coefficients. This line, estimated using an OLS regression, crosses zero at percentile $p=85.1$. This implies that increases in relative mobility are associated with higher expected rank outcomes for children with parents below percentile 85.1 and lower expected rank outcomes for children with parents above percentile 85.1. To illustrate the intuition for this result, Panel B plots hypothetical rank-rank relationships in two representative CZs, one of which has more relative mobility than the other. Panel A implies that in such a pairwise comparison, the two rank-rank relationships cross at the 85th percentile on average, as illustrated in Panel B. 


\section{FIGURE VIII: Correlates of Spatial Variation in Upward Mobility}

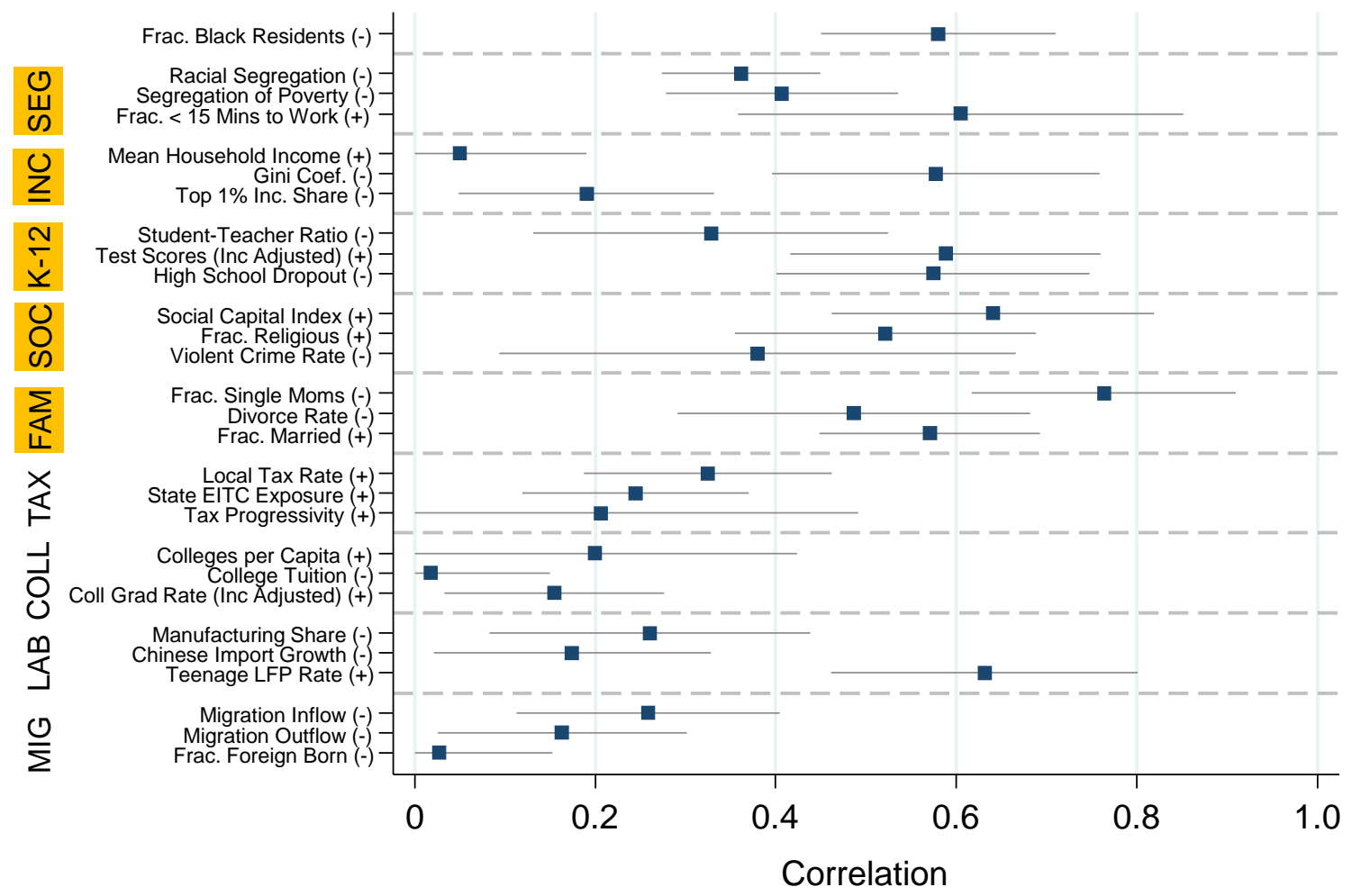

Notes: This figure shows the correlation of various CZ-level characteristics with absolute upward mobility $\left(\bar{r}_{25}\right)$ across CZs. For each characteristic listed on the y axis, the dot represents the absolute value of the unweighted correlation of the variable with $\bar{r}_{25}$ across CZs. The horizontal bars show the $95 \%$ confidence interval based on standard errors clustered at state level. Positive correlations are shown by $(+)$ on the y axis; negative correlations are shown by $(-)$. We consider covariates in ten broad categories: racial demographics, segregation, properties of the income distribution, K-12 education, social capital, family structure, local tax policies, college education, labor market conditions, and migration rates. The categories with the highest correlations are highlighted. See Column 1 of Appendix Table VII for the point estimates corresponding to the correlations plotted here. See Section VI, Online Data Table IX, and Online Appendix G for definitions of each of the correlates. CZ-level data on the covariates used in this figure are reported in Online Data Table VIII. 


\section{FIGURE IX: Race and Upward Mobility}

\section{A. Upward Mobility for Individuals in $80 \%+$ White ZIP Codes}

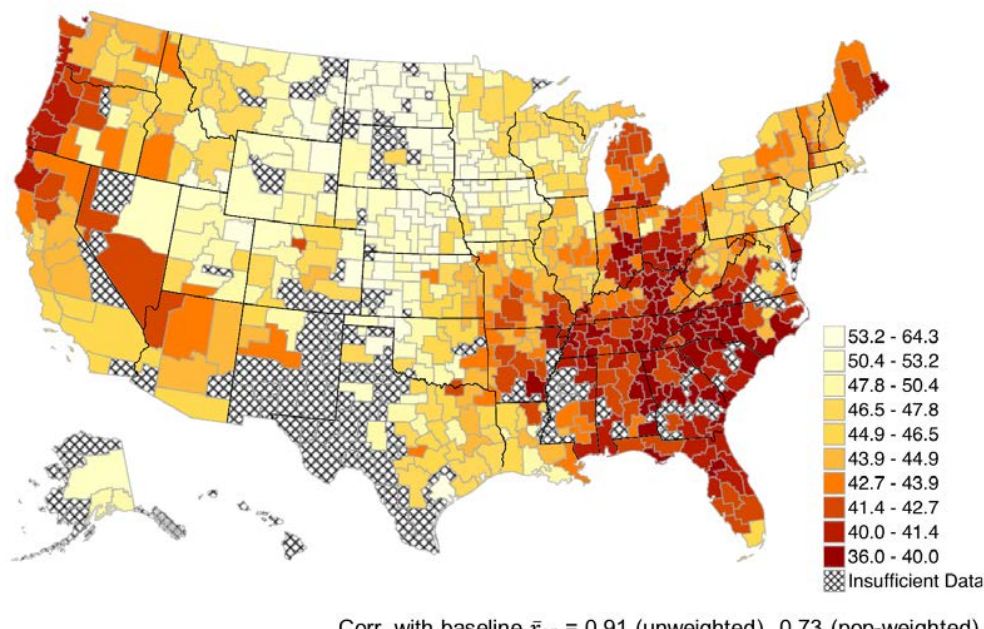

B. Impact of Changing Racial Composition of Sample on CZ-Level Estimates of Upward Mobility

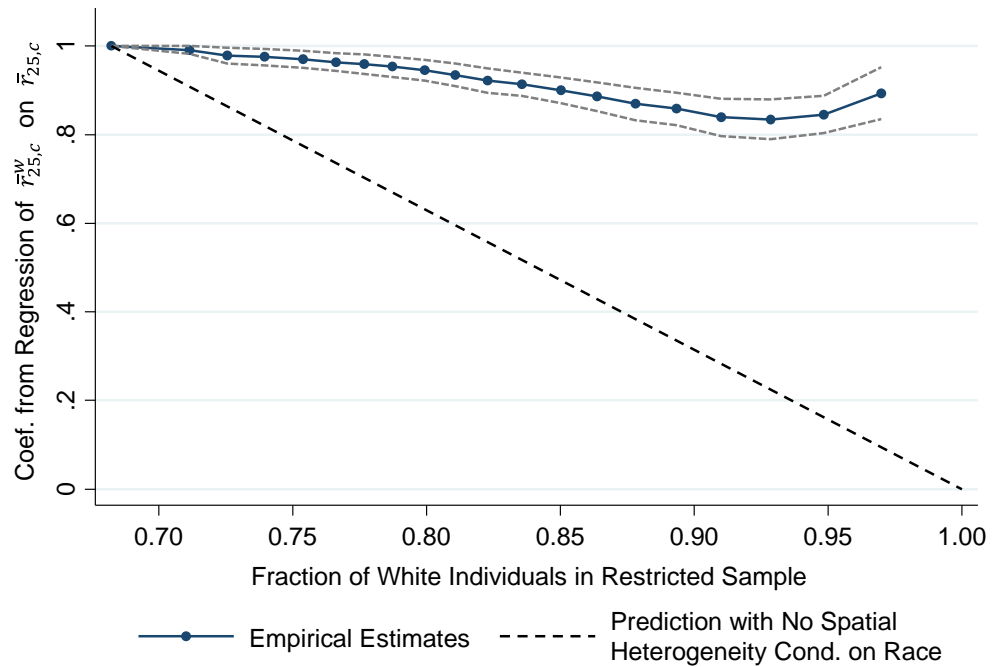

Notes: Panel A presents a heat map of absolute upward mobility for individuals living in ZIP codes with $80 \%$ or more white residents. This figure replicates Figure VIa, restricting the sample used to estimate the rank-rank regression in each $\mathrm{CZ}$ to parents living in ZIP codes with $80 \%$ or more white residents. Note that we color the entire CZ based on the resulting estimate of upward mobility (not just the ZIP codes used in the estimation) for comparability to other figures. CZs with fewer than 250 children living in ZIP codes with $>80 \%$ white share are omitted and shaded with the cross-hatch pattern. We report the unweighted and population-weighted correlation coefficients between this measure and absolute upward mobility presented in Figure VIa across CZs. To construct Panel B, we first compute upward mobility in each CZ, restricting the sample to individuals living in ZIP codes that are more than $w \%$ white, which we denote by $\bar{r}_{25, c}^{w}$. We then regress $\bar{r}_{25, c}^{w}$ on $\bar{r}_{25, c}$, our baseline estimates of upward mobility based on the full sample, using an unweighted OLS regression with one observation per CZ with available data. We vary $w$ from $0 \%$ to $95 \%$ in increments of $5 \%$ and plot the resulting regression coefficients against the fraction of white individuals in each of the subsamples. The confidence interval, shown by the dotted lines around the point estimates, is based on standard errors clustered at the state level. The dashed diagonal line shows the predicted relationship if there were no spatial heterogeneity in upward mobility conditional on race. 


\section{ONLINE APPENDIX FIGURE I Dollar-Weighted vs. Traditional IGE Estimates}

A. Log of Mean Child Income vs. Mean of Log Child Income

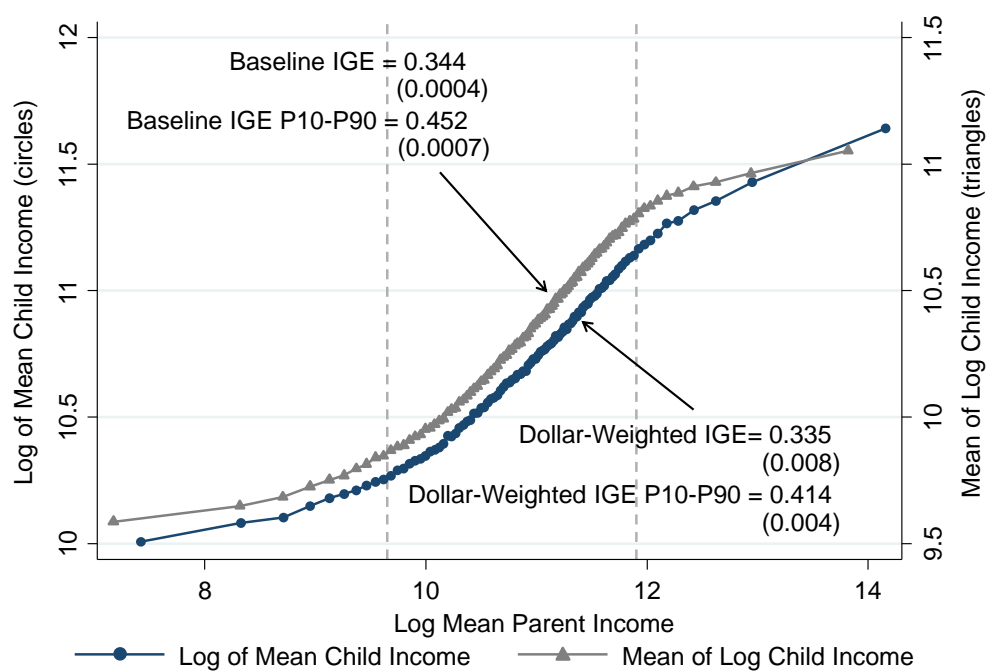

B. Dollar-Weighted IGE by Age of Child Income Measurement

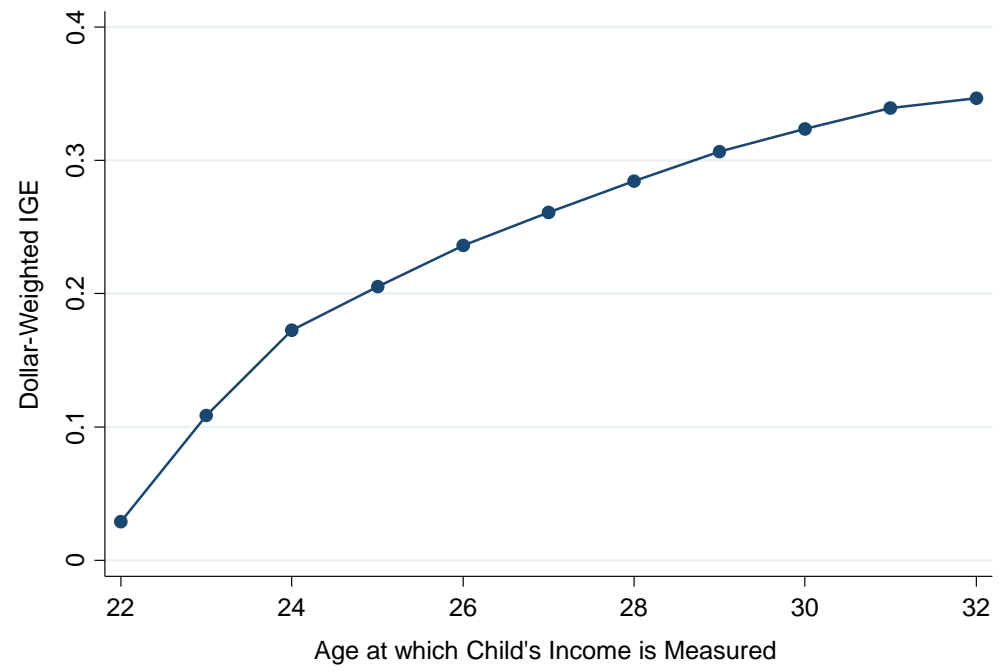

Notes: This figure compares dollar-weighted (Mitnik et al. 2014) and traditional IGE estimates. Panel A is based on the core sample (1980-82 birth cohorts) and baseline family income definitions for parents and children. The series in circles (left axis) plots log of mean child income against log of mean parent income. The series is constructed by taking the logs of the points in Figure Ia; however, here we do not omit the top income bin. The slope coefficients, which correspond to the dollar-weighted IGE defined in Appendix C, and standard errors are estimated by OLS on the binned data. The series in triangles (right axis) reports the mean of $\log$ child income vs. the mean of log parent income (reproducing the series in Figure Ib). The slope coefficients and standard errors for the traditional IGE are estimated on the microdata. The dashed lines in Panel A show the 10th and 90th percentiles of the parent income distribution. Panel B shows how the dollar-weighted IGE varies with the age at which child income is measured. We estimate the dollar-weighted IGE by grouping parents into 100 bins based on their income rank and regressing the log of mean child income on the log of mean parent income across the 100 bins. The figure plots the slope from this regression vs. the age at which child income is measured. We measure child income in 2011-12 and analyze how the IGE varies across birth cohorts, as in Figure IIIa; see notes to that figure for further details. The first point corresponds to the children in the 1990 birth cohort, who are 21-22 when their incomes are measured in 2011-12 (denoted by age 22 on the figure). The last point corresponds to the 1980 cohort, who are 31-32 (denoted by 32) when their incomes are measured. 
ONLINE APPENDIX FIGURE II

Additional Evidence on Robustness of Intergenerational Mobility Estimates

A. IGE Estimates by Age of Child Income Measurement

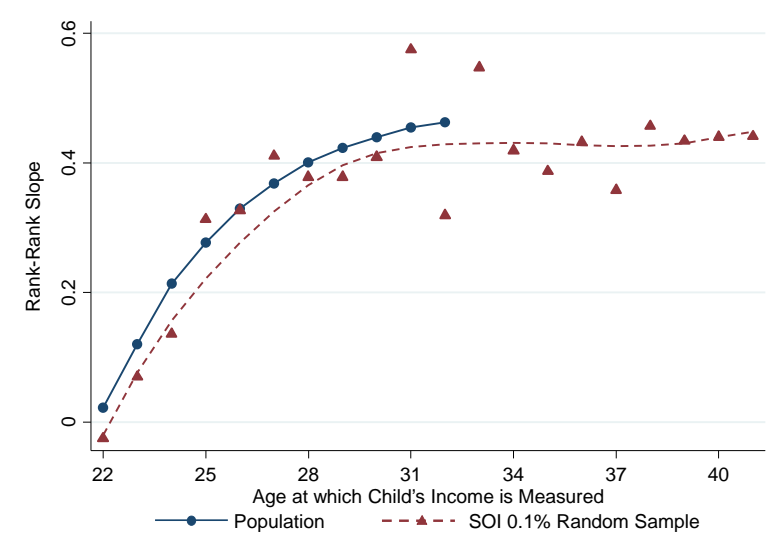

C. College Attendance Gradient by Age of Child When Parent Income is Measured

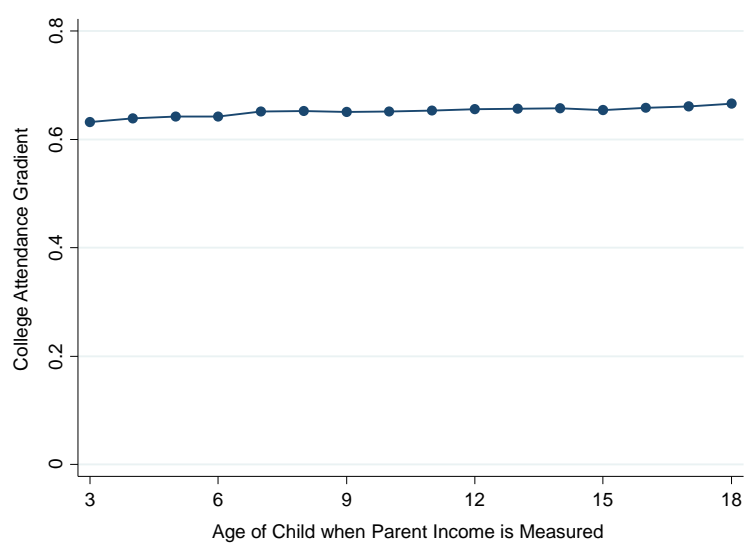

\section{B. Rank-Rank Slope by Age of Parent Income Measurement}

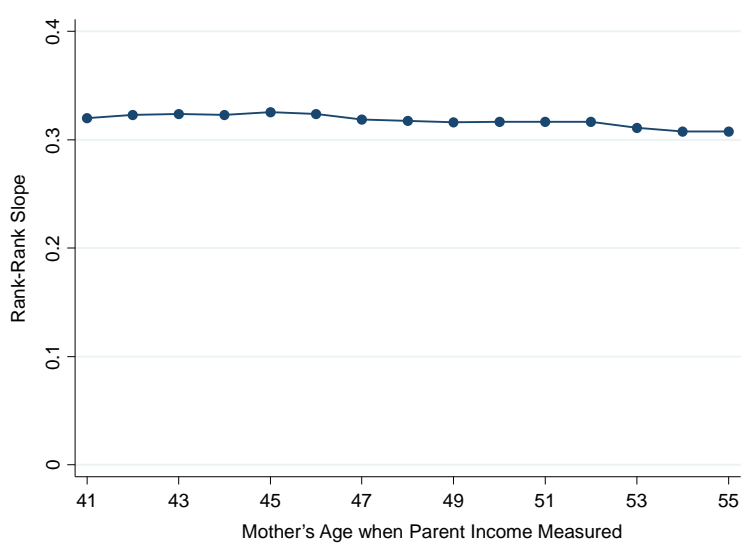

D. Rank-Rank Slope by Number of Years Used to Measure Child Income

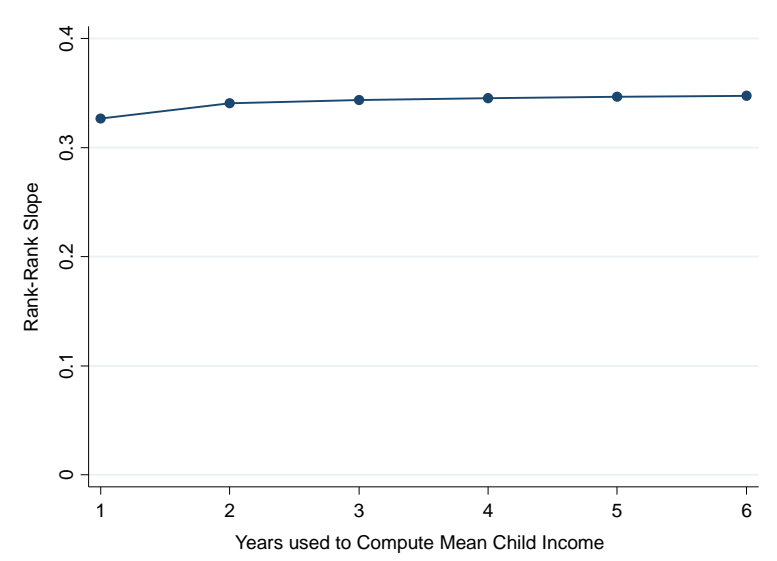

Notes: This figure evaluates the robustness of intergenerational mobility measures to lifecycle and attenuation bias. Panel A evaluates the robustness of the IGE to changes in the age at which child income is measured. Panel B evaluates the robustness of the rank-rank slope to changes in the age at which parent income is measured. Panel $\mathrm{C}$ evaluates the robustness of the college attendance gradient to the age of the child when parent income is measured. Panel D evaluates the robustness of the rank-rank slope to the number of years used to measure the child's income. In Panel A, we estimate the log-log IGE (excluding children with zero income), varying the age at which child income is measured. We restrict the sample to parents with income between the 10th and 90th percentile when estimating the IGE, as shown in Figure Ib. We measure child income in 2011-12 and analyze how the IGE varies across birth cohorts, as in Figure IIIa; see notes to that figure for further details. In Panel B, each point shows the slope coefficient from an OLS regression of child income rank on parent income rank (as in Figure IIa), using the core sample and varying the age at which parent income rank is measured. The first point measures parent income in 1996, when the mean age of mothers is 41 . The last point measures income in 2010 , when parents are 55. Panel C reproduces Appendix Figure 2b from Chetty et al. (2014). In this figure, each point shows the slope coefficient from an OLS regression of an indicator for the child attending college at age 19 on parent income rank (similar to Figure IVa), varying the year in which parent income rank is measured from 1996 to 2011. In this series, we use data from the 1993 birth cohort, which allows us to analyze parent income starting when children are 3 years old in 1996 . We list the age of the child on the $\mathrm{x}$ axis to evaluate whether the gradient differs when children are young (although parent age is of course also rising in lockstep). In Panel D, each point shows the slope coefficient from the same rank-rank regression as in Panel B using the core sample, but here we always use a five-year (1996-2000) mean to measure parent income and vary the number of years used to compute mean child income. The point for one year measures child income in 2012 only. The point for two years uses mean child income in 2011-12. We continue adding data for prior years; the 6th point uses mean income in years $2007-2012$. 


\section{ONLINE APPENDIX FIGURE III \\ Boston Commuting Zone}

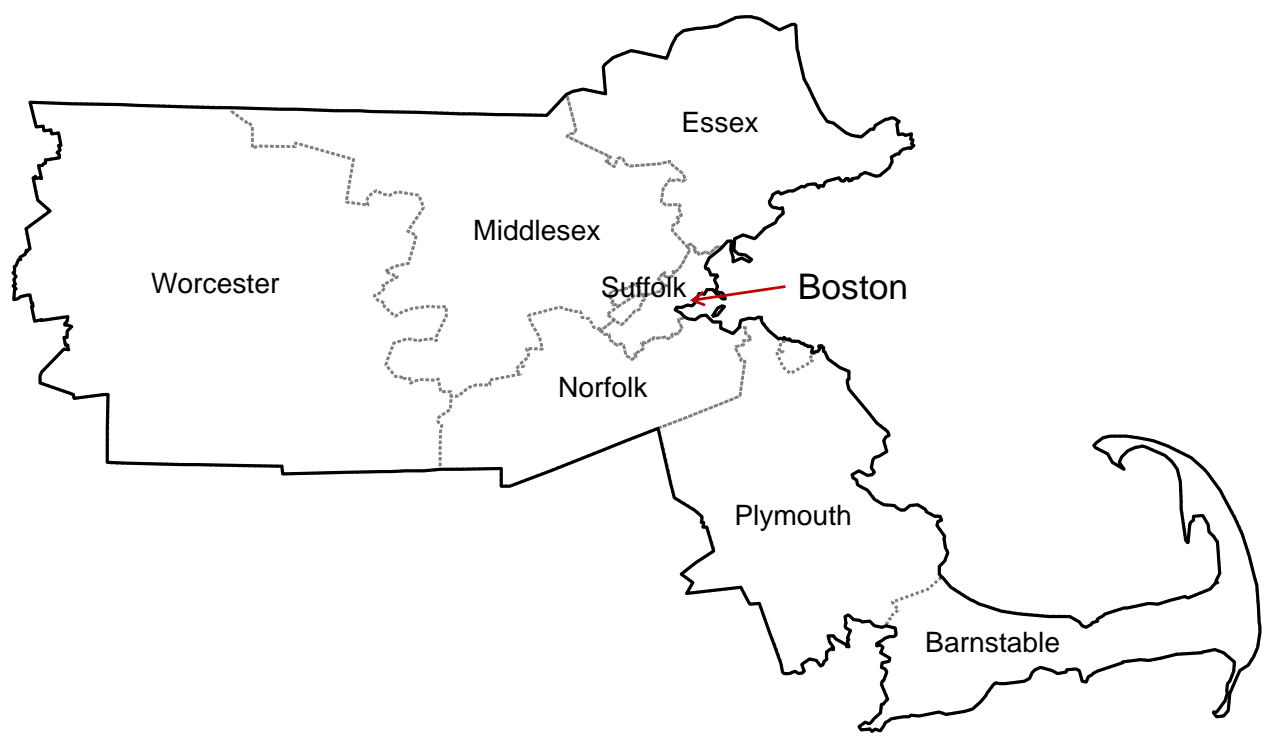

Notes: This figure shows a map of the counties that comprise the Boston Commuting Zone. The city of Boston is shown by the arrow. 
ONLINE APPENDIX FIGURE IV

Rank-Rank Relationships and Income Distributions in the 20 Largest CZs

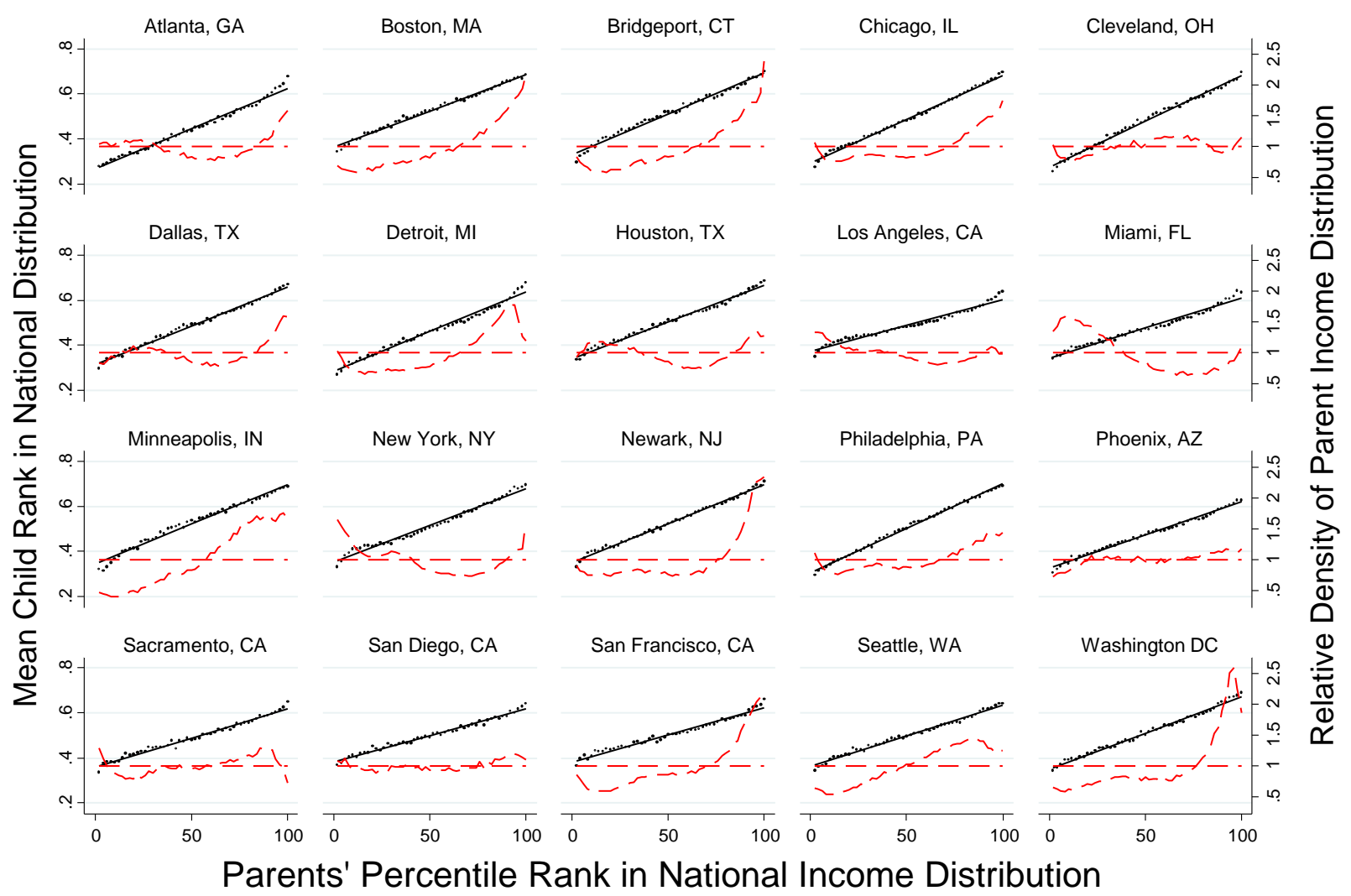

Notes: These figures present non-parametric binned scatter plots (shown by the points and solid line, left y-axis) of the relationship between child and parent income ranks in the twenty largest CZs based on population in the 2000 Census. All figures are based on the core sample (1980-82 birth cohorts) and baseline family income definitions for parents and children. Children are assigned to commuting zones based on the location of their parents. Parent and child percentile ranks are always defined at the national level, not the $\mathrm{CZ}$ level. To construct each rank-rank series, we group parents into 50 equally sized (two percentile point) bins and plot the mean child percentile rank vs. the mean parent percentile rank within each bin. The dashed curve (right y-axis) in each panel depicts the income distribution in the CZ relative to the national distribution. This curve plots the share of parents with income in each bin in the $\mathrm{CZ}$ divided by the share in the same bin in the national income distribution. By construction, this curve averages to one in each $\mathrm{CZ}$, shown by the horizontal dashed line in each panel. 


\section{ONLINE APPENDIX FIGURE V \\ Estimates of Absolute Upward Mobility Pooling 1980-82 and 1980-85 Cohorts}

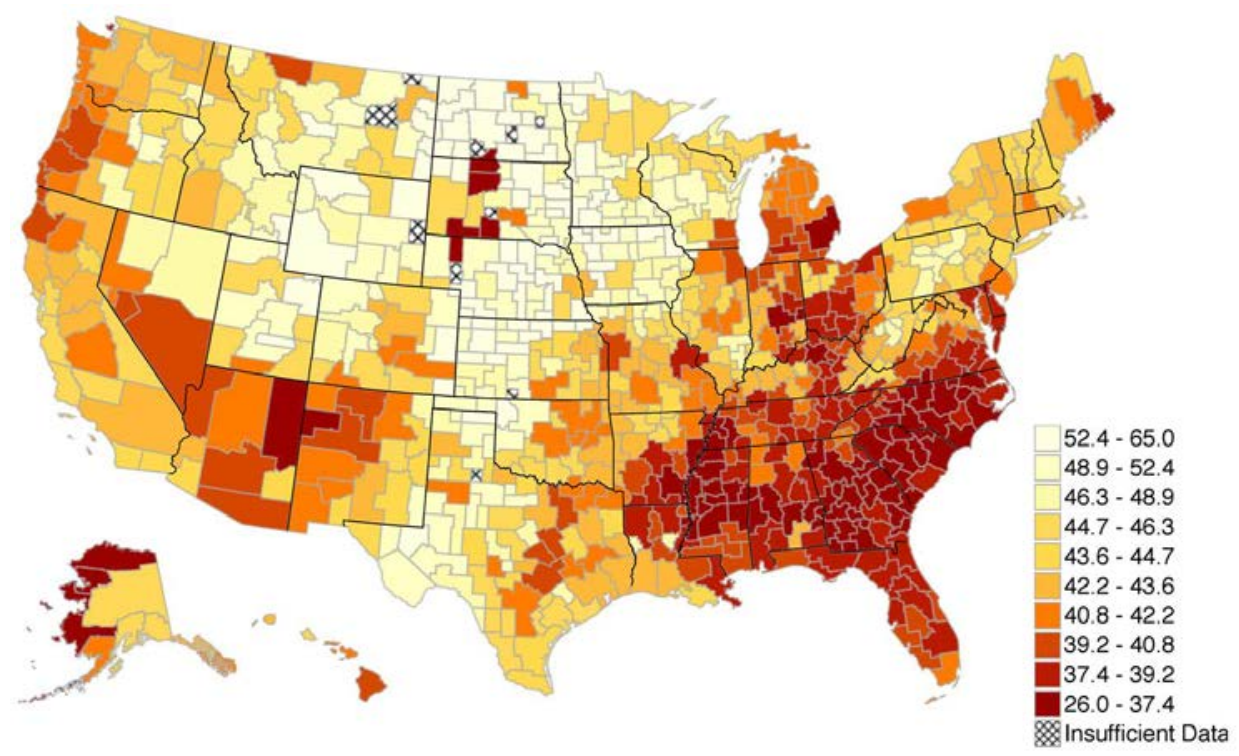

Notes: The figure presents the map of absolute upward mobility by CZ shown on the project homepage (www.equality-ofopportunity.org). For the $709 \mathrm{CZs}$ that have at least 250 children in the 1980-82 cohorts, we compute absolute upward mobility exactly as in Figure VIa. For an additional $22 \mathrm{CZs}$ that have fewer than 250 children in the $1980-82$ cohorts but at least 250 children in the 1980-85 cohorts, we report estimates of absolute upward mobility using the 1980-85 birth cohorts. We estimate absolute upward mobility using exactly the same procedure as described in the notes to Figure VIa. The map is constructed by grouping CZs into ten deciles based on the hybrid absolute mobility measure and shading the areas so that lighter colors correspond to higher absolute mobility. Areas with fewer that 250 children in the $1980-85$ cohorts are shaded with the cross-hatch pattern. The CZ-level statistics underlying this map are reported in Online Data Table V. 


\section{ONLINE APPENDIX FIGURE VI \\ Alternative Measures of Upward Mobility}

A. Absolute Upward Mobility Adjusted for Local Cost-of-Living

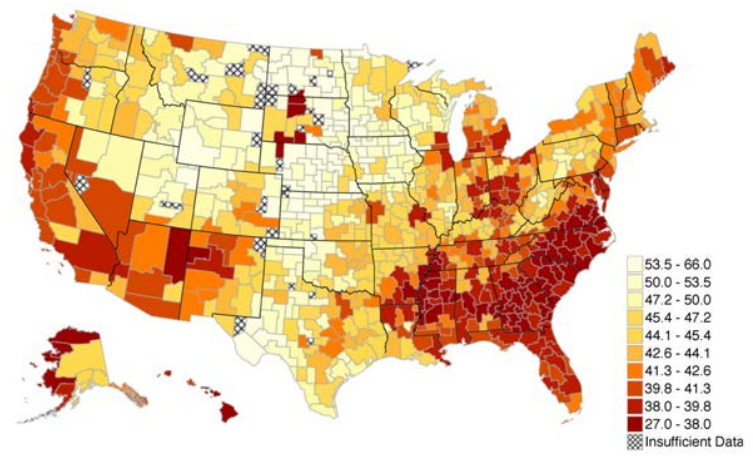

Corr. with baseline $\bar{r}_{25}=0.98$ (unweighted), 0.86 (pop-weighted)
B. Probability of Reaching Top Quintile from Bottom Quintile

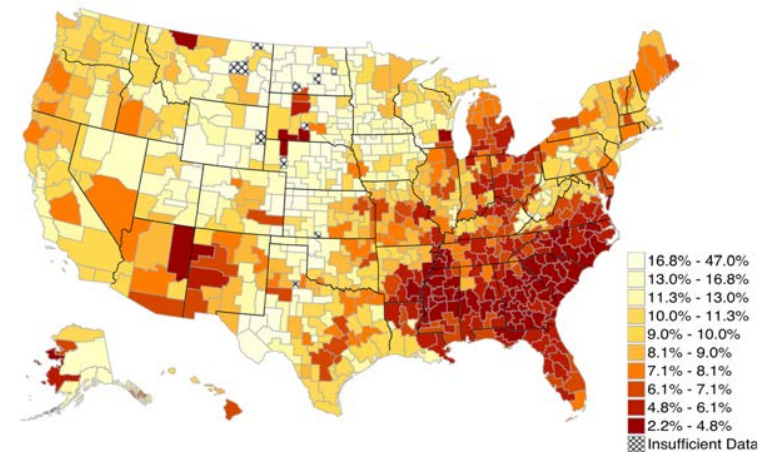

Corr. with baseline $\bar{r}_{25}=0.91$ (unweighted), 0.92 (pop-weighted)

C. Fraction of Children Above Poverty Line Given Parents at 25th Percentile

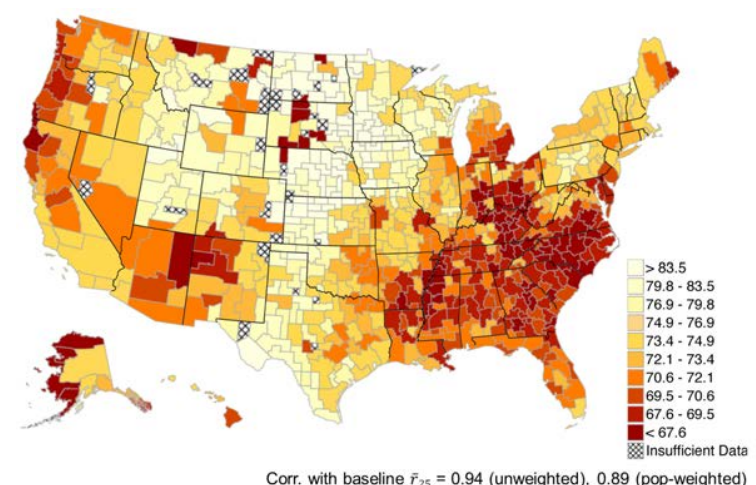

Notes: These figures present heat maps for alternative measures of upward income mobility. Children are assigned to commuting zones based on the location of their parents (when the child was claimed as a dependent), irrespective of where they live as adults. All panels use baseline family income definitions for parents. Panels A and C use the core sample (1980-82 birth cohorts) and panel B uses the 1980-85 birth cohorts. Panel A replicates Figure VIa, adjusting for differences in cost-of-living across areas. To construct this figure, we first deflate parent income by a cost-of-living index (COLI) for the parent's CZ when he/she claims the child as a dependent and child income by a COLI for the child's CZ in 2012. We then compute parent and child ranks using the resulting real income measures and replicate the procedure in Figure VIa exactly. The COLI is constructed using data from the ACCRA price index combined with information on housing values and other variables as described in Appendix A. Panel B presents a heat map of the probability that a child reaches the top quintile of the national family income distribution for children conditional on having parents in the bottom quintile of the family income distribution for parents. These probabilities are taken directly from Online Data Table VI. Panel C shows the fitted values at parent rank 25 from a regression of an indicator for child family income being above the poverty line on parent income rank (see Appendix F for details). The maps are constructed by grouping CZs into ten deciles and shading the areas so that lighter colors correspond to higher mobility. Areas with fewer that 250 children in the core sample (or the 1980-85 cohorts for Panel B), for which we have inadequate data to estimate mobility, are shaded with the cross-hatch pattern. We report the unweighted and population-weighted correlation coefficient across CZs between these mobility measures and the baseline measure in Figure VIa. The CZ-level statistics underlying Panels A and C are reported in Online Data Table V. 


\section{ONLINE APPENDIX FIGURE VII \\ The Geography of College Attendance by Parent Income Gradients}

\section{A. Slope of College Attendance-Parent Rank Gradients by CZ}

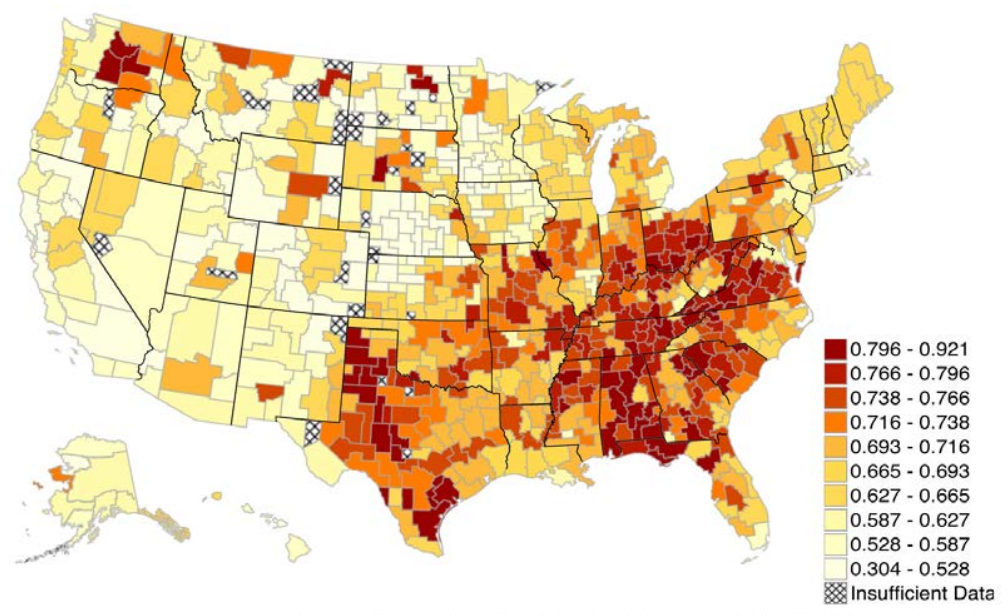

Corr. with baseline $\bar{r}_{100^{-}} \bar{r}_{0}=0.68$ (unweighted), 0.72 (pop-weighted)

\section{B. College Attendance Rates for Children with Parents at the 25th Percentile by CZ}

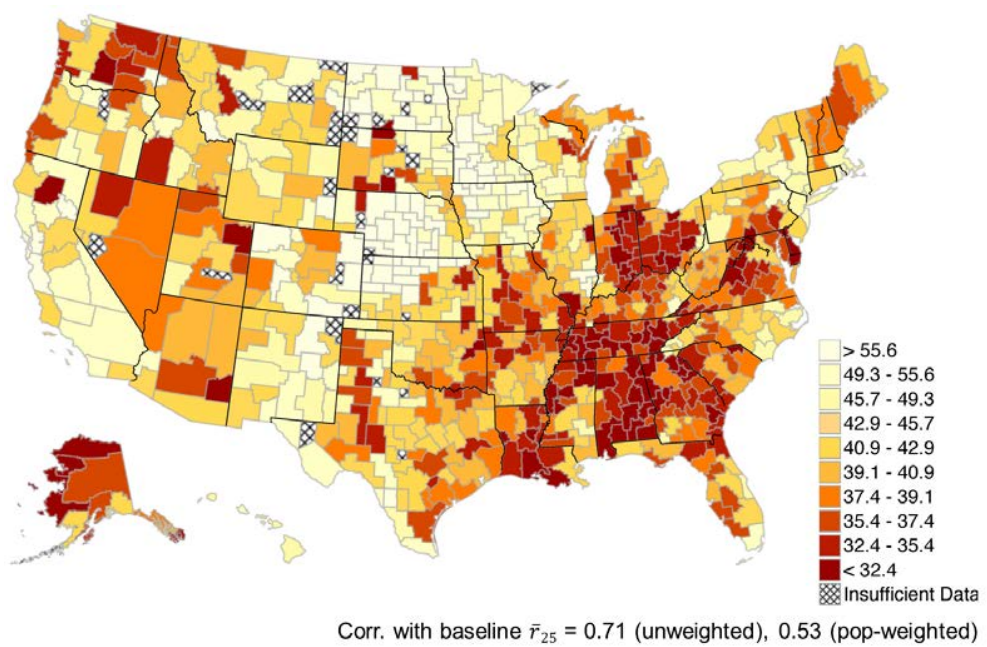

Notes: To construct these figures, we regress an indicator for college attendance on parent income rank (in the national distribution) for each CZ separately. College attendance is defined by the presence of a 1098-T form filed by a college on behalf of the student. We use the core sample (1980-82 birth cohorts) and baseline family income definitions for parents. Children are assigned to commuting zones based on the location of their parents (when the child was claimed as a dependent), irrespective of where they live as adults. In Panel A, we map the slope coefficients on the college attendance indicator from the CZ-level regressions. Panel B maps the fitted values from the regressions at parent rank 25. The maps are constructed by grouping CZs into ten deciles and shading the areas so that lighter colors correspond to higher mobility (smaller slopes in Panel A and higher fitted values in Panel B). Areas with fewer that 250 children in the core sample, for which we have inadequate data to estimate mobility, are shaded with the cross-hatch pattern. We report the unweighted and populationweighted correlation coefficients across CZs between these mobility measures and the baseline measures in Figure VI. The CZ-level statistics underlying these figures are reported in Online Data Table V. 


\section{ONLINE APPENDIX FIGURE VIII \\ The Geography of College Quality by Parent Income Gradients}

\section{A. College Quality Gradient (P75-P25) by CZ}

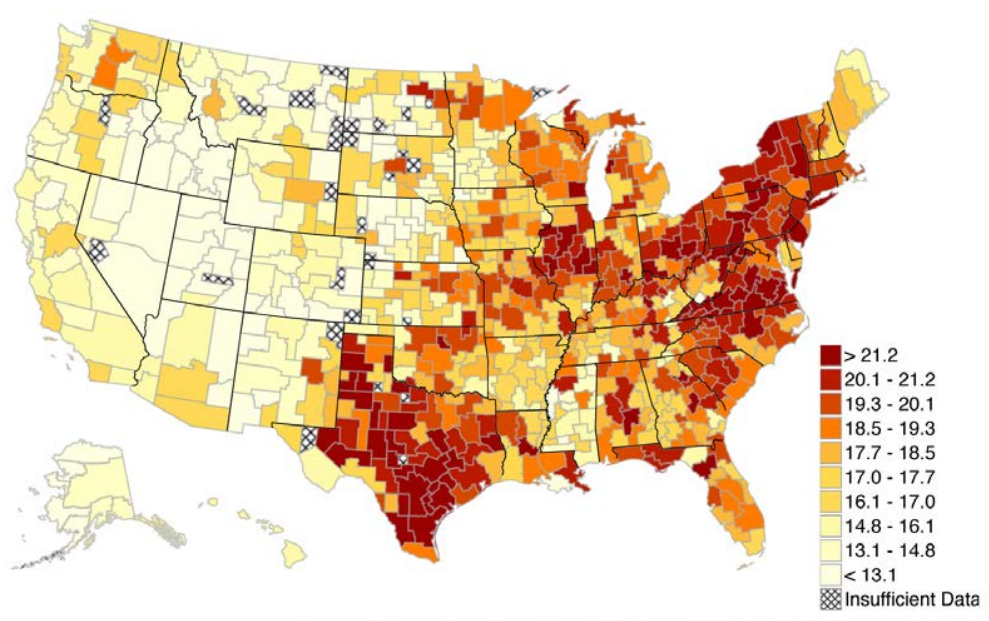

Corr. with baseline $\bar{r}_{100^{-}} \bar{r}_{0}=0.51$ (unweighted), 0.65 (pop-weighted)

\section{B. Mean College Quality Rank for Children with Parents at the 25th Percentile by CZ}

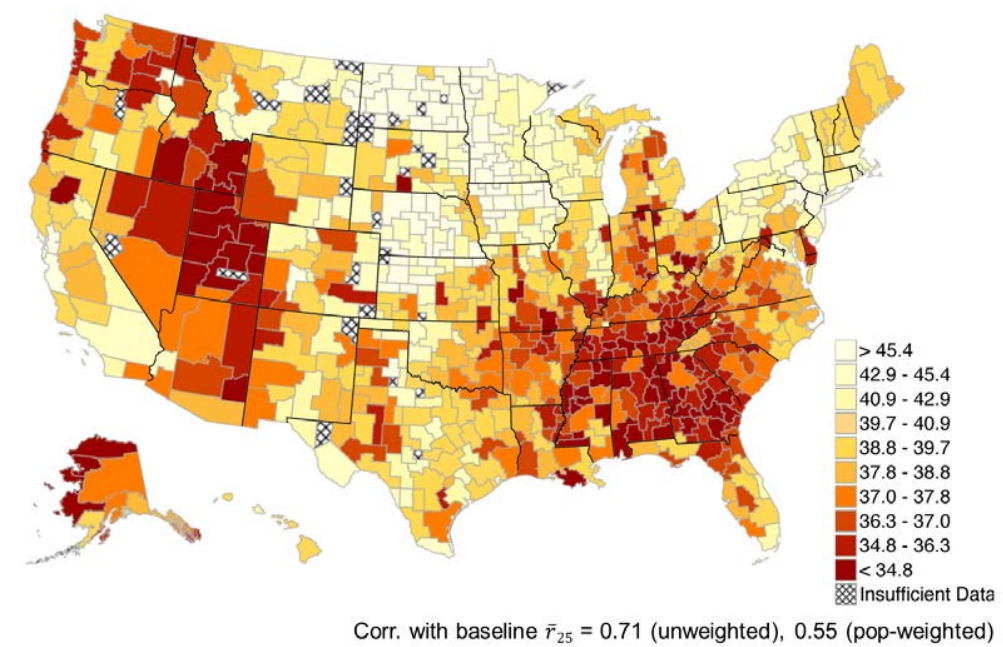

Notes: To construct these figures, we regress college quality rank on a quadratic in parent income rank (in the national distribution) for each CZ separately. College quality rank is defined as the percentile rank of the college that the child attends at age 20 based on the mean earnings at age 31 of children who attended the same college (children who do not attend college are included in a separate "no college" group); see Section III.B for further details. We use the core sample (1980-82 birth cohorts) and baseline family income definitions for parents. Children are assigned to commuting zones based on the location of their parents (when the child was claimed as a dependent), irrespective of where they live as adults. In Panel A, we map the college quality income gradient, defined as the difference between the fitted values at parent rank 75 and parent rank 25 from the CZ-level regressions. Panel B maps the fitted values of college quality rank at parent rank 25 from these regressions. The maps are constructed by grouping CZs into ten deciles and shading the areas so that lighter colors correspond to higher mobility (smaller gradients in Panel A and higher fitted values in Panel B). Areas with fewer that 250 children in the core sample, for which we have inadequate data to estimate mobility, are shaded with the cross-hatch pattern. We report the unweighted and population-weighted correlation coefficients across CZs between these mobility measures and the baseline measures in Figure VI. The CZ-level statistics underlying these figures are reported in Online Data Table V. 


\section{ONLINE APPENDIX FIGURE IX The Geography of Teenage Birth by Parent Income Gradients}

\section{A. Slope of Teenage Birth-Parent Rank Gradients by CZ}

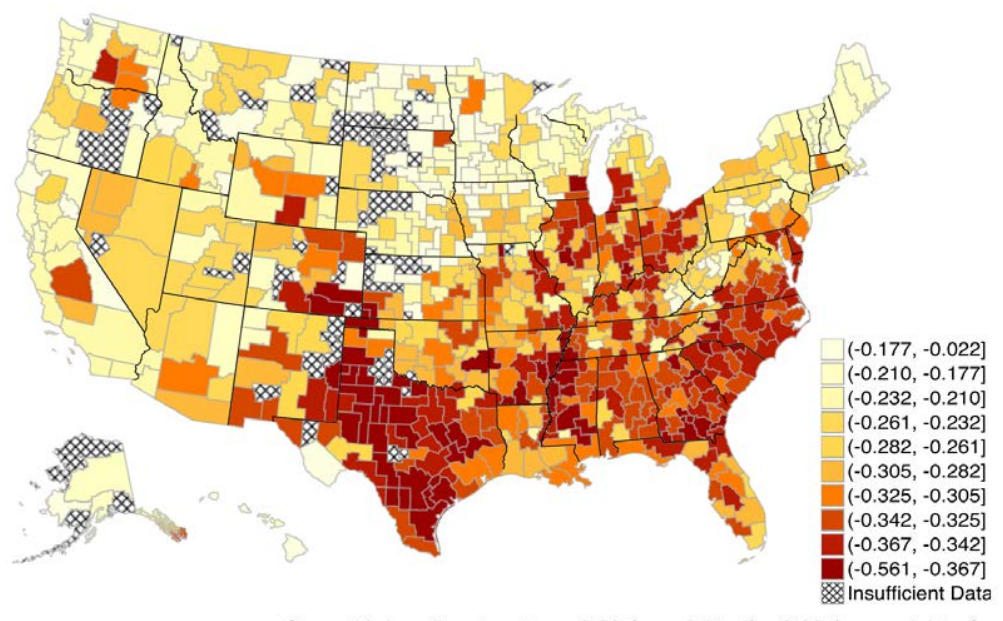

Corr. with baseline $\bar{r}_{100}-\bar{r}_{0}=-0.58$ (unweighted), -0.68 (pop-weighted)

\section{B. Teenage Birth Rates for Children with Parents at the 25th Percentile by CZ}

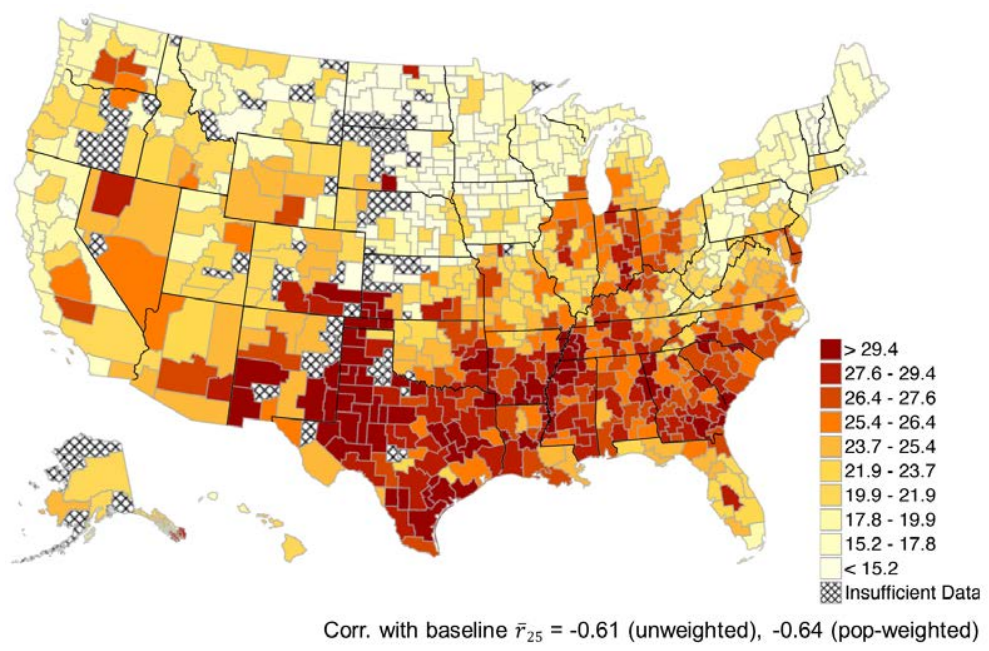

Notes: To construct these figures, we regress an indicator for teenage birth on parent income rank (in the national distribution) for each CZ separately. Teenage birth is defined as ever claiming a dependent child who was born while the mother was aged 13-19. We use female children in the core sample (1980-82 birth cohorts) and baseline family income definitions for parents. Children are assigned to commuting zones based on the location of their parents (when the child was claimed as a dependent), irrespective of where they live as adults. In Panel A, we map the slope coefficient on the teenage birth indicator from the CZlevel regressions. Panel B maps the fitted values from these regressions at parent income rank 25. The maps are constructed by grouping CZs into ten deciles and shading the areas so that lighter colors correspond to smaller slopes (in magnitudes) in Panel A and smaller fitted values in Panel B. Areas with fewer that 250 female children in the core sample, for which we have inadequate data to estimate mobility measures, are shaded with the cross-hatch pattern. We report the unweighted and population-weighted correlation coefficients across CZs between these mobility measures and the baseline measures in Figure VI. The CZ-level statistics underlying these figures are reported in Online Data Table V. 


\section{ONLINE APPENDIX FIGURE X \\ Segregation and Upward Mobility}

A. Upward Mobility vs. Theil Index of Racial Segregation in CZ

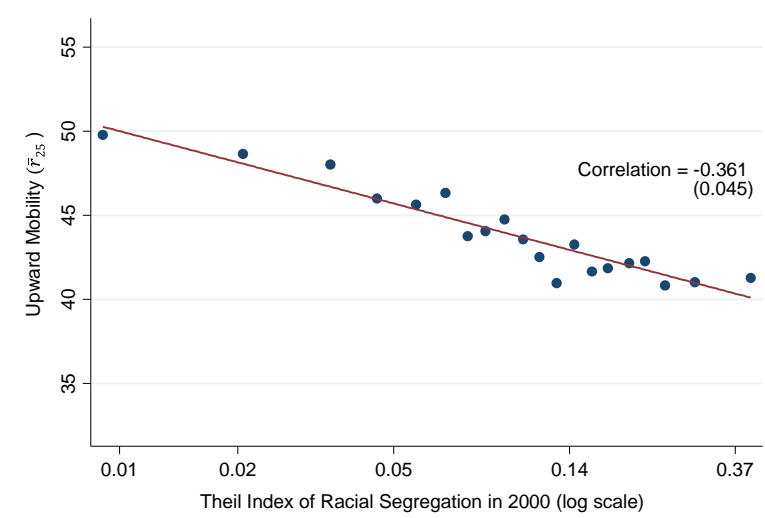

B. Upward Mobility vs. Rank-Order Index of Income Segregation in CZ

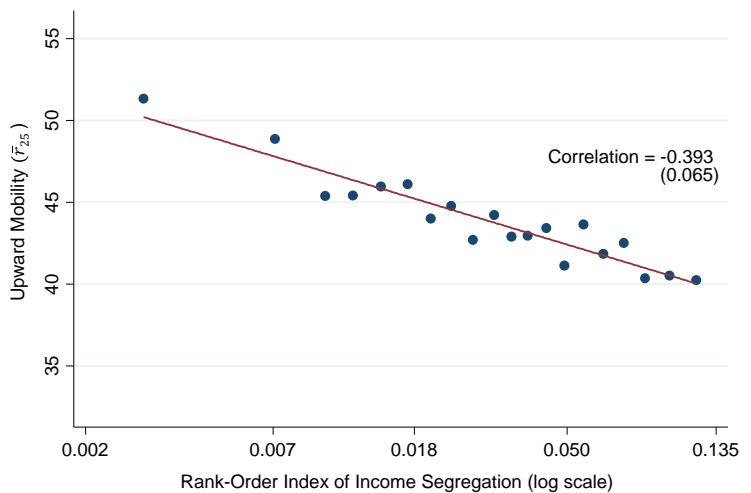

Notes: Panel A presents a binned scatter plot of absolute upward mobility $\left(\bar{r}_{25}\right)$ vs. a multi-group Theil index of racial segregation (based on census tract level data from the 2000 Census). To construct this figure, we group CZs into twenty equally sized bins (vingtiles) based on their segregation index. We then plot the mean level of absolute upward mobility vs. the mean segregation index within each of the twenty bins (using a log scale on the $\mathrm{x}$ axis). Panel B presents an analogous binned scatter plot of absolute upward mobility vs. the rank-order index of income segregation from Reardon (2011). See text for details on the construction of these segregation indices. Note that these binned scatter plots provide a non-parametric representation of the conditional expectation function, but they do not show the variance in the underlying data across CZs. The correlations between the variables are estimated using the underlying CZ-level data, with standard errors (reported in parentheses) clustered by state. The correlations are estimated in levels (not logs) for consistency with Appendix Table VII. 


\section{ONLINE APPENDIX FIGURE XI}

\section{Local Income Distributions and Upward Mobility}

A. Upward Mobility vs. Mean Income in CZ

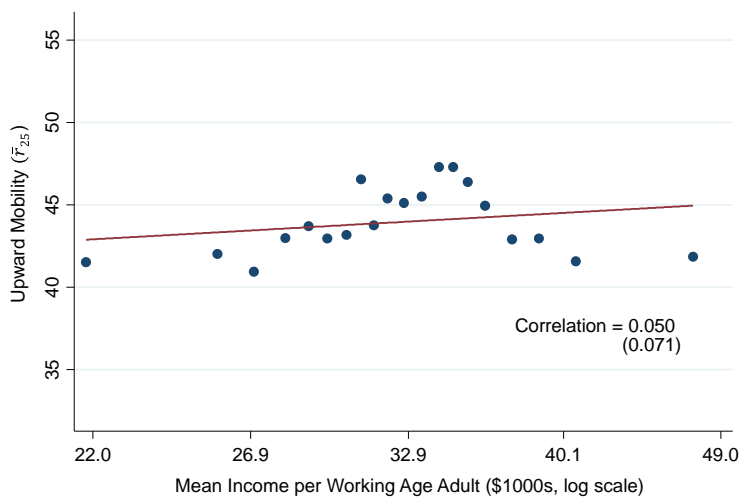

B. Upward Mobility vs. Gini Coefficient in CZ The "Great Gatsby" Curve Within the U.S.

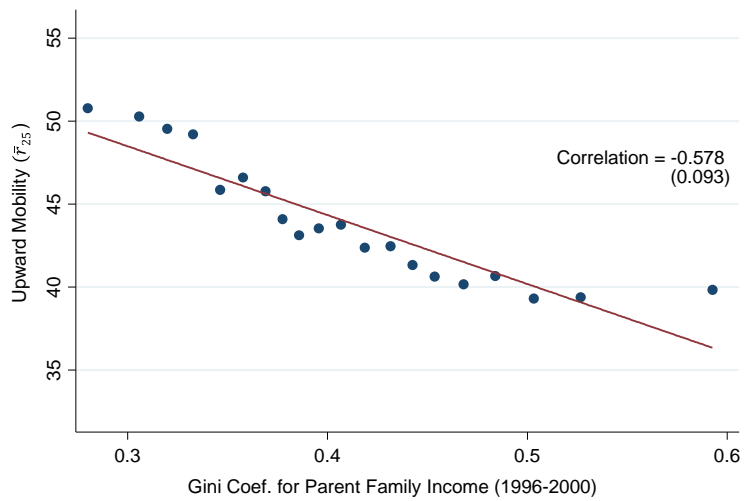

C. Upward Mobility vs. Top 1\% Income Share in CZ

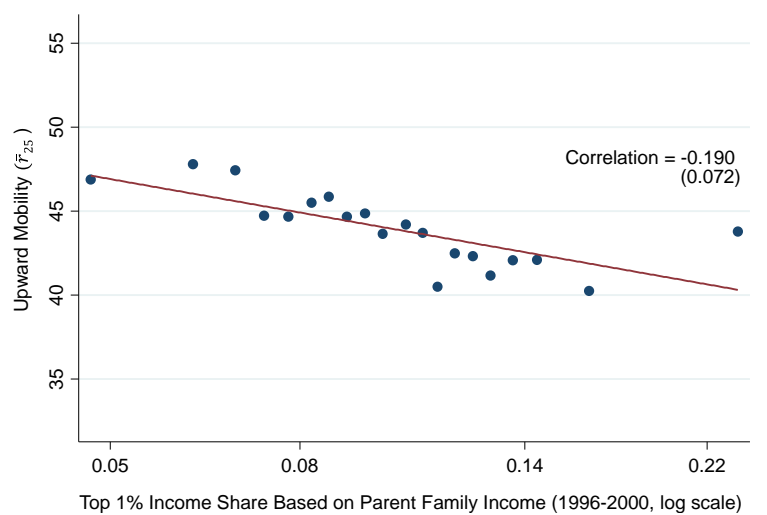

Notes: Panel A presents a binned scatter plot of absolute upward mobility $\left(\bar{r}_{25}\right)$ vs. mean income per working age adult in the CZ (based on data from the 2000 Census). To construct this figure, we group CZs into twenty equally sized bins (vingtiles) based on mean income levels. We then plot the mean level of absolute upward mobility vs. the mean income level within each of the twenty bins (using a log scale on the $\mathrm{x}$ axis). Panel B presents an analogous binned scatter plot of absolute upward mobility vs. the Gini coefficient in the CZ, computed based on the core sample and mean parent income for 1996-2000. Panel C presents a binned scatter plot of absolute upward mobility vs. the fraction of income in the CZ accruing to parents in the top $1 \%$ of the local distribution (using a log scale on the $\mathrm{x}$ axis), again using the core sample and parents' average income for 1996-2000. Note that these binned scatter plots provide a non-parametric representation of the conditional expectation function, but they do not show the variance in the underlying data across CZs. The correlations between the variables are estimated using the underlying CZ-level data, with standard errors (reported in parentheses) clustered by state. The correlations are estimated in levels (not logs) for consistency with Appendix Table VII. 


\section{ONLINE APPENDIX FIGURE XII \\ Single-Parent Families and Upward Mobility}

A. Upward Mobility vs. Fraction Single Mothers in CZ

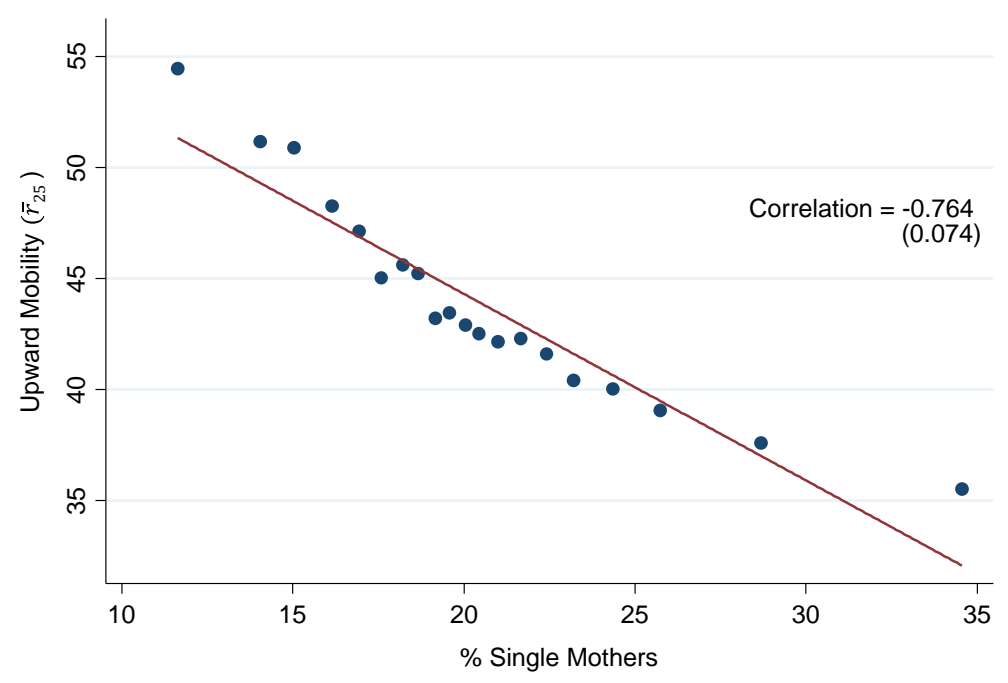

B. Upward Mobility for Children with Married Parents vs. Fraction Single Mothers in CZ

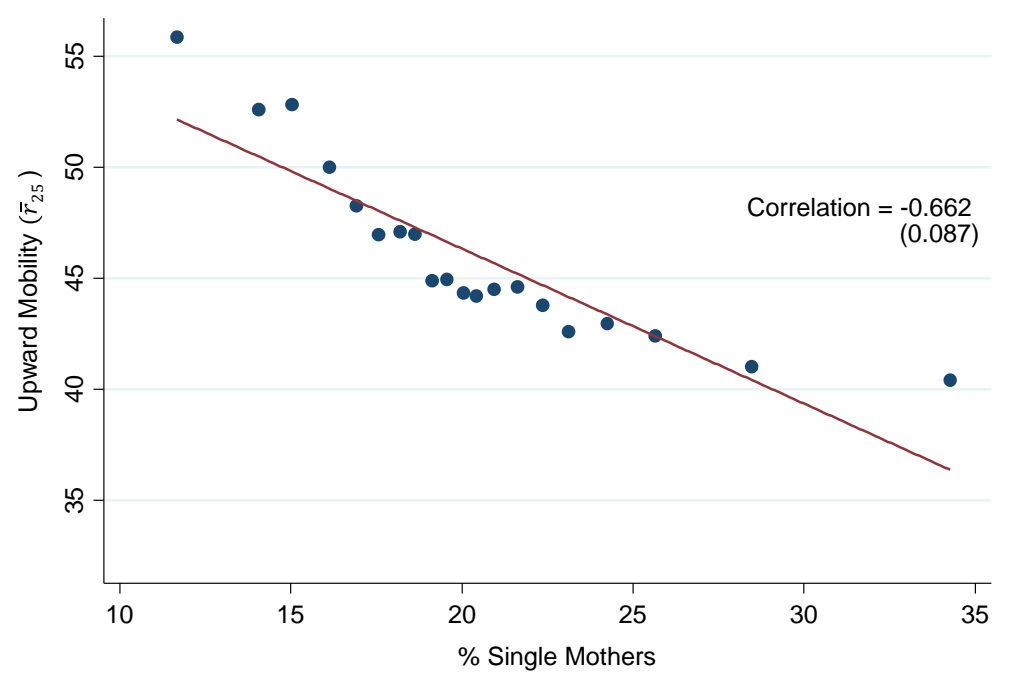

Notes: Panel A presents a binned scatter plot of absolute upward mobility $\left(\bar{r}_{25}\right)$ vs. the fraction of children being raised by single mothers in the CZ (based on data from the 2000 Census). To construct this figure, we group CZs into twenty equally sized bins (vingtiles) based on the fraction of single parents. We then plot the mean level of absolute upward mobility vs. the mean fraction of single parents within each of the twenty bins. Panel B replicates Panel A, restricting the sample used to estimate upward mobility in each CZ to children whose own parents are married in the year they first claim the child as a dependent. Note that these binned scatter plots provide a non-parametric representation of the conditional expectation function, but they do not show the variance in the underlying data across CZs. The correlations between the variables are estimated using the underlying CZ-level data, with standard errors (reported in parentheses) clustered by state. 


\section{ONLINE APPENDIX FIGURE XIII \\ Predicted vs. Actual Time Trends in Relative Mobility}

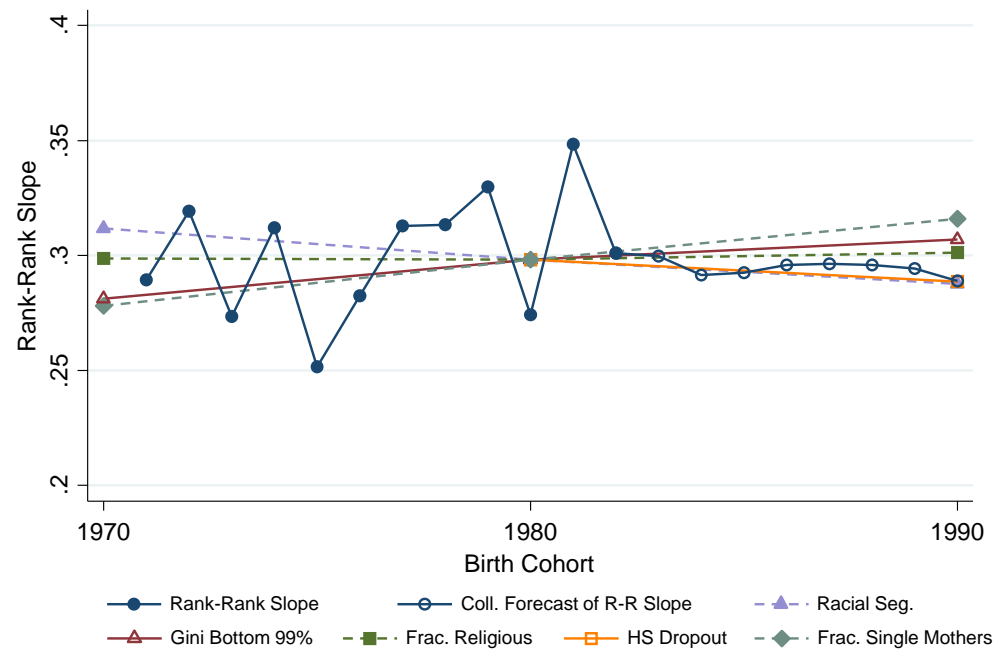

Notes: This figure compares actual trends in rank-rank slopes at the national level, estimated in Chetty et al. (2014), with projected changes based on trends in the five factors most strongly correlated with differences in mobility across CZs in the cross-section. The series in circles is from Chetty et al. (2014, Figure 2). The solid circles show estimates of rank-rank slopes by birth cohort using the SOI $0.1 \%$ sample. The open circles show forecasts of the rank-rank slope based on income measured at age 26 and the college attendance rates using the population data. The other series show projections of trends, each based on a different factor: (1) Theil index of racial segregation, (2) high school dropout rate, (3) Gini coefficient, (4) violent crime arrest rate, and (5) fraction of single parents. We construct these projections based on unweighted univariate CZ-level regressions of relative mobility on each factor separately. We normalize the projections (by adding a constant) so that their values match the mean observed rank-rank slope (i.e., the mean value of the series in circles) from 1971-1990. See Appendix I for further details. 